\title{
Distress and Anxiety during the COVID-19 Pandemic as Revealed through Helpline Calls
}

\author{
Marius Brülhart ( $\nabla$ marius.brulhart@unil.ch ) \\ University of Lausanne https://orcid.org/0000-0001-5483-0219 \\ Valentin Klotzbücher \\ University of Freiburg https://orcid.org/0000-0001-9382-6757 \\ Rafael Lalive \\ University of Lausanne \\ Stephanie Reich \\ University of Freiburg
}

\section{Social Sciences - Article}

Keywords: COVID-19, lockdown measures, mental health, anxiety

Posted Date: May 25th, 2021

DOI: https://doi.org/10.21203/rs.3.rs-538751/v1

License: (9) This work is licensed under a Creative Commons Attribution 4.0 International License.

Read Full License

Version of Record: A version of this preprint was published at Nature on November 17th, 2021. See the published version at https://doi.org/10.1038/s41586-021-04099-6. 
. Distress and Anxiety during the COVID-19 Pandemic as 2 Revealed through Helpline Calls

3

4

\author{
Marius Brülhart ${ }^{1}$, Valentin Klotzbücher ${ }^{2}$, Rafael Lalive ${ }^{1}$, and Stephanie K. Reich ${ }^{2}$ \\ May 19, 2021
}

The COVID-19 crisis affects mental health. We use helpline calls to quantify this effect. Helpline calls offer a real-time measure of 'revealed' anxiety across a range of topics. We have collected data on 7 million calls from from 19 countries. We find that calls peaked at $35 \%$ above pre-pandemic levels, six weeks after the initial outbreak. The increase was mainly driven by fear (including fear of infection), loneliness, and, later in the pandemic, physical-health concerns. Relationship issues, economic problems, violence, and suicidal ideation, however, were less prevalent than before the pandemic. This pattern is apparent both during the first wave and during subsequent waves of the pandemic. Issues directly tied to COVID-19 therefore seem to have substituted rather than exacerbated underlying anxieties. Conditional on infection rates, suicide-related calls increased when containment policies became more stringent and decreased when income support was extended. This implies that financial relief can allay the distress triggered by lockdown measures.

The COVID-19 pandemic has affected the physical, economic, and mental health of nations. While the evolution of epidemiological and economic indicators can be tracked at high frequency and with short time lags, measurement of populations' mental health is more difficult. This statistical blind spot could lead to policymakers neglecting mental health issues, to the extent that they attribute more weight to aspects that can be measured well.

We seek to narrow this measurement gap by providing quantitative evidence on the state of mental health under COVID-19. Our approach is to document the growth and composition of calls to helplines across multiple countries. This indicator has two main advantages. First, helpline calls can be considered as a manifestation of revealed anxiety. Unlike choosing between different options when answering a survey question, calling a helpline involves an unprompted incurrence of a mental and time cost. In that respect, helpline calls represent an unfiltered measure of mental distress,

\footnotetext{
${ }^{1}$ University of Lausanne and CEPR (London)

${ }^{2}$ University of Freiburg
} 
unaffected by researchers' study design. A second major advantage is coverage: information about helpline calls is digitally recorded with daily frequency in numerous countries and across a wide range of conversation topics. A major challenge for research - and a first-order issue for policymakers - is to distinguish the differential impact of, on the one hand, the pandemic itself and, on the other hand, policy choices in the form of non-pharmaceutical interventions (NPIs) and economic compensation measures. In the pandemic, fear of infection with SARS-CoV-2 is an important potential source of mental distress. Non-pharmaceutical interventions designed to contain infections through social distancing might also affect mental health, as they potentially exacerbate unemployment, financial stress, loneliness, relationship problems, and pre-existing mental vulnerabilities. Those are in turn well-recognized risk factors for suicide [1-8]. Comparable helpline data across multiple different jurisdictions (countries and U.S. states), allow us to exploit differences in the timing of the pandemic and of policy measures to statistically isolate the effect of each of those variables on mental health outcomes.

Telephone helplines are well-established institutions for mental health protection and suicide prevention in many countries, and they offer support immediately, anonymously, cheaply, and accessibly for all members of the population $[9,10]$. Some helplines specialize on particular issues such as suicide, children, or violence against women. Suicide helplines, for example, have been shown to reduce suicide rates [11], and calls to suicide helplines have been shown to predict variations in suicide rates [12]. Helplines can be expected to be particularly relevant in the pandemic, when face-to-face contacts carry infection risks and may even be impossible due to NPIs such as stay-athome orders. This has been shown previously: Google searches for the U.S. Disaster Distress helpline increased significantly in spring 2020 [13], as did the frequency of calls by repeat callers [14]. To our knowledge, no other scientific study of helpline calls in the pandemic has as yet been attempted, apart from our two pilot analyses of helpline calls in Germany and Switzerland during the first half of $2020[15,16]$.

We have collected call data from 23 helplines operating in 19 countries, together covering approximately 7 million individual calls. Data are available for 2019, 2020, and, in some cases, early 2021 . The comprehensive availability of data for 2019 allows us to partial out seasonal effects unrelated to the 
pandemic. The data cover 14 European countries, the United States, China, Hong Kong, Israel, and Lebanon. Full details are provided in the Supplementary Materials. All helplines in our sample keep digital logs of calls. In most cases, these logs report call topics and caller characteristics, including estimated age and gender, as recorded by helpline operators.

We consider the analysis of helpline calls as a complement, not a substitute, to established approaches, such as survey evidence [17] or suicide statistics [18, 19]. Mental health surveys and suicide statistics can be highly informative measurement tools, but they tend to be low-frequency and available with a lag. A notable exception is Japan, where suicide statistics are reported frequently and have already been subject to scientific analysis within the COVID-19 context [20]. Higher-frequency monitoring has been performed in the context of the COVID-19 pandemic based on online searches as recorded by Google Trends [13, 21-23], by tracking visits to emergency departments[24, 25], and by monitoring calls to the police for help with domestic disputes[26-28]. In line with our findings, the available evidence based on such indicators suggests that the COVID-19 pandemic has had significant deleterious effects on public mental health [29,30]. None of those studies has been able to draw on indicators with as broad a country, time and topic coverage as ours.

\section{Results}

\section{Helpline call volumes significantly increased after the onset of the pandemic, but decreased again} after six weeks. When we pool and size-weight the data for our 21 sample helplines, we observe a peak call volume, reached six weeks after the outbreak of the pandemic, that exceeds the prepandemic level by $35 \%$ (95\% CI: 22.6 to $48.3 \%$; see Fig. 1). With the country-specific outbreak defined as the date when more than one SARS-CoV-2 infection per 100,000 inhabitants was recorded (Fig. 1a), we see a significant increase for the first time in week 3, peaking in week 6 at around 35\%, gradually decreasing back towards pre-pandemic levels by around week 11 . When we instead define the starting point of the pandemic as the entry into force of the first shelter-in-place (SIP) order (Fig. 1b), we observe a significant increase for the first time in week 2, reaching a steady peak level during weeks $3-8$, and decreasing thereafter. The different time profiles are mainly explained by the fact that SIP orders on average were issued some 2 to 3 weeks after local outbreaks. 
A) Call-volumes around the local outbreak (\%)

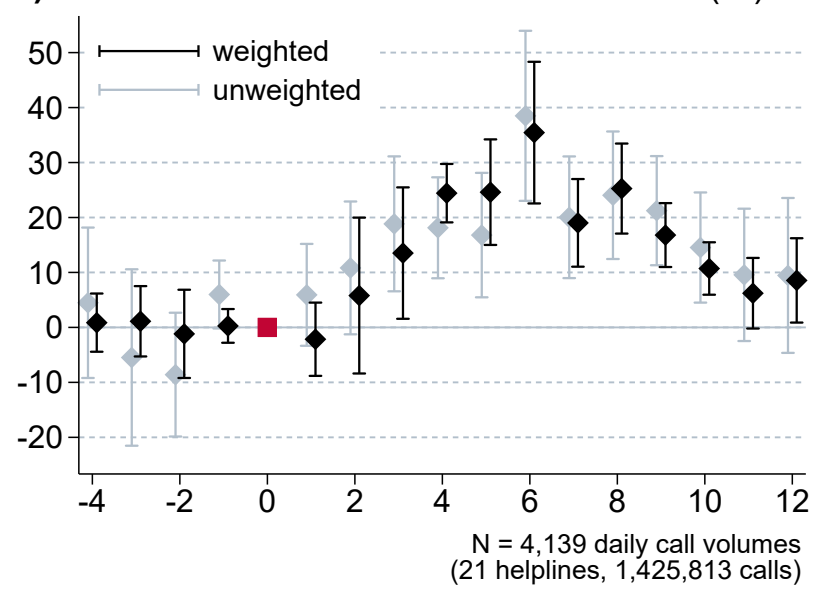

B) Around the introduction of SIP orders

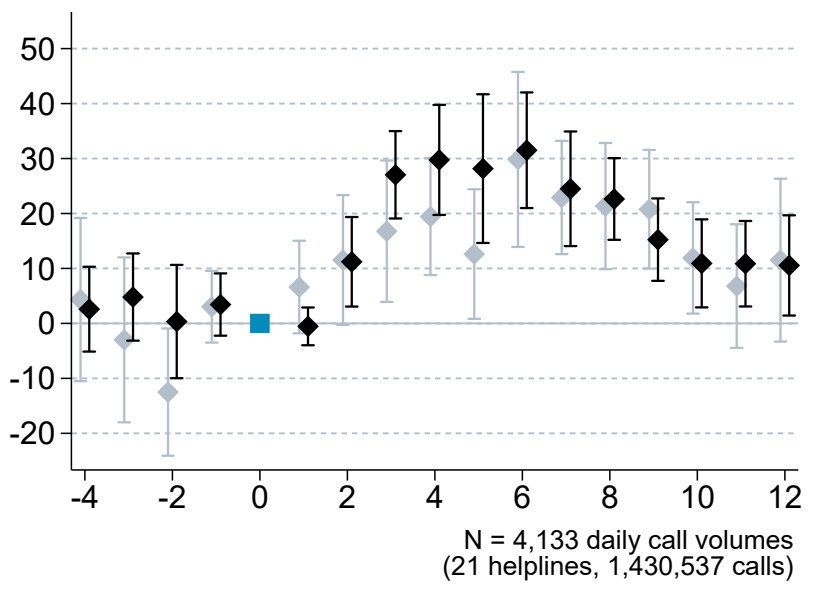

Figure 1: Evolution of total helpline call numbers during the first wave

Event study models; dependent variable is $\ln$ (daily helpline calls+1). The sample includes daily data for 21 helplines during the period from 4 weeks before to 12 weeks after the event date in early 2020, and, for 17 of the 21 helplines, the corresponding days of 2019. Coefficients on week indicators, plotted with $95 \%$ confidence intervals, show the average percentage change in call volumes relative to reference week 0 , which represents the week when (A) the cumulative number of COVID-19 infections exceeded 1 per 100,000 inhabitants [31], or (B) shelter-in-place orders were introduced [32]. Models include helpline fixed effects interacted with year, week-of-year and day-of-week indicators. See Methods, equation (1). Standard errors are clustered at the helpline-week level. Results on data weighted by total number of calls recorded for each helpline during the sample period (black); and unweighted models (gray). Supplementary Table S1 and Fig. S1 show the trends in call volumes and country-specific event dates separately for the 21 helplines. Table S2 shows detailed regression results underlying the graphs.

The gradual nature of the increase in call volumes could to some extent be due to capacity constraints. Some helplines initially had to leave some of the additional calls unanswered and only gradually managed to adjust capacity to the new level of demand. Because of this capacity constraint, the evolution of recorded aggregate call numbers should be interpreted as a lower-bound estimate of the true increase in the number of people who sought to call a helpline in the first wave of the pandemic. However, unanswered calls are not pre-screened, and call answering is thus a random process unrelated to the motives of the caller. Hence, our data provide representative information on the reasons for calling even if some calls were left unanswered because of capacity constraints.

The main drivers of increased call numbers in the first wave were fear and loneliness. We analyze the reasons for calling for 12 helplines that are general in scope and for which we have individual call-level information on conversation topics. We present our main results relating to call topics in 
Fig. 2. Panel A(i) of Fig. 2 shows that most pre-COVID-19 pandemic calls were made because of relationship issues (36\%), loneliness (21\%), or various fears and anxieties (14\%). Women made $62 \%$ of total calls, and $63 \%$ of calls were made by people aged $30-60$.

We present our main results relating to call topics in Fig. 2. Panel a(i) of Fig. 2 shows that most pre-COVID-19 pandemic calls were made because of relationship issues (36\%), loneliness (21\%) or various fears and anxieties (14\%). Women made $62 \%$ of total calls, and $63 \%$ of calls were made by people aged 30-60.

During the first wave of the pandemic, the composition of calls changed significantly (see Panel A(ii) of Fig. 2). The biggest increase in calls was recorded in the category 'fear' (+2.4 p.p.). This category includes calls made out of fear of infection with SARS-CoV-2. The other category of calls whose share increased during the first wave of the pandemic was 'loneliness' (+1.5 p.p.). The share of all other conversation topics decreased during the first wave. Significant relative decreases were observed for the topics 'relationships' (-2.5 p.p.), 'livelihood' (i.e. economic worries, -0.7 p.p.), 'violence' (-0.4 p.p.), and addiction (-0.2 p.p.). We detect no statistically significant change in the share of calls made out of suicidal ideation. These results show that the first wave of the pandemic and associated lockdown measures led to a less than proportional increase in calls about domestic violence, addiction, and suicidal ideation relative to the overall increase in calls.

In Panel B of Fig. 2, we decompose post-pandemic changes in topic shares by gender and age group. Among the particularly noteworthy results, we observe that the strong increase in fear-related calls was entirely driven by the over-30s, both male and female. This is consistent with the fact that vulnerability to COVID-19 increases monotonically with age. The share of suicide-related calls fell particularly strongly for men under 30. That same category of young men stands out with an increase in the share of calls related to addiction and relationships. Conversely, women under 30 stand out as having slight increases in call shares due to violence and economic worries, even though both those increases are not statistically significant. 
A) Conversation topics around the pandemic outbreak

(i) Pre-outbreak shares of topics/issues (\%)

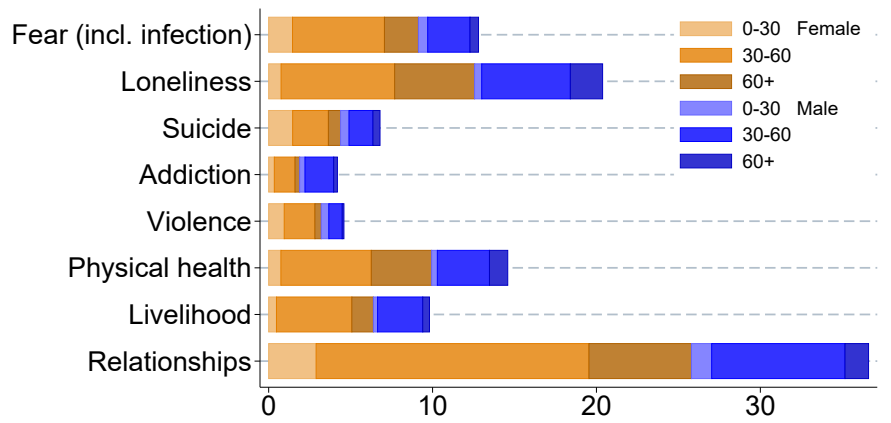

(ii) Post-outbreak change (percentage-points)

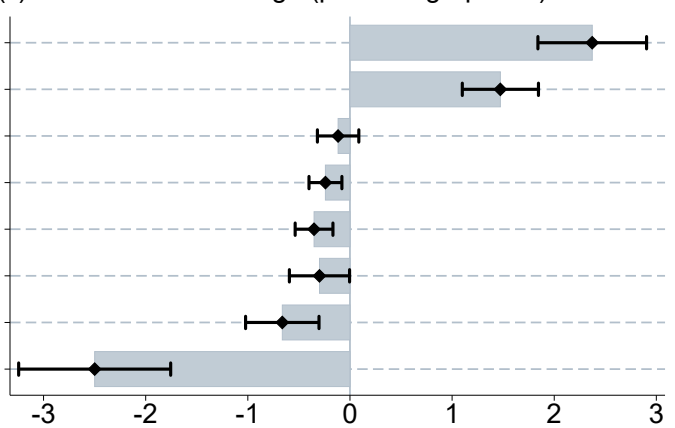

B) Post outbreak change by gender and age group (percentage-points)

(i) Fears (incl. of infection)

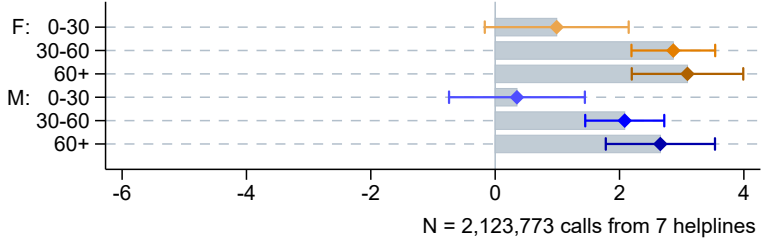

(iii) Suicide

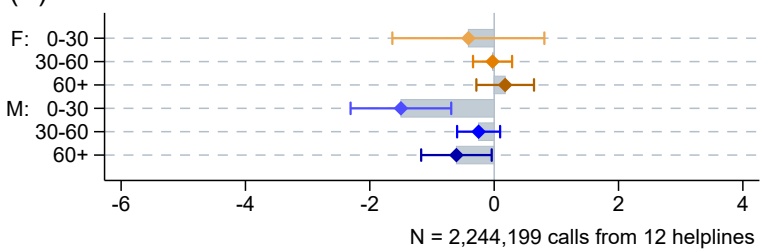

(v) Violence

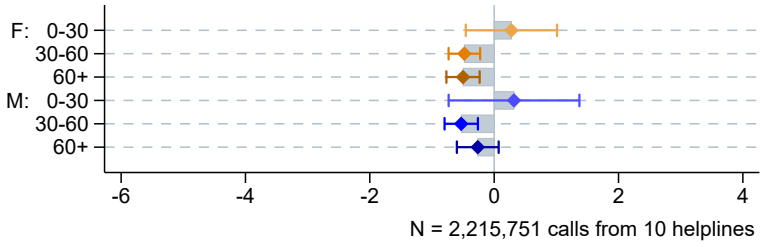

(vii) Livelihood

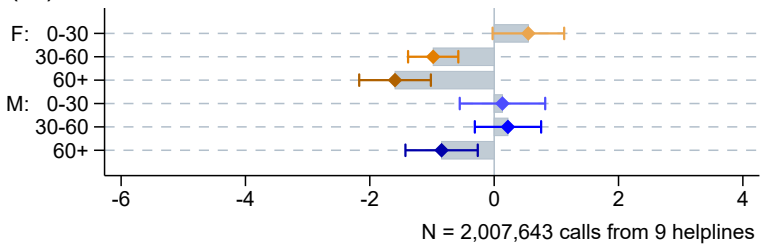

(ii) Loneliness

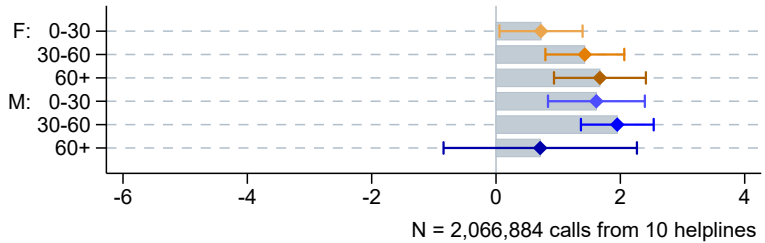

(iv) Addiction

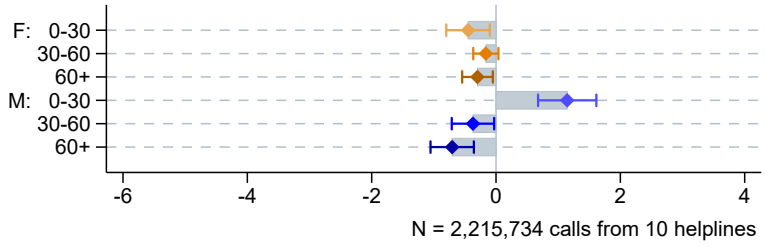

(vi) Physical health

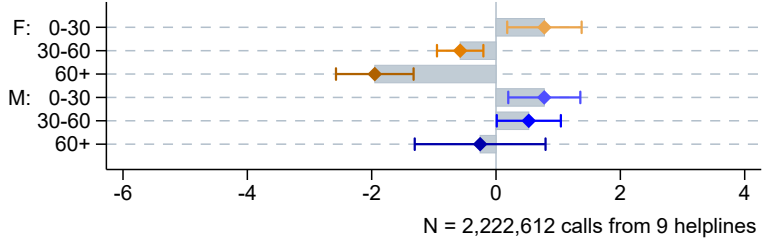

(viii) Relationships

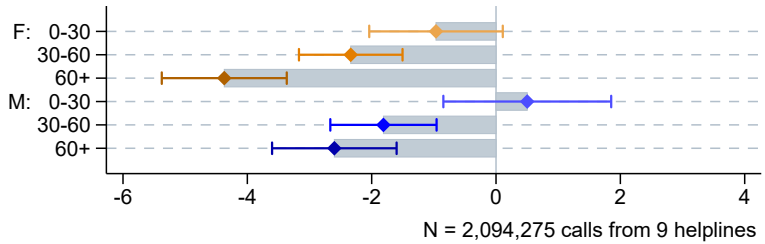

\section{Figure 2: Helpline conversation topics in the first COVID-19 wave}

(A) Main conversation topics by sex and age group: (i) Pre-pandemic shares, before 1/100,000 COVID-19 infections/inhabitants was recorded [31], (ii) estimated coefficients for binary variable post outbreak with $95 \%$ confidence intervals. Separate linear probability regression models with dependent variable set to one for calls related to the respective topic. Models include helpline fixed effects, interacted with year, week-of-year, and day-of-week indicators. See Methods, equations (2) and (3). Standard errors are clustered at the helpline-week level. (B) Changes by caller sex and age group; coefficient estimates for interaction terms of group indicators with binary variable post outbreak. Main effects for sex and age group not reported. Supplementary Tables S3, S4, and S5 show descriptive statistics for the estimation sample overall and separately by helpline, Table S6 shows detailed estimation results. 
Overall, our results suggest that the observed increase in helpline calls during the first wave of the COVID-19 pandemic was driven to a large extent by fears of the virus itself and by loneliness in the context of shelter-in-place orders, rather than domestic violence, addiction, or suicidal ideation. Many commentators had anticipated strong increases in domestic violence, addiction and suicidal ideation. While helpline calls due to such issues increased in the first half of 2020, they did so less strongly than helpline calls that were more directly linked to the pandemic - be it out of fear of infection or of loneliness in the context of shelter-in-place requirements.

\section{Helpline calls during the second and third waves of COVID-19 resembled those of the first wave.} For the two largest helplines in our sample, Germany (Telefonseelsorge) and France (S.O.S. Amitié), we have received data up until 31 March 2021, allowing us to analyze helpline calls beyond the first wave of the pandemic. The left-hand-side panels of Fig. 3 show that call volumes increased again in the second half of 2020, in parallel with an increase in infections and a tightening of NPIs. While in Germany the volume of calls has increased continuously into early 2021, in France it fell again after a peak in December 2020. These diverging patterns correlate with stronger up- and downswings in both infections and the stringency of government measures in France compared to Germany.

Conversation topic patterns resemble each other both between the two countries and between the two distinguished periods of the pandemic (Figs. 2 and 3). As in the first wave, fear (incl. of the fear infection) and loneliness were the conversation topics that saw their share of calls increase most, whereas the share of calls because of relationship issues decreased markedly. The share of calls related to suicide shrank further during subsequent waves. Conversely, the share of calls related to problems with physical health increased in the second/third waves. This could be related to a larger share of the population being infected with SARS-CoV-2, or to health worries because of restricted opportunities for physical activity. Similar to the first wave, additional calls focused predominantly on issues linked directly with the pandemic: fear of infection, loneliness, and - new in subsequent waves - physical health. 

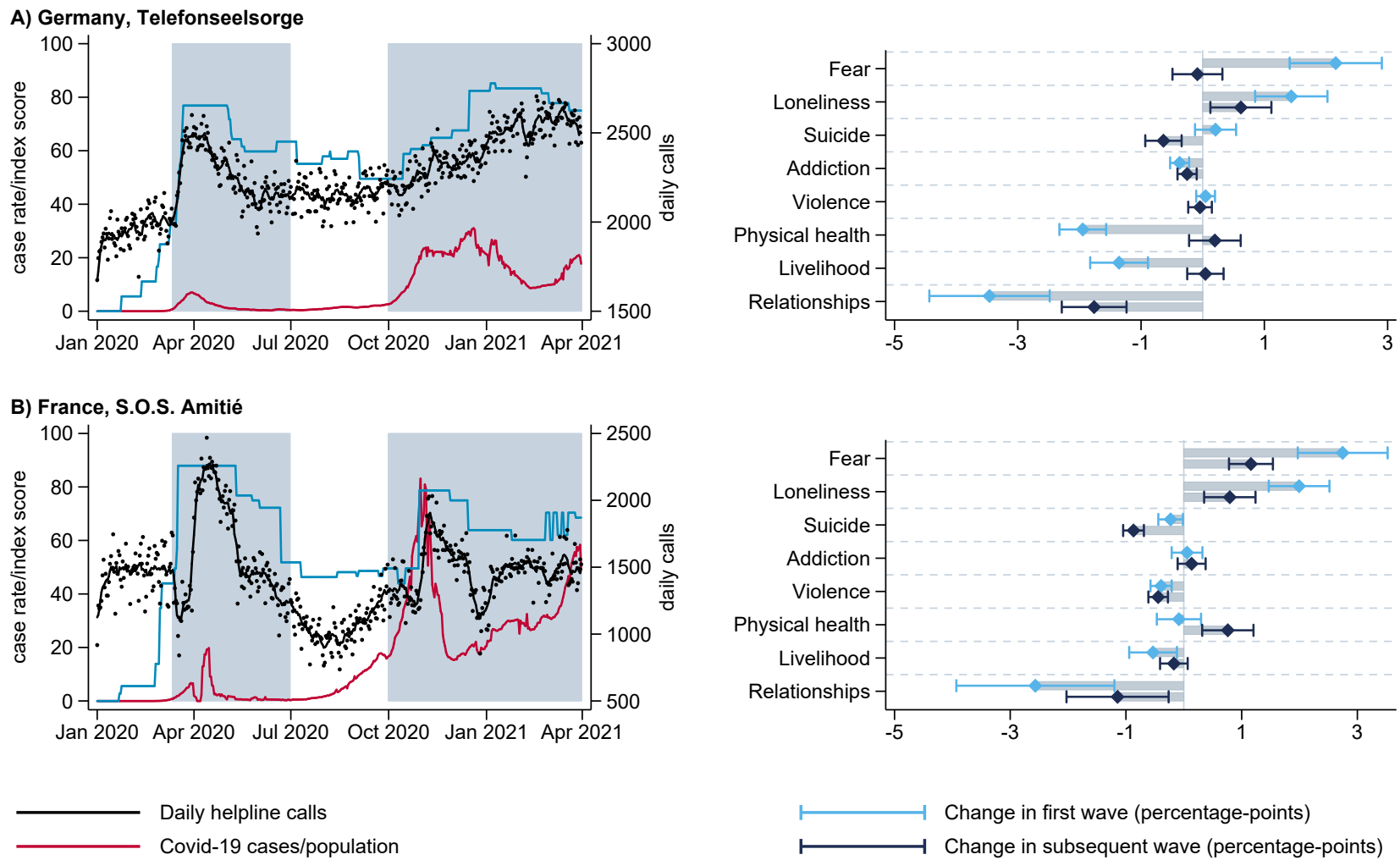

Figure 3: Helpline calls in Germany and France during the first and subsequent waves Helpline calls and topics recorded for (A) Germany (Telefonseelsorge) and (B) France (S.O.S. Amitié). Plots on the left show the seven-day moving average sum of daily helpline calls in black (right axis), with government response stringency index in blue [32], and the seven-day moving average of newly confirmed COVID-19 cases per million population and day in red (left axis) [31]. Shaded areas indicate first- and subsequent-wave periods. Plots on the right show estimated coefficients for binary variables denoting the two periods with $95 \%$ confidence intervals, based on separate linear probability regression models with dependent variable set to one for calls related to the respective topic. Models include year, week-of-year, and day-of-week fixed effects. See Methods, equation (4). Standard errors are clustered at the week level. Supplementary Table S7 shows detailed regression results. 
Calls related to suicidal ideation decreased when case numbers rose, increased when containment measures were tightened and decreased when income support was extended. Helpline call data allow us to use panel data regression to isolate partial correlations between policy measures and indicators of mental health. A particularly informative empirical laboratory for this analysis are calls to the National Suicide Prevention Lifeline (Lifeline) in the United States. We have data for 2019, 2020, and early 2021, allowing us to exploit the considerable intra-national (state-level) variation of epidemiological situations and policy measures observed within the United States. Thanks to coordination across the network of crisis centers that constitute the Lifeline through a common set of general guidelines, institutional and measurement issues that complicate comparisons across diverse sets of helplines and nations are less of a concern in this dataset. Moreover, calls to the Lifeline have been used to predict the incidence of actual suicides, e.g. by [12]. As a helpline focused on suicide, however, the Lifeline does not allow us to track changes in the composition of mental health problems.

Fig. 4 presents our main findings. The averaged time trends shown in Panel A reveal that calls to the Lifeline were no higher in 2020 than in 2019 during the first wave, but somewhat higher during subsequent waves of COVID-19. Panel A(ii) illustrates the heterogeneity in the number and evolution of calls across states. It is this variation that we seek to 'explain' with state-week variation in infections and policies. In Panel B of Fig. 4 , we show the variation of our three explanatory variables: COVID-19 cases [31], NPIs as measured by the components 'containment and closure policies' summarized in the stringency index, and the generosity of public compensation payments to workers as measured by the component 'income support' of the Oxford COVID-19 Government Response Tracker [32]. These graphs illustrate the longitudinal variation of the independent variables in our regression analyses. In Panel C of Fig. 4, we summarize our regression results (see Table S8 for the precise model specification). The left-hand chart shows estimates from data that are pooled across the entire duration of the pandemic. We find that increases in SARS-CoV-2 infections, ceteris paribus, were associated with statistically significant decreases in the number of calls to the suicide helpline. The estimated coefficient implies that a $10 \%$ increase in infections leads to a drop in calls to the suicide helpline of some $0.1 \%$. 
A) National Suicide Prevention Lifeline

(i) Weekly calls across US states ('000)

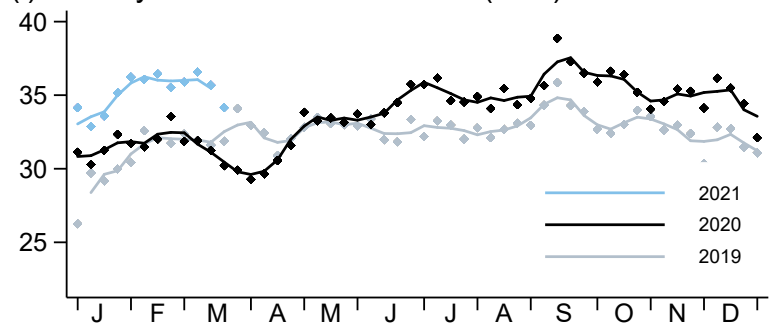

(ii) Log calls, deviation from state mean

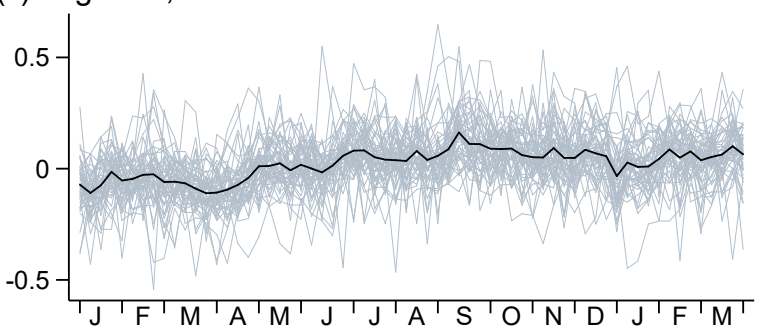

B) Local pandemic dynamics and government response

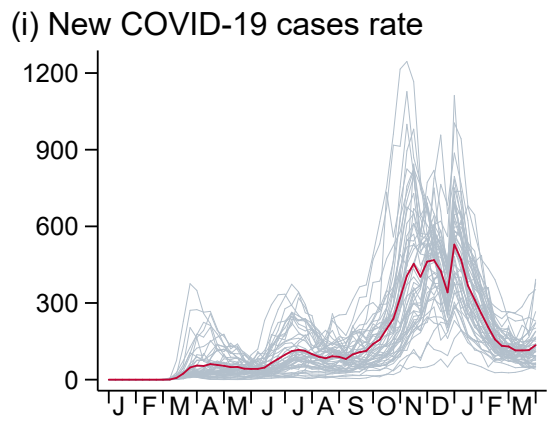

(ii) Stringency index
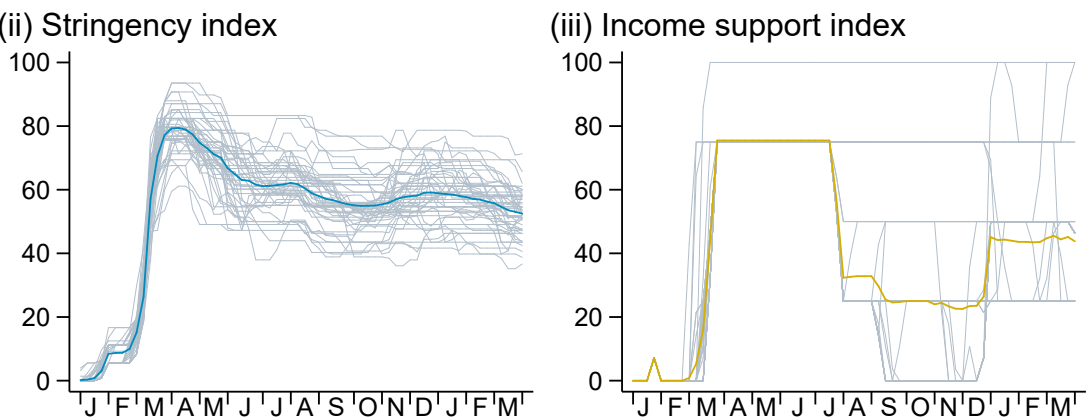

C) Coefficient estimates, Log-log model with state and week fixed effects (elasticities)

(i) Baseline model

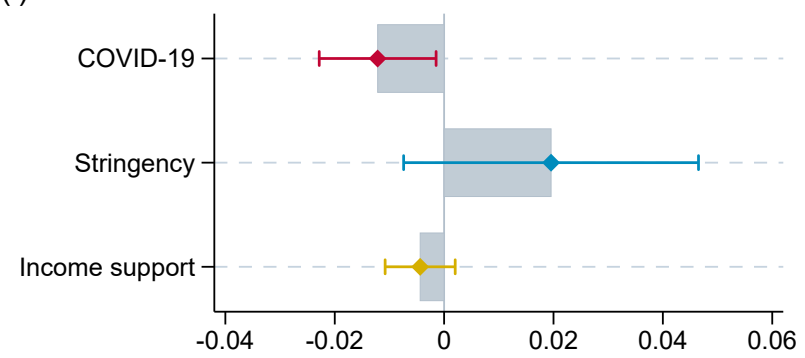

(ii) Time-varying effects

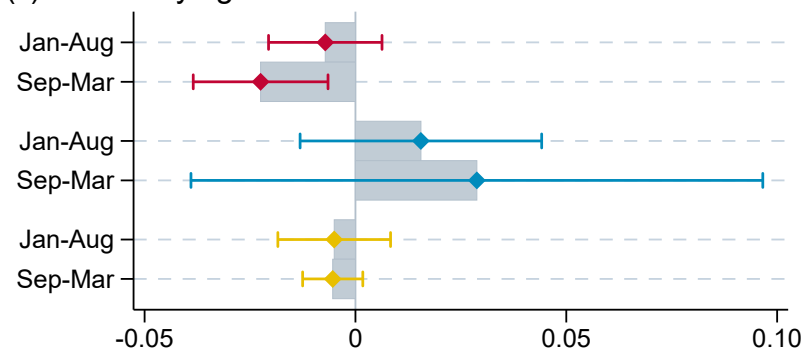

Figure 4: Calls to the National Suicide Prevention Lifeline, COVID-19, and policy in the United States (A) National Suicide Prevention Lifeline, (i) overall sum of weekly calls routed to centers in 51 states by year, with 3-week moving average; (ii) deviation of log calls from the state mean in gray, overall weekly average in black. (B) Weekly average scores for (i) newly confirmed COVID-19 infections per 100,000 population [31], (ii) government response stringency index, and (iii) income support index [32]. Individual state values in gray. (C) Sub-national panel model including state and week fixed effects, dependent variable is $\ln ($ Lifeline calls +1$)$ and independent variables are measured in logs as well. Estimated coefficients with $95 \%$ confidence intervals, standard errors are clustered at the state-month level. See Methods, equation (5). Tables S8 and S9 show detailed estimation results and alternative specifications.

One interpretation of this result is that the pandemic itself attenuates suicidal anxieties, perhaps

by shifting people's focus on the distress of others, or on their own fear of the pandemic. This interpre- 
tation is consistent with the evolution of calls to the U.S. Disaster Distress Helpline, which is aimed at providing crisis counseling to people affected by COVID-19: calls to that helpline increased very strongly in the initial phase of the pandemic, suggesting some substitution away from pre-existing anxieties toward more proximate COVID-19-related sources of distress (see Fig. S2 in the Supplementary Materials). Policy interventions in the shape of more stringent state-level NPIs or more generous state-level income support measures are not found to have statistically significant effects on Lifeline calls. Taking the somewhat imprecisely estimated coefficients at face value, however, suggests that stricter NPIs were followed by a slight increase in Lifeline calls, while income support policies had the opposite effect. The point estimate on the NPI stringency measure implies that tightening measures by $10 \%$ raised the volume of calls to the suicide helpline by some $0.2 \%$.

The right-hand-side chart of Panel C in Fig. 4 shows the estimated effects of the three explanatory variables separately for the first and the subsequent waves of the pandemic, with the cutoff date placed at September 1,2020. We find that the dampening effect on Lifeline calls of the pandemic itself (measured through confirmed infections) increased across the two pandemic waves. The effects on Lifeline calls of more stringent NPIs or more generous income support, however, did not noticeably differ across waves of the pandemic. Taken together, these estimates confirm that the mental-health implications of the pandemic remained relatively stable across the first and subsequent waves. Table S9 shows that these qualitative results are robust across a range of panel regression specifications. 


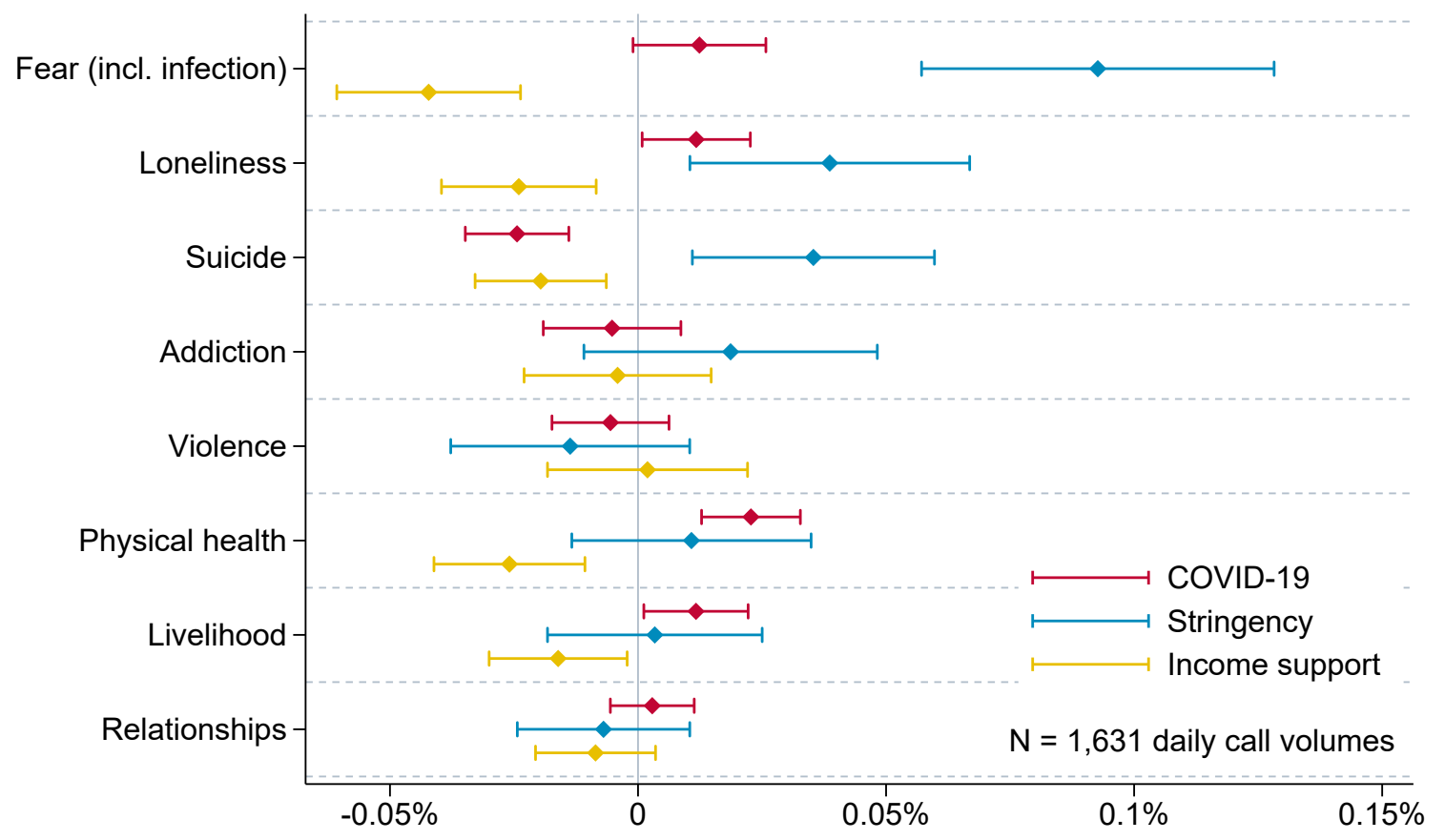

Figure 5: Daily calls by conversation topic, COVID-19, and policy in Germany and France Coefficients from separate regression models by topic with $95 \%$ confidence interval. The dependent variable is $\ln$ (Daily calls +1 ) and the independent variables are defined as $\ln$ (COVID-19 case rate +1$), \ln$ (Stringency index+1), and $\ln ($ Income support index+1) [31,32]. The sample includes all calls featuring at least one recorded conversation topic to Telefonseelsorge (Germany) and S.O.S. Amitié (France), from January 1, 2019 to March 31, 2021, aggregated to daily totals. All models include helpline indicators, interacted with year, week-of-year, and day-of-week fixed effects. See Methods, equation (7). Standard errors are clustered at the helpline-week level. Supplementary Table S12 shows detailed regression results.

The pattern observed in U.S. suicide helpline data is corroborated by a corresponding regression analysis based on the German and French helplines (Fig. 5): ceteris paribus, rising infection rates and more generous income support policies were followed by drops in the number of helpline calls due to suicidal ideation, whereas more stringent NPIs were followed by more suicide-related calls.

These effects are estimated to be statistically significant, and consistent with those based on the U.S. Lifeline. Our findings suggest that public compensation payments for pandemic-induced losses not only reduce economic hardship but also have broader benefits: more generous income support is found to lead to fewer calls because of fear, loneliness, suicidal ideation, physical health concerns and, as expected, economic anxiety ('livelihood', see Fig. 5). 
Table 1: Helpline data

\begin{tabular}{lllrrc}
\hline Country & Helpline & Total calls & Data start & Data end \\
\hline A & Germany & Telefonseelsorge Deutschland & $1,500,938$ & 01.01 .2019 & 31.03 .2021 \\
& France & S.O.S. Amitié & $1,153,029$ & 01.01 .2019 & 31.03 .2021 \\
Netherlands & De Luisterlijn & 454,820 & 01.01 .2019 & 30.06 .2020 \\
Germany & Nr. gegen Kummer (children) & 208,924 & 01.01 .2019 & 18.02 .2021 \\
Belgium & Tele-Onthaal & 189,386 & 01.01 .2019 & 28.06 .2020 \\
Austria & Telefonseelsorge Österreich & 89,619 & 01.01 .2019 & 30.06 .2020 \\
China & Hope 24 Line & 65,519 & 01.01 .2019 & 25.06 .2020 \\
& Italy & Telefono Amico & 54,999 & 01.01 .2019 & 01.06 .2020 \\
Slovenia & Zaupni telefon Samarijan & 43,494 & 01.01 .2019 & 14.01 .2021 \\
& Germany & Nr. gegen Kummer (parents) & 31,363 & 01.01 .2019 & 18.02 .2021 \\
& Czech Republic & Modrá linka & 19,871 & 01.01 .2019 & 12.06 .2020 \\
& Israel & SAHAR Emotional support chat & 10,099 & 01.01 .2020 & 24.12 .2020 \\
& Portugal & S.O.S. Voz Amiga & 9,930 & 02.01 .2019 & 15.06 .2020 \\
& Germany & Muslimisches Seelsorgetelefon & 5,485 & 01.01 .2020 & 08.12 .2020 \\
& Lebanon & Embrace Lifeline & 5,020 & 02.01 .2019 & 01.07 .2020 \\
& Luxembourg & SOS Détresse & 1,928 & 01.01 .2020 & 21.06 .2020 \\
& Bosnia Herzeg. & Plavi Telefon & 1,034 & 01.01 .2019 & 23.10 .2020 \\
& Hong Kong & Samaritan Befrienders & 635 & 23.01 .2020 & 06.10 .2020 \\
\hline B Switzerland & Die Dargebotene Hand & 110,177 & 28.02 .2019 & 30.06 .2020 \\
& Hungary & LESZ & 79,491 & 01.01 .2019 & 31.05 .2020 \\
& Finland & MIELI Mental Health & 32,148 & 01.01 .2020 & 30.06 .2020 \\
\hline C & United States & National Suicide Prevention Lifeline & $3,858,039$ & 01.01 .2019 & 21.03 .2021 \\
& & Disaster Distress Helpline & 78,861 & 01.01 .2019 & 21.03 .2021 \\
\hline
\end{tabular}

\section{Methods}

Helpline call data Our sample of helplines includes large, general crisis helplines, dedicated suicide prevention helplines, as well as some helplines that focus on specific groups such as children, parents, or immigrants. The selection of sample headlines was based (a) on an internet search of well-documented helplines and (b) on receiving data from those helplines. Of 154 helplines contacted, we received data from 37 helplines. The information from 23 of these was of sufficiently detailed coverage and consistency to be included in our pooled analyses. Table 1 lists the included helplines, classified based on the format of the available data. The

most detailed information was provided by the helplines in panel (A), where we have received individual conversation-level data, including information on caller's sex and approximate age, as well as on the issues discussed during the conversation. From the three additional helplines in panel (B), we received aggregate time series of daily call volumes, with separate series by gender, age category and topic. Moreover, for the two helplines in panel (C), we received sub-national weekly series of call volumes across US States. In contrast to the data in (A) and (B), the number of calls does not refer to answered calls and actual conversations, but to the raw number of calls routed to local centers. 
Call volumes after the pandemic outbreak For Fig. 1, we combine the time series data (B) with aggregates based on the call-level data (A) in a daily panel of call volumes for 21 helplines, covering the time up to June, 302020 if available. Note that for 4 of the helplines (MIELI, S.O.S. Détresse, SAHAR, Muslimisches Seelsorgetelefon) no data is available for 2019. We then look exclusively on the period from 4 weeks before to 12 weeks after the country-specific event date in 2020, as well as, if available, the corresponding days of the year 2019. To summarize the overall dynamics, we estimate the following model:

$$
\ln (\text { Calls })_{h, t}=\sum_{\tau=-4}^{-1} \gamma^{\tau} \text { Week }_{h, t}^{\tau}+\sum_{\tau=1}^{12} \gamma^{\tau} \text { Week }_{h, t}^{\tau}+\xi_{h} \times \Theta_{t}+\epsilon_{h, t}
$$

The dependent variable is the natural logarithm of the number of calls to helpline $h$ recorded on day $t$. We define the local outbreak as (a) the date when the cumulative number of COVID-19 cases per population exceeded 1/100,000 or (b) when shelter-in-place orders were first introduced [31, 32]. For both versions, we define indicator variables $W_{e e} k_{h, t}^{\tau}$ that are set to one for days in event week number $\tau \in[-4,12]$ in 2020. The model includes helpline fixed effects $\xi_{h}$, interacted with year, week-of-year and day-of-week indicators, summarized in the vector $\Theta_{t}$. The reference category is the week of the pandemic outbreak, and the coefficients $\gamma^{\tau}$ allow us to track the percentage deviation in daily calls compared to week 0. See Figure S1 and Table S1 in the supplementary materials for details on event dates and call volumes for each of the 21 included helplines.

Helpline data, individual calls To investigate changes in conversation topics in Fig. 2, we focus on the call-level data (from helplines in Panel (A) of Table 1) and combine information from 12 helplines in a database of more than 2 million calls. For each helpline, we categorize calls based on the recorded information on the problems of callers and the topics discussed. Precise categorizations of call topics differ across helplines, but they are sufficiently similar to allow us to map them into to the following common categories: loneliness (social isolation, entrapment), fear (general fear, anxiety, fear of infection with SARS-Cov-2), suicide (suicidal ideation, suicidal thoughts or plans, suicide attempts, suicide of others), addiction (drugs, alcohol, other addictions), violence (physical violence and abuse, sexual harassment, rape), physical health (disease, longterm illness, disability), and two broad categories for livelihood (work situation, unemployment, financial problems, housing), and relationships (family life, parenting, marriage and intimate relationships, separation). Note that, as some topics are not recorded at all for some helplines, the sample size differs depending on which topic we look at: the largest sample includes data from 12 helplines, where we can distinguish calls related to suicide from calls concerning other issues.

Additionally, we have coded the sex and age category of each caller, and (where possible) further characteristics such as marital status, living situation and occupational status. In the supplementary materials, we provide a more detailed description of each sample helpline. As helplines record age categories differently, our classification cannot be fully precise. Using the boundaries of available age groups, the group of callers below 30 includes only those that were recorded in an age group with an upper limit below 30 . The same logic applies to the group of callers older than 60 , and the middle category in some cases includes also individuals whose age is slightly below 30 years or above 60 .

For Fig. 2 we restrict the sample to calls recorded for the time from 1 January 2019 through 30 June 2020, where information on sex and age group of callers is available. When estimating the relative importance 
of a topic, we define the dependent variable $T_{i, h, t}$ as equal to one for call $i$ to helpline $h$ on day $t$ if the conversation was related to topic T (Fear, Loneliness, Suicide, Addiction, Violence, Physical health, Livelihood, or Relationships), and zero for unrelated calls, where another topic was recorded. Calls without information on caller issues or conversation topics are not included. Based on the date when the cumulative number of COVID-19 cases per population exceeded 1/100,000 in the country of operation [31], we define an indicator Post outbreak $_{h, t}$ and estimate a linear probability model as in equation 2:

$$
T_{i, h, t}=\gamma \text { Post outbreak } k_{h, t}+\xi_{h} \times \Theta_{t}+\epsilon_{i, t}
$$

The model includes helpline indicators $\xi_{h}$ to account for time invariant differences among helplines. We further add year, week-of-year and day-of-week indicators, summarized in the vector $\Theta_{t}$, interacted with the helpline fixed effects, to account for secular trends and for seasonal and day-of-week effects. Standard errors are clustered at the helpline-week level.

When estimating heterogeneous effects, we estimate alternative specifications including individual caller characteristics and interaction terms. To illustrate the change in topics for different groups, we classify callers into six non-overlapping groups, denoted in the vectors Sex (male, female) and Age group (below 30, 30-60, above 60). In the model illustrated in equation 3, we interact the post-outbreak variable with all six group indicators, so that the coefficients represent the group-specific changes in topic shares:

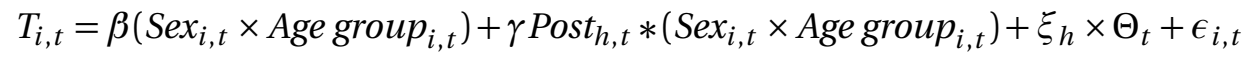

For the main effects of caller sex and age groups, indicators for the reference group of male callers in the 30-60 age category are omitted. Tables S3 to S6 in the supplementary materials show descriptive statistics and detailed estimation results.

For the analysis of the longer time horizon and the second wave in Fig. 3, we focus on call level data from Germany and France, from January, 12019 through March, 31 2021. We estimate a specification similar to the previous approach, separately for the two helplines and each topic. To distinguish the changes around the outbreak from later adjustments during the subsequent wave, we define two indicator variables $W^{l}$ and $W^{2}$ denoting two periods. The first covers the time from 11 March 2020, when the World Health Organization declared the outbreak a pandemic, to 30 June 2020, when the number of infections decreased again and containment measures were relaxed both in Germany and in France. The second period indicator is equal to one for the time after 1 October 2020. equation 4 illustrates the estimated model:

$$
T_{i, t}=\gamma_{1} W_{t}^{1}+\gamma_{2} W_{t}^{2}+\Theta_{t}+\epsilon_{i, t}
$$

As we analyze the two helplines separately, we do not include helpline fixed effects here, but capture secular trends and seasonal patterns through the inclusion of year, week-of-year, and day-of-week indicators. Standard errors are clustered at the week level.

Call volumes across U.S. states The analysis of sub-national call volumes in Fig. 4 relies on data on weekly call volumes routed to the National Suicide Prevention Lifeline (Lifeline). The analysis is based on weekly 
call volumes for US States and Territories over 116 weeks, starting in 2019 with the week ending on January 6, and up to the week ending on Sunday, March 21, 2020 Based on phone numbers, the state from which calls were placed can be inferred, even though internal migration means that this classification is subject to measurement error. We focus on calls from 50 US states and the District of Columbia. While the Lifeline receives calls from Canadian provinces, its mission is to serve the US. Calls from Canada, from other countries and of unknown origin are therefore not included.

In order to measure the timing and intensity of government responses consistently across time, countries and sub-national regions, we rely on aggregate policy indices from the Oxford COVID-19 Government Response Tracker [32]. In particular, we use two policy indices, the Government Response Stringency Index, and the Income Support Index. The stringency index shows the strictness of containment policies and restrictions of personal freedom, and is based on an unweighted average of 8 component scores for stay-at-home requirements, workplace and public transport closures, restrictions on public events, gatherings, domestic and international travel, and information campaigns. The income support index reflects the availability of financial support. To obtain a comparable measure, we construct the index score using the ordinal measure and the flag for sectoral targeting to arrive at a value between 0 and 100. As we rely on the sub-national information on policies in US states, it is important to note that we use the total index scores: whenever national policies were more restrictive than those of individual states, the higher score is imputed. Data on the daily number of newly confirmed COVID-19 cases and deaths are taken from the JHU CSSE data repository [31].

The panel structure allows us to exploit the idiosyncratic variation within states $j$ over time (weeks $w$ ) while controlling for overall trends. We estimate a two-way error component model as illustrated in equation 5:

$$
\ln (\text { Calls }+1)_{j, w}=\pi_{1} \ln (\text { COVID-19+1 })_{j, w}+\pi_{2} \ln (\text { Stringency }+1)_{j, w}+\pi_{3} \ln (\text { Inc. support }+1)_{j, w}+\xi_{j}+\theta_{w}+\epsilon_{j, w}
$$

The dependent variable is the natural logarithm of the number of calls plus one, COVID-19 is defined as one plus the sum of newly confirmed COVID-19 cases in week $w$ per 100,000 people, while Stringency and Income support are calculated as weekly averages of the respective daily index scores. State fixed effects $\xi_{j}$ absorb all time-invariant factors, and our analysis is therefore based on the idiosyncratic within-state variation in call volumes over time. The inclusion of week indicators $\theta_{w}$ allows us to capture all nation-wide and global effects and to focus solely on the relative differences in pandemic exposure and policy response. Standard errors are clustered at the state-month level.

To investigate the extent to which the relationship changed over time, we re-estimate the model as in equation 6 . Here, we include the three main explanatory variables interacted with two indicators variables that are set to 1 for the time period from January to July 2020, and for September 2020 to March 2021 respectively.

$$
\begin{aligned}
\ln (\text { Calls }+1)_{j, w}= & (\text { Jan-Aug }) *\left[\pi_{1} \ln (\text { COVID }-19+1)_{j, w}+\pi_{2} \ln (\text { Stringency }+1)_{j, w}+\pi_{3} \ln (\text { Inc. support }+1)_{j, w}\right] \\
& +(\text { Sep-Mar }) *\left[\pi_{1} \ln (\text { COVID }-19+1)_{j, w}+\pi_{2} \ln (\text { Stringency }+1)_{j, w}+\pi_{3} \ln (\text { Inc. support }+1)_{j, w}\right] \\
& +\xi_{j}+\theta_{w}+\epsilon_{j, w}
\end{aligned}
$$

For the analysis in Fig. 5, we combine the previous approaches and estimate the relationship between call volumes and the three variables as illustrated in equation 7 , based on topic-specific call volumes to 
Telefonseelsorge (Germany) and S.O.S. Amitié (France) during the time from January 1, 2019 to March 31, 2021.

$$
\ln (\text { Calls }+1)_{h, t}=\pi_{1} \ln (\text { COVID }-19+1)_{h, t}+\pi_{2} \ln (\text { Stringency }+1)_{h, t}+\pi_{3} \ln (\text { Inc. support }+1)_{h, t}+\xi_{h} \times \Theta_{t}+\epsilon_{h, t}
$$

In contrast to the sub-national panel of US states, here we do not include week fixed effects but capture secular trends and seasonal patterns through helpline fixed effects, interacted with year, week-of-year, and day-of-week indicators. Standard errors are clustered at the helpline-week level.

\section{References}

[1] Ridley, M., Rao, G., Schilbach, F. \& Patel, V. Poverty, depression, and anxiety: Causal evidence and mechanisms. Science 370, eaay0214 (2020). URL https ://doi .org/10.1126/s cience .aay0214.

[2] McInerney, M., Mellor, J. M. \& Nicholas, L. H. Recession depression: mental health effects of the 2008 stock market crash. Journal of Health Economics 32, 1090-1104 (2013). URL https ://doi .org/10. 1016/j.jhealeco.2013.09.002.

[3] Parmar, D., Stavropoulou, C. \& Ioannidis, J. P. A. Health outcomes during the 2008 financial crisis in Europe: systematic literature review. BMJ 354, i4588 (2016). URL https : //doi .org/10 . 1136/bmj . i4588.

[4] Chang, S.-S., Stuckler, D., Yip, P. \& Gunnell, D. Impact of 2008 global economic crisis on suicide: time trend study in 54 countries. BMJ 347, f5239 (2013). URL https ://doi .org/10 .1136/bmj .f5239.

[5] Phillips, J. A. \& Nugent, C. N. Suicide and the Great Recession of 2007-2009: the role of economic factors in the 50 US states. Social Science \& Medicine 116, 22-31 (2014). URL https : //doi .org/10 .1016/j . socscimed.2014.06.015.

[6] Nordt, C., Warnke, I., Seifritz, E. \& Kawohl, W. Modelling suicide and unemployment: a longitudinal analysis covering 63 countries, 2000-11. The Lancet Psychiatry 2, 239-245 (2015). URL http://dx . doi . org/10.1016/S2215-0366(14)00118-7.

[7] Gunnell, D. et al. Suicide risk and prevention during the COVID-19 pandemic. The Lancet Psychiatry 7, 468-471 (2020). URL https ://doi.org/10.1016/S2215-0366 (20)30171-1.

[8] Zortea, T. C. et al. The impact of infectious disease-related public health emergencies on suicide, suicidal behavior, and suicidal thoughts. Crisis 0 (2020). URL https : //doi . org/10 . 1027/0227-5910/ a000753.

[9] Leach, L. S. \& Christensen, H. A systematic review of telephone-based interventions for mental disorders. Journal of Telemedicine and Telecare 12, 122-129 (2006). URL https : //doi .org/10 .1258/ 135763306776738558.

[10] Coveney, C. M., Pollock, K., Armstrong, S. \& Moore, J. Callers' experiences of contacting a national suicide prevention helpline. Crisis 33, 313-324 (2012). URL https : //doi . org/10 . 1027/0227-5910/ a000151. 
[11] De Leo, D., Buono, M. D. \& Dwyer, J. Suicide among the elderly: the long-term impact of a telephone support and assessment intervention in northern Italy. British Journal of Psychiatry 181, 226-229 (2002). URL https://doi.org/10.1192/bjp.181.3.226.

[12] Choi, D. et al. Development of a machine learning model using multiple, heterogeneous data sources to estimate weekly US suicide fatalities. JAMA Network Open 3, e2030932 (2020). URL https ://doi .org/ 10.1001/jamanetworkopen.2020.30932.

[13] Halford, E. A., Lake, A. M. \& Gould, M. S. Google searches for suicide and suicide risk factors in the early stages of the COVID-19 pandemic. PLOS ONE 15, e0236777 (2020). URL https ://doi .org/10 .1371/ journal . pone. 0236777.

[14] Turkington, R. et al. Behavior of callers to a crisis helpline before and during the COVID-19 pandemic: quantitative data analysis. JMIR Mental Health 7, e22984 (2020). URL http: //dx .doi .org/10 . 2196/ 22984.

[15] Armbruster, S. \& Klotzbücher, V. Lost in lockdown? COVID-19, social distancing, and mental health in Germany. Covid Economics: Vetted and real-time papers 22, 117-153 (2020). URL https : //cepr .org/ file/9096/download?token=RZOVZVi5.

[16] Brülhart, M. \& Lalive, R. Daily suffering: Helpline calls during the COVID-19 crisis. Covid Economics: Vetted and Real-Time Papers 19, 143-158 (2020). URL https ://cepr.org/file/9088/download? token $=\mathrm{c} 6 \mathrm{oU} 20 \mathrm{eH}$.

[17] Richter, D., Riedel-Heller, S. \& Zürcher, S. Mental health problems in the general population during and after the first lockdown phase due to the SARS-Cov-2 pandemic: Rapid review of multi-wave studies. Epidemiology and Psychiatric Sciences 30, E27 (2021). URL https ://doi .org/10.1017/ s2045796021000160.

[18] John, A., Pirkis, J., Gunnell, D., Appleby, L. \& Morrissey, J. Trends in suicide during the COVID-19 pandemic. BMJ 371, m4352 (2020). URL http://dx . doi .org/10.1136/bmj .m4352.

[19] Pirkis, J. et al. Suicide trends in the early months of the COVID-19 pandemic: Interrupted time series analysis of preliminary data from 21 countries. The Lancet Psychiatry (2021). URL https : //doi .org/ 10.1016/S2215-0366(21)00091-2.

[20] Tanaka, T. \& Okamoto, S. Increase in suicide following an initial decline during the COVID-19 pandemic in Japan. Nature Human Behaviour 5, 229-238 (2021). URL https ://doi .org/10.1038/ s41562-020-01042-z.

[21] Brodeur, A., Clark, A. E., Fleche, S. \& Powdthavee, N. COVID-19, lockdowns and well-being: evidence from Google Trends. Journal of Public Economics 193, 104346 (2020). URL https ://doi .org/10.1016/j . jpubeco.2020.104346. 
[22] Fetzer, T., Hensel, L., Hermle, J. \& Roth, C. Coronavirus perceptions and economic anxiety. Review of Economics and Statistics 1-36 (2020). URL https : //doi .org/10.1162/rest_a_00946.

[23] Tran, U. S. et al. Low validity of Google Trends for behavioral forecasting of national suicide rates. PLOS ONE 12 (2017). URL https : //doi .org/10.1371/journal . pone. 0183149.

[24] Faust, J. S. et al. Suicide deaths during the COVID-19 stay-at-home advisory in Massachusetts, March to May 2020. JAMA Network Open 4, e2034273-e2034273 (2021). URL https ://doi .org/10.1001/ jamanetworkopen.2020.34273.

[25] Holland, K. M. et al. Trends in US emergency department visits for mental health, overdose, and violence outcomes before and during the COVID-19 pandemic. JAMA Psychiatry 78, 372-379 (2021). URL https : //doi.org/10.1001/jamapsychiatry.2020.4402.

[26] Baron, E. J., Goldstein, E. G. \& Wallace, C. T. Suffering in silence: how COVID-19 school closures inhibit the reporting of child maltreatment. Journal of Public Economics 190, 1-13 (2020). URL https ://doi. org/10.1016/j.jpubeco.2020.104258.

[27] Bullinger, L. R., Carr, J. B. \& Packham, A. COVID-19 and crime: effects of stay-at-home orders on domestic violence. American Journal of Health Economics (2021). URL https : //doi .org/10 . 1086/713787.

[28] Leslie, E. \& Wilson, R. Sheltering in place and domestic violence: evidence from calls for service during COVID-19. Journal of Public Economics 189, 104241 (2020). URL https : //doi .org/10 .1016/j . jpubeco.2020.104241.

[29] Banks, J., Xu, X. et al. The mental health effects of the first two months of lockdown during the COVID-19 pandemic in the UK. Fiscal Studies 41, 685-708 (2020). URL https : //doi .org/10.1111/1475-5890. 12239.

[30] Holman, E. A., Thompson, R. R., Garfin, D. R. \& Silver, R. C. The unfolding COVID-19 pandemic: a probability-based, nationally representative study of mental health in the United States. Science Advances 6, eabd5390 (2020). URL https ://doi .org/10.1126/sciadv.abd5390.

[31] Dong, E., Du, H. \& Gardner, L. An interactive web-based dashboard to track COVID-19 in real time. The Lancet Infectious Diseases 20, 533-534 (2020). URL https : //doi .org/10 . 1016/S1473-3099 (20) 30120-1.

[32] Hale, T. et al. A global panel database of pandemic policies (Oxford COVID-19 Government Response Tracker). Nature Human Behaviour 5, 529-538 (2021). URL https ://doi .org/10.1038/ s41562-021-01079-8. 


\section{Acknowledgments}

We thank the following people and helplines for sharing their expertise and for granting us access to their data:

Carola Hochhauser and Antonia Kesselring (Telefonseelsorge, Austria), Jennifer Pots (Tele-Onthaal, Belgium), Maja Kovacevic (Plavi Telefon, Bosnia and Herzegovina), Rujun Ma and Wenping Ni (Hope 24 Line, China), Hana Regnerova (Modrá linka, Czech Republic), Hervé Dumont (S.O.S. Amitié, France), Susanna Winter (MIELI, Finland), Ludger Storch and Bernd Blömeke (Telefonseelsorge, Germany), Imran Sagir (Muslimisches Seelsorgetelefon, Germany), Heidi Schütz (Nummer gegen Kummer, Germany), Hsuan-Chia (Samaritan Befrienders, Hong Kong), Eva Brandisz (LESZ, Hungary), Yael Levy (Sahar, Israel), Monica Petra (Telefono Amico, Italy), Pia Zeinoun (Embrace Lifeline, Lebanon), Sébastien Hay (SOS Détresse, Luxembourg), Jaap Jakobs (De Luisterlijn, Netherlands), Francisco Paulino (SOS Voz Amiga, Portugal), Kristina Bogataj (Zaupni telefon Samarijan, Slovenia), Sabine Basler (Die Dargebotene Hand, Switzerland), Alena Goldstein, Johnathan Higgins, and Sean Murphy, Vibrant Emotional Health (National Suicide Prevention Lifeline and Disaster Distress Helpline, USA).

We thank Charles Efferson and Laurent Keller for helpful comments.

Funding We are grateful to the Swiss National Science Foundation (NCCR LIVES -'Overcoming Vulnerability: Life Course Perspectives') for financial support.

Author contributions All authors contributed equally to this work.

Competing interests The authors declare that they have no competing interests.

Data availability Data were provided by helplines for the sole purpose of this research project, subject to non-disclosure agreements. We will be happy to ask our data providers to allow us to share the sub-set of data required to replicate all of our analyses. Given that these data would reveal no information that can be tracked to individuals, we are hopeful of obtaining data providers' agreement. 


\section{Supplementary Materials}

\section{Supplementary tables and figures}

Table S1: Daily call volumes around the pandemic outbreak, 21 helplines

\begin{tabular}{|c|c|c|c|c|}
\hline Country & Helpline & Outbreak & SIP introduction & Number of calls \\
\hline Germany & Telefonseelsorge Deutschland & 8 Mar. & 9 Mar. & 408464 \\
\hline France & S.O.S. Amitié & 7 Mar. & 17 Mar. & 369736 \\
\hline Netherlands & De Luisterlijn & 7 Mar. & 6 Mar. & 210098 \\
\hline Belgium & Tele-Onthaal & 7 Mar. & 18 Mar. & 86733 \\
\hline Switzerland & Die Dargebotene Hand & 4 Mar. & 17 Mar. & 86512 \\
\hline Germany & Nr. gegen Kummer (children) & 8 Mar. & 9 Mar. & 67178 \\
\hline Austria & Telefonseelsorge Österreich & 8 Mar. & 16 Mar. & 38198 \\
\hline Hungary & LESZ & 21 Mar. & 12 Mar. & 34762 \\
\hline Italy & Telefono Amico & 27 Feb. & 23 Feb. & 28114 \\
\hline China & Hope 24 Line & 2 Feb. & 23 Jan. & 25663 \\
\hline Finland & MIELI Mental Health & 11 Mar. & 16 Mar. & 22420 \\
\hline Slovenia & Zaupni telefon Samarijan & 10 Mar. & 14 Mar. & 14240 \\
\hline Germany & Nr. gegen Kummer (parents) & 8 Mar. & 9 Mar. & 9532 \\
\hline Czech Rep. & Modrá linka & 13 Mar. & 15 Mar. & 9243 \\
\hline Israel & SAHAR Emotional support chat & 13 Mar. & 17 Mar. & 5734 \\
\hline Portugal & S.O.S. Voz Amiga & 13 Mar. & 19 Mar. & 4565 \\
\hline Lebanon & Embrace Lifeline & 13 Mar. & 16 Mar. & 2518 \\
\hline Germany & Muslimisches Seelsorgetelefon & 8 Mar. & 9 Mar. & 1916 \\
\hline Luxembourg & SOS Détresse & 11 Mar. & 17 Mar. & 1290 \\
\hline Bosnia & Plavi Telefon & 18 Mar. & 20 Mar. & 656 \\
\hline Hong Kong & Samaritan Befrienders & 24 Feb. & 8 Feb. & 432 \\
\hline
\end{tabular}

Note: Helplines included in the analysis of daily call volumes underlying Fig. 1. Columns 3 and 4 show the local pandemic outbreak (the day when more than 100 cases per 100,000 population have been recorded)[31], and the date of SIP introduction (when shelter-in-place requirements were first introduced)[32] in the country of operation. Column 5 shows the sum of calls recorded on days included in the analysis of Fig. 1a, using the available data for the period from 4 weeks before to 12 weeks after the outbreak date in 2020, and the corresponding days of the year 2019. 

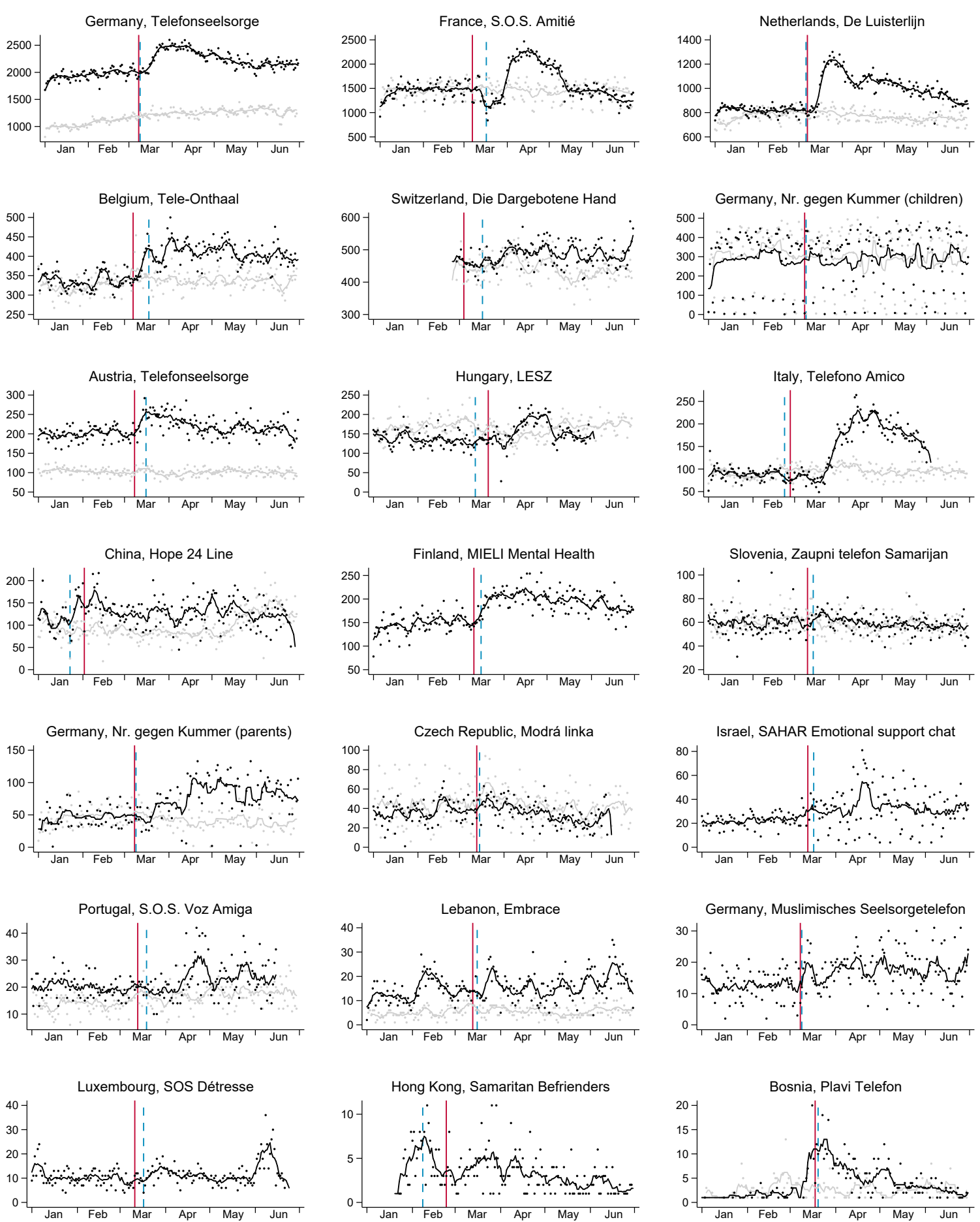

\section{Figure S1: Evolution of daily helpline call volumes during the first wave}

Sum of daily helpline contacts with seven-day moving average, January-June 2020 (black) and 2019 (light grey, not available for all helplines). The solid red line shows the date of the pandemic outbreak, when more than 199 cases per 100,000 population have been recorded[31]; the dashed blue line shows the date when shelter-in-place requirements were first introduced[32] in the country of operation. 
Table S2: Call volumes during the first wave - event study results

\begin{tabular}{|c|c|c|c|c|}
\hline \multirow[t]{2}{*}{ Event week 0: } & \multicolumn{2}{|c|}{ Local outbreak } & \multicolumn{2}{|c|}{ Shelter-in-place order } \\
\hline & (1) & (2) & (3) & (4) \\
\hline Week -4 & $\begin{array}{c}0.045 \\
{[-0.092,0.182]}\end{array}$ & $\begin{array}{c}0.009 \\
{[-0.044,0.062]}\end{array}$ & $\begin{array}{c}0.043 \\
{[-0.105,0.192]}\end{array}$ & $\begin{array}{c}0.026 \\
{[-0.051,0.103]}\end{array}$ \\
\hline Week -3 & $\begin{array}{c}-0.055 \\
{[-0.215,0.106]}\end{array}$ & $\begin{array}{c}0.011 \\
{[-0.053,0.075]}\end{array}$ & $\begin{array}{c}-0.030 \\
{[-0.180,0.120]}\end{array}$ & $\begin{array}{c}0.048 \\
{[-0.031,0.127]}\end{array}$ \\
\hline Week -2 & $\begin{array}{c}-0.086 \\
{[-0.199,0.027]}\end{array}$ & $\begin{array}{c}-0.012 \\
{[-0.092,0.069]}\end{array}$ & $\begin{array}{c}-0.125 \\
{[-0.241,-0.009]}\end{array}$ & $\begin{array}{c}0.003 \\
{[-0.100,0.106]}\end{array}$ \\
\hline Week -1 & $\begin{array}{c}0.060 \\
{[-0.002,0.122]}\end{array}$ & $\begin{array}{c}0.003 \\
{[-0.028,0.033]}\end{array}$ & $\begin{array}{c}0.030 \\
{[-0.035,0.096]}\end{array}$ & $\begin{array}{c}0.034 \\
{[-0.022,0.091]}\end{array}$ \\
\hline Week 1 & $\begin{array}{c}0.059 \\
{[-0.033,0.152]}\end{array}$ & $\begin{array}{c}-0.022 \\
{[-0.088,0.045]}\end{array}$ & $\begin{array}{c}0.066 \\
{[-0.018,0.150]}\end{array}$ & $\begin{array}{c}-0.005 \\
{[-0.040,0.029]}\end{array}$ \\
\hline Week 2 & $\begin{array}{c}0.108 \\
{[-0.013,0.229]}\end{array}$ & $\begin{array}{c}0.058 \\
{[-0.084,0.200]}\end{array}$ & $\begin{array}{c}0.115 \\
{[-0.003,0.233]}\end{array}$ & $\begin{array}{c}0.112 \\
{[0.031,0.194]}\end{array}$ \\
\hline Week 3 & $\begin{array}{c}0.188 \\
{[0.066,0.311]}\end{array}$ & $\begin{array}{c}0.135 \\
{[0.016,0.255]}\end{array}$ & $\begin{array}{c}0.168 \\
{[0.039,0.296]}\end{array}$ & $\begin{array}{c}0.270 \\
{[0.191,0.350]}\end{array}$ \\
\hline Week 4 & $\begin{array}{c}0.181 \\
{[0.089,0.273]}\end{array}$ & $\begin{array}{c}0.244 \\
{[0.191,0.297]}\end{array}$ & $\begin{array}{c}0.194 \\
{[0.088,0.301]}\end{array}$ & $\begin{array}{c}0.297 \\
{[0.197,0.398]}\end{array}$ \\
\hline Week 5 & $\begin{array}{c}0.168 \\
{[0.055,0.281]}\end{array}$ & $\begin{array}{c}0.246 \\
{[0.150,0.342]}\end{array}$ & $\begin{array}{c}0.126 \\
{[0.008,0.244]}\end{array}$ & $\begin{array}{c}0.282 \\
{[0.146,0.417]}\end{array}$ \\
\hline Week 6 & $\begin{array}{c}0.385 \\
{[0.230,0.540]}\end{array}$ & $\begin{array}{c}0.354 \\
{[0.226,0.483]}\end{array}$ & $\begin{array}{c}0.298 \\
{[0.139,0.458]}\end{array}$ & $\begin{array}{c}0.315 \\
{[0.210,0.420]}\end{array}$ \\
\hline Week 7 & $\begin{array}{c}0.200 \\
{[0.090,0.311]}\end{array}$ & $\begin{array}{c}0.190 \\
{[0.110,0.270]}\end{array}$ & $\begin{array}{c}0.229 \\
{[0.126,0.332]}\end{array}$ & $\begin{array}{c}0.245 \\
{[0.141,0.349]}\end{array}$ \\
\hline Week 8 & $\begin{array}{c}0.240 \\
{[0.124,0.356]}\end{array}$ & $\begin{array}{c}0.253 \\
{[0.171,0.335]}\end{array}$ & $\begin{array}{c}0.214 \\
{[0.099,0.328]}\end{array}$ & $\begin{array}{c}0.226 \\
{[0.152,0.301]}\end{array}$ \\
\hline Week 9 & $\begin{array}{c}0.212 \\
{[0.113,0.312]}\end{array}$ & $\begin{array}{c}0.168 \\
{[0.110,0.226]}\end{array}$ & $\begin{array}{c}0.208 \\
{[0.100,0.316]}\end{array}$ & $\begin{array}{c}0.152 \\
{[0.077,0.227]}\end{array}$ \\
\hline Week 10 & $\begin{array}{c}0.145 \\
{[0.045,0.246]}\end{array}$ & $\begin{array}{c}0.107 \\
{[0.059,0.155]}\end{array}$ & $\begin{array}{c}0.119 \\
{[0.018,0.220]}\end{array}$ & $\begin{array}{c}0.109 \\
{[0.029,0.189]}\end{array}$ \\
\hline Week 11 & $\begin{array}{c}0.096 \\
{[-0.025,0.216]}\end{array}$ & $\begin{array}{c}0.062 \\
{[-0.002,0.126]}\end{array}$ & $\begin{array}{c}0.068 \\
{[-0.045,0.180]}\end{array}$ & $\begin{array}{c}0.109 \\
{[0.031,0.186]}\end{array}$ \\
\hline Week 12 & $\begin{array}{c}0.095 \\
{[-0.046,0.235]}\end{array}$ & $\begin{array}{c}0.086 \\
{[0.009,0.162]}\end{array}$ & $\begin{array}{c}0.115 \\
{[-0.033,0.263]}\end{array}$ & $\begin{array}{c}0.106 \\
{[0.014,0.197]}\end{array}$ \\
\hline Weighted & No & YES & No & YES \\
\hline \# Helplines & 21 & 21 & 21 & 21 \\
\hline \# Observations & 4,139 & 4,139 & 4,133 & 4,133 \\
\hline
\end{tabular}

Note: Evolution of total helpline call numbers during the first wave. The dependent variable is the natural logarithm of daily helpline call volumes. The sample includes the period from 4 weeks before to 12 weeks after the event date in 2020, as well as the corresponding days of the year 2019. Coefficients show the average percentage change in daily calls compared to reference week 0 , which represents the week of a) the pandemic outbreak, defined as the date when the cumulative number of COVID-19 infections exceeded 1 per 100,000 inhabitants, or b) the date when shelter-in-place orders first entered into force. Standard errors in parentheses are clustered at the helpline-month level. 
Table S3: Call-level data January 2019-June 2020: Estimation sample

\begin{tabular}{llrrrrc}
\hline Country & Helpline & Calls & Female & Age 0-30 & Age 30-60 & Age 60+ \\
\hline Germany & Telefonseelsorge Deutschland & 768,694 & 0.69 & 0.15 & 0.55 & 0.30 \\
France & S.O.S. Amitié & 736,491 & 0.54 & 0.04 & 0.78 & 0.18 \\
Netherlands & De Luisterlijn & 328,565 & 0.67 & 0.09 & 0.72 & 0.20 \\
Germany & Nr. gegen Kummer (children) & 134,893 & 0.59 & 1.00 & 0.00 & 0.00 \\
Belgium & Tele-Onthaal & 115,588 & 0.67 & 0.13 & 0.57 & 0.29 \\
Italy & Telefono Amico & 54,999 & 0.41 & 0.06 & 0.85 & 0.09 \\
Austria & Telefonseelsorge Österreich & 54,687 & 0.69 & 0.09 & 0.58 & 0.33 \\
Slovenia & Zaupni telefon Samarijan & 28,956 & 0.47 & 0.01 & 0.90 & 0.09 \\
Germany & Nr. gegen Kummer (parents) & 19,339 & 0.88 & 0.11 & 0.81 & 0.08 \\
China & Hope 24 Line & 19,100 & 0.54 & 0.63 & 0.37 & 0.00 \\
Israel & SAHAR Emotional supportchat & 4,771 & 0.69 & 0.42 & 0.57 & 0.02 \\
Lebanon & Embrace Lifeline & 3,537 & 0.54 & 0.67 & 0.27 & 0.06 \\
\hline
\end{tabular}

Note: Helplines included in the call-level analysis of conversation topics during the first wave in Fig. 2. The sample includes calls recorded for the time from 1 January 2019 through 30 June 2020, where information on sex and age group of callers is available. Columns 4 to 7 show the shares of calls recorded for female callers and the three approximate age groups.

Table S4: Caller characteristics and topics in the estimation sample

\begin{tabular}{lrrr}
\hline & \multicolumn{1}{c}{ Share } & Sum of calls & Observations \\
\hline Female & 0.623 & $1,413,105$ & $2,269,620$ \\
Age 0-30 & 0.156 & 354,716 & $2,269,620$ \\
Age 30-60 & 0.630 & $1,429,318$ & $2,269,620$ \\
Age 60+ & 0.214 & 485,586 & $2,269,620$ \\
Fears & 0.136 & 289,498 & $2,123,773$ \\
Loneliness & 0.206 & 425,151 & $2,066,884$ \\
Suicide & 0.069 & 154,198 & $2,244,199$ \\
Addiction & 0.041 & 91,581 & $2,215,734$ \\
Violence & 0.045 & 100,102 & $2,215,751$ \\
Physical health & 0.144 & 319,835 & $2,222,612$ \\
Livelihood & 0.096 & 191,944 & $2,007,643$ \\
Relationships & 0.360 & 753,049 & $2,094,275$ \\
\hline Total calls & $2,269,620$ & & \\
\hline
\end{tabular}

Note: Overall distribution of calls included in the estimation sample (Fig. 2). 
Table S5: Individual call level data

\begin{tabular}{llcccccccc}
\hline Country & Helpline & Fears & Loneli. & Suicide & Addict. & Violence & P. health & Livelih. & Relations. \\
\hline Germany & Telefonseelsorge Deutschland & 0.15 & 0.21 & 0.13 & 0.03 & 0.03 & 0.16 & 0.12 & 0.43 \\
France & S.O.S. Amitié & 0.08 & 0.17 & 0.04 & 0.04 & 0.03 & 0.13 & 0.06 & 0.28 \\
Netherlands & De Luisterlijn & 0.32 & 0.51 & 0.03 & 0.05 & 0.08 & 0.15 & 0.15 & 0.37 \\
Germany & Nr. gegen Kummer (children) & 0.04 & 0.05 & 0.00 & 0.06 & 0.11 & 0.05 & & \\
Belgium & Tele-Onthaal & 0.05 & 0.20 & 0.09 & 0.09 & 0.07 & 0.30 & 0.44 \\
Italy & Telefono Amico & & 0.07 & 0.04 & 0.07 & 0.10 & 0.03 & 0.02 & 0.45 \\
Austria & Telefonseelsorge Österreich & 0.07 & 0.26 & 0.01 & 0.02 & 0.01 & 0.05 & 0.03 & 0.06 \\
Slovenia & Zaupni telefon Samarijan & & 0.19 & 0.01 & 0.04 & 0.02 & & 0.02 & \\
Germany & Nr. gegen Kummer (parents) & & 0.04 & 0.00 & 0.05 & 0.23 & 0.04 & 0.02 & 0.39 \\
China & Hope 24 Line & & & 0.02 & & & 0.06 & 0.09 & 0.30 \\
Israel & SAHAR Emotional support chat & 0.18 & 0.28 & 0.17 & 0.01 & 0.03 & & 0.28 & 0.30 \\
Lebanon & Embrace Lifeline & & & 0.35 & & & & & \\
\hline
\end{tabular}

Note: Overall shares of topics in the estimation sample, January 2019-June 2020 (Fig. 2), by helpline. 
Table S6: Changing conversation topics following the pandemic outbreak

\begin{tabular}{|c|c|c|c|c|c|c|c|c|}
\hline a) & (1) Fear & (2) Loneliness & (3) Suicide & (4) Addiction & (5) Violence & (6) Phys. Health & (7) Livelihood & (8) Relationships \\
\hline Post outbreak & $\begin{array}{c}0.024 \\
{[0.018,0.029]}\end{array}$ & $\begin{array}{c}0.015 \\
{[0.011,0.018]}\end{array}$ & $\begin{array}{c}-0.001 \\
{[-0.003,0.001]}\end{array}$ & $\begin{array}{c}-0.002 \\
{[-0.004,-0.001]}\end{array}$ & $\begin{array}{c}-0.004 \\
{[-0.005,-0.002]}\end{array}$ & $\begin{array}{c}-0.003 \\
{[-0.006,-0.000]}\end{array}$ & $\begin{array}{c}-0.007 \\
{[-0.010,-0.003]}\end{array}$ & $\begin{array}{c}-0.025 \\
{[-0.032,-0.018]}\end{array}$ \\
\hline $\begin{array}{l}\text { \# Helplines } \\
\text { \# Observations }\end{array}$ & $\begin{array}{c}7 \\
2,123,773\end{array}$ & $\begin{array}{c}10 \\
2,066,884\end{array}$ & $\begin{array}{c}12 \\
2,244,199\end{array}$ & $\begin{array}{c}10 \\
2,215,734\end{array}$ & $\begin{array}{c}10 \\
2,215,751\end{array}$ & $\begin{array}{c}9 \\
2,222,612\end{array}$ & $\begin{array}{c}9 \\
2,007,643\end{array}$ & $\begin{array}{c}9 \\
2,094,275\end{array}$ \\
\hline b) & (9) Fear & (10) Loneliness & (11) Suicide & (12) Addiction & (13) Violence & (14) Phys. Health & (15) Livelihood & (16) Relationships \\
\hline Post ${ }^{*}$ Female ${ }^{*}$ Age 0-30 & $\begin{array}{c}0.010 \\
{[-0.002,0.021]}\end{array}$ & $\begin{array}{c}0.007 \\
{[0.001,0.014]}\end{array}$ & $\begin{array}{c}-0.004 \\
{[-0.016,0.008]}\end{array}$ & $\begin{array}{c}-0.004 \\
{[-0.008,-0.001]}\end{array}$ & $\begin{array}{c}0.003 \\
{[-0.005,0.010]}\end{array}$ & $\begin{array}{c}0.008 \\
{[0.002,0.014]}\end{array}$ & $\begin{array}{c}0.006 \\
{[-0.000,0.011]}\end{array}$ & $\begin{array}{c}-0.010 \\
{[-0.020,0.001]}\end{array}$ \\
\hline Post ${ }^{*}$ Female ${ }^{*}$ gge 30-60 & $\begin{array}{c}0.029 \\
{[0.022,0.035]}\end{array}$ & $\begin{array}{c}0.014 \\
{[0.008,0.021]}\end{array}$ & $\begin{array}{c}-0.000 \\
{[-0.003,0.003]}\end{array}$ & $\begin{array}{c}-0.002 \\
{[-0.004,0.000]}\end{array}$ & $\begin{array}{c}-0.005 \\
{[-0.007,-0.002]}\end{array}$ & $\begin{array}{c}-0.006 \\
{[-0.009,-0.002]}\end{array}$ & $\begin{array}{c}-0.010 \\
{[-0.014,-0.006]}\end{array}$ & $\begin{array}{c}-0.023 \\
{[-0.032,-0.015]}\end{array}$ \\
\hline Post $^{*}$ Female $*$ Age $60+$ & $\begin{array}{c}0.031 \\
{[0.022,0.040]}\end{array}$ & $\begin{array}{c}0.017 \\
{[0.009,0.024]}\end{array}$ & $\begin{array}{c}0.002 \\
{[-0.003,0.006]}\end{array}$ & $\begin{array}{c}-0.003 \\
{[-0.005,-0.001]}\end{array}$ & $\begin{array}{c}-0.005 \\
{[-0.008,-0.002]}\end{array}$ & $\begin{array}{c}-0.019 \\
{[-0.026,-0.013]}\end{array}$ & $\begin{array}{c}-0.016 \\
{[-0.022,-0.010]}\end{array}$ & $\begin{array}{c}-0.044 \\
{[-0.054,-0.034]}\end{array}$ \\
\hline Post $^{*}$ Male ${ }^{*}$ Age 0-30 & $\begin{array}{c}0.004 \\
{[-0.007,0.014]}\end{array}$ & $\begin{array}{c}0.016 \\
{[0.008,0.024]}\end{array}$ & $\begin{array}{c}-0.015 \\
{[-0.023,-0.007]}\end{array}$ & $\begin{array}{c}0.011 \\
{[0.007,0.016]}\end{array}$ & $\begin{array}{c}0.003 \\
{[-0.007,0.014]}\end{array}$ & $\begin{array}{c}0.008 \\
{[0.002,0.014]}\end{array}$ & $\begin{array}{c}0.001 \\
{[-0.006,0.008]}\end{array}$ & $\begin{array}{c}0.005 \\
{[-0.008,0.019]}\end{array}$ \\
\hline Post ${ }^{*}$ Male ${ }^{*}$ Age $30-60$ & $\begin{array}{c}0.021 \\
{[0.014,0.027]}\end{array}$ & $\begin{array}{c}0.020 \\
{[0.014,0.025]}\end{array}$ & $\begin{array}{c}-0.003 \\
{[-0.006,0.001]}\end{array}$ & $\begin{array}{c}-0.004 \\
{[-0.007,-0.000]}\end{array}$ & $\begin{array}{c}-0.005 \\
{[-0.008,-0.003]}\end{array}$ & $\begin{array}{c}0.005 \\
{[0.000,0.010]}\end{array}$ & $\begin{array}{c}0.002 \\
{[-0.003,0.008]}\end{array}$ & $\begin{array}{c}-0.018 \\
{[-0.027,-0.010]}\end{array}$ \\
\hline Post*Male ${ }^{*}$ Age $60+$ & {$[0.027$} & {$\left[\begin{array}{c}0.007 \\
{[-0.008,0.023]}\end{array}\right.$} & $\begin{array}{c}-0.006 \\
{[-0.012,-0.000]}\end{array}$ & $\begin{array}{c}-0.007 \\
{[-0.011,-0.004]}\end{array}$ & $\begin{array}{c}-0.003 \\
{[-0.006,0.001]}\end{array}$ & {$[-0.003$} & $\begin{array}{c}-0.008 \\
{[-0.014,-0.003]}\end{array}$ & $\begin{array}{c}-0.026 \\
{[-0.036,-0.016]}\end{array}$ \\
\hline Female $^{*}$ Age 0-30 & $\begin{array}{c}0.085 \\
{[0.078,0.093]}\end{array}$ & $\begin{array}{c}-0.106 \\
{[-0.111,-0.102]}\end{array}$ & $\begin{array}{c}0.141 \\
{[0.134,0.148]}\end{array}$ & $\begin{array}{c}-0.041 \\
{[-0.044,-0.039]}\end{array}$ & $\begin{array}{c}0.056 \\
{[0.052,0.060]}\end{array}$ & $\begin{array}{c}-0.053 \\
{[-0.058,-0.048]}\end{array}$ & $\begin{array}{c}-0.054 \\
{[-0.058,-0.049]}\end{array}$ & $\begin{array}{c}0.094 \\
{[0.087,0.100]}\end{array}$ \\
\hline Female*Age 30-60 & $\begin{array}{c}0.039 \\
{[0.036,0.041]}\end{array}$ & $\begin{array}{c}-0.021 \\
{[-0.026,-0.017]}\end{array}$ & $\begin{array}{c}-0.003 \\
{[-0.005,-0.000]}\end{array}$ & $\begin{array}{c}-0.033 \\
{[-0.034,-0.031]}\end{array}$ & $\begin{array}{c}0.016 \\
{[0.015,0.018]}\end{array}$ & $\begin{array}{c}0.025 \\
{[0.021,0.028]}\end{array}$ & $\begin{array}{c}0.009 \\
{[0.007,0.012]}\end{array}$ & $\begin{array}{c}0.126 \\
{[0.122,0.130]}\end{array}$ \\
\hline Female*Age $60+$ & {$[0.020,0.026]$} & $\begin{array}{c}0.086 \\
{[0.083,0.089]}\end{array}$ & $\begin{array}{c}-0.027 \\
{[-0.031,-0.024]}\end{array}$ & $\begin{array}{c}-0.049 \\
{[-0.051,-0.046]}\end{array}$ & $\begin{array}{c}-0.004 \\
{[-0.006,-0.003]}\end{array}$ & $\begin{array}{c}0.103 \\
{[0.097,0.109]}\end{array}$ & $\begin{array}{c}-0.032 \\
{[-0.037,-0.028]}\end{array}$ & $\begin{array}{c}0.063 \\
{[0.059,0.068]}\end{array}$ \\
\hline Male $^{*}$ Age 0-30 & $\begin{array}{c}0.066 \\
{[0.059,0.073]}\end{array}$ & $\begin{array}{c}-0.098 \\
{[-0.103,-0.093]}\end{array}$ & $\begin{array}{c}0.113 \\
{[0.108,0.119]}\end{array}$ & $\begin{array}{c}-0.017 \\
{[-0.021,-0.014]}\end{array}$ & $\begin{array}{c}0.045 \\
{[0.041,0.050]}\end{array}$ & $\begin{array}{c}-0.058 \\
{[-0.063,-0.053]}\end{array}$ & $\begin{array}{c}-0.039 \\
{[-0.043,-0.034]}\end{array}$ & $\begin{array}{c}0.071 \\
{[0.065,0.076]}\end{array}$ \\
\hline Male Age 60+ & $\begin{array}{c}-0.013 \\
{[-0.016,-0.009]}\end{array}$ & $\begin{array}{c}0.133 \\
{[0.127,0.139]}\end{array}$ & $\begin{array}{c}0.004 \\
{[0.001,0.007]}\end{array}$ & $\begin{array}{c}-0.026 \\
{[-0.028,-0.023]}\end{array}$ & $\begin{array}{c}-0.009 \\
{[-0.011,-0.008]}\end{array}$ & $\begin{array}{c}0.069 \\
{[0.065,0.074]}\end{array}$ & $\begin{array}{c}-0.040 \\
{[-0.045,-0.036]}\end{array}$ & $\begin{array}{c}-0.065 \\
{[-0.072,-0.058]}\end{array}$ \\
\hline $\begin{array}{l}\text { \# Helplines } \\
\text { \# Observations }\end{array}$ & $\begin{array}{c}7 \\
2,123,773\end{array}$ & $\begin{array}{c}10 \\
2,066,884\end{array}$ & $\begin{array}{c}12 \\
2,244,199\end{array}$ & $\begin{array}{c}10 \\
2,215,734\end{array}$ & $\begin{array}{c}10 \\
2,215,751\end{array}$ & $\begin{array}{c}9 \\
2,222,612\end{array}$ & $\begin{array}{c}9 \\
2,007,643\end{array}$ & $\begin{array}{c}9 \\
2,094,275\end{array}$ \\
\hline
\end{tabular}

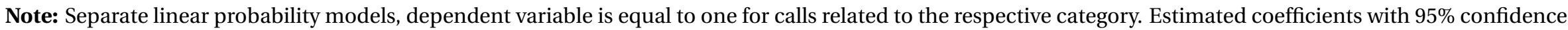

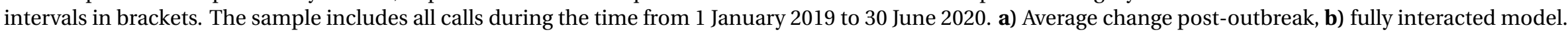

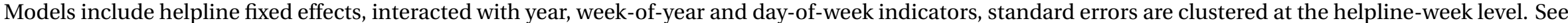
Methods, equations 2 and 3. 
Table S7: Helpline calls in Germany and France during the first and subsequent waves

\begin{tabular}{|c|c|c|c|c|c|c|c|c|}
\hline a) Germany & (1) Fear & (2) Loneliness & (3) Suicide & (4) Addiction & (5) Violence & (6) Phys. Health & (7) Livelihood & (8) Relationships \\
\hline First wave & $\begin{array}{c}0.022 \\
{[0.014,0.029]}\end{array}$ & $\begin{array}{c}0.014 \\
{[0.009,0.020]}\end{array}$ & $\begin{array}{c}0.002 \\
{[-0.001,0.005]}\end{array}$ & $\begin{array}{c}-0.004 \\
{[-0.005,-0.002]}\end{array}$ & $\begin{array}{c}0.000 \\
{[-0.001,0.002]}\end{array}$ & $\begin{array}{c}-0.019 \\
{[-0.023,-0.016]}\end{array}$ & $\begin{array}{c}-0.014 \\
{[-0.018,-0.009]}\end{array}$ & $\begin{array}{c}-0.035 \\
{[-0.044,-0.025]}\end{array}$ \\
\hline Subseq. wave & $\begin{array}{c}-0.001 \\
{[-0.005,0.003]}\end{array}$ & $\begin{array}{c}0.006 \\
{[0.001,0.011]}\end{array}$ & $\begin{array}{c}-0.006 \\
{[-0.009,-0.003]}\end{array}$ & $\begin{array}{c}-0.003 \\
{[-0.004,-0.001]}\end{array}$ & $\begin{array}{c}-0.000 \\
{[-0.002,0.001]}\end{array}$ & $\begin{array}{c}0.002 \\
{[-0.002,0.006]}\end{array}$ & $\begin{array}{c}0.000 \\
{[-0.003,0.003]}\end{array}$ & $\begin{array}{c}-0.018 \\
{[-0.023,-0.012]}\end{array}$ \\
\hline \# Observations & $1,481,813$ & $1,481,813$ & $1,481,847$ & $1,481,813$ & $1,481,813$ & $1,481,813$ & $1,534,509$ & $1,534,509$ \\
\hline b) France & (1) Fear & (2) Loneliness & (3) Suicide & (4) Addiction & (5) Violence & (6) Phys. Health & (7) Livelihood & (8) Relationships \\
\hline First wave & $\begin{array}{c}0.027 \\
{[0.020,0.035]}\end{array}$ & $\begin{array}{c}0.020 \\
{[0.015,0.025]}\end{array}$ & $\begin{array}{c}-0.002 \\
{[-0.004,-0.000]}\end{array}$ & $\begin{array}{c}0.001 \\
{[-0.002,0.003]}\end{array}$ & $\begin{array}{c}-0.004 \\
{[-0.006,-0.002]}\end{array}$ & $\begin{array}{c}-0.001 \\
{[-0.005,0.003]}\end{array}$ & $\begin{array}{c}-0.005 \\
{[-0.009,-0.001]}\end{array}$ & $\begin{array}{c}-0.026 \\
{[-0.039,-0.012]}\end{array}$ \\
\hline Subseq. wave & $\begin{array}{c}0.012 \\
{[0.008,0.015]}\end{array}$ & $\begin{array}{c}0.008 \\
{[0.004,0.012]}\end{array}$ & $\begin{array}{c}-0.009 \\
{[-0.010,-0.007]}\end{array}$ & $\begin{array}{c}0.001 \\
{[-0.001,0.004]}\end{array}$ & $\begin{array}{c}-0.004 \\
{[-0.006,-0.003]}\end{array}$ & $\begin{array}{c}0.008 \\
{[0.003,0.012]}\end{array}$ & $\begin{array}{c}-0.002 \\
{[-0.004,0.001]}\end{array}$ & $\begin{array}{c}-0.011 \\
{[-0.020,-0.003]}\end{array}$ \\
\hline \# Observations & $1,153,029$ & $1,153,029$ & $1,153,029$ & $1,153,029$ & $1,153,029$ & $1,153,029$ & $1,153,029$ & $1,153,029$ \\
\hline
\end{tabular}

Note: Separate linear probability models, dependent variable is equal to one for calls related to the respective category. Estimated coefficients with $95 \%$ confidence intervals in brackets. The sample includes all calls during the time from 1 January 2019 to 30 June 2020. Models include year, week-of-year and day-of-week fixed effects, standard errors are clustered at the helpline-week level. See Materials and methods, equation 4. 
Table S8: Lifeline calls across US states

\begin{tabular}{lcccc}
\hline & $(1)$ & $(2)$ & $(3)$ & $(4)$ \\
\hline $\log ($ COVID-19 case rate +1$)$ & 0.017 & -0.014 & -0.013 & -0.012 \\
& {$[0.012,0.022]$} & {$[-0.023,-0.006]$} & {$[-0.023,-0.004]$} & {$[-0.023,-0.001]$} \\
$\log$ (Stringency index+1) & 0.013 & 0.028 & 0.018 & 0.020 \\
& {$[0.004,0.023]$} & {$[0.009,0.047]$} & {$[-0.002,0.039]$} & {$[-0.007,0.047]$} \\
$\log$ (Income support index+1) & -0.009 & -0.008 & -0.006 & -0.004 \\
& {$[-0.014,-0.005]$} & {$[-0.013,-0.002]$} & {$[-0.012,-0.000]$} & {$[-0.011,0.002]$} \\
\hline State/province FE & YES & YES & YES & YES \\
Year FE & YES & YES & YES & \\
Month FE & & & YES & YES \\
Week-of-year FE & & & 51 & 51 \\
Week FE & & 51 & 5,909 & 5,909 \\
\# States/provinces & 5,909 & 5,909 & 5,909 & \\
\hline
\end{tabular}

Note: Sub-national panel model including state and week fixed effects, dependent variable is $\log ($ Lifeline calls +1$)$ and independent variables are measured in logs as well. Estimated coefficients with 95\% confidence intervals, standard errors are clustered at the state-month level. See Methods and materials, equation 5.

Table S9: Lifeline calls across US states: Interacted model

\begin{tabular}{|c|c|c|c|c|}
\hline & (1) & (2) & (3) & (4) \\
\hline Jan-Aug* $\log ($ COVID- 19 case rate +1$)$ & $\begin{array}{c}0.017 \\
{[0.008,0.027]}\end{array}$ & $\begin{array}{c}-0.009 \\
{[-0.021,0.003]}\end{array}$ & $\begin{array}{c}-0.008 \\
{[-0.021,0.004]}\end{array}$ & $\begin{array}{c}-0.007 \\
{[-0.021,0.006]}\end{array}$ \\
\hline Jan-Aug* $\log ($ Stringency index +1$)$ & $\begin{array}{c}0.002 \\
{[-0.008,0.012]}\end{array}$ & $\begin{array}{c}0.024 \\
{[0.004,0.045]}\end{array}$ & $\begin{array}{c}0.019 \\
{[-0.003,0.041]}\end{array}$ & $\begin{array}{c}0.016 \\
{[-0.013,0.044]}\end{array}$ \\
\hline Jan-Aug* $\log ($ Income support index +1$)$ & $\begin{array}{c}-0.003 \\
{[-0.013,0.007]}\end{array}$ & $\begin{array}{c}-0.010 \\
{[-0.020,0.001]}\end{array}$ & $\begin{array}{c}-0.013 \\
{[-0.024,-0.002]}\end{array}$ & $\begin{array}{c}-0.005 \\
{[-0.018,0.008]}\end{array}$ \\
\hline Sep-Mar $* \log ($ COVID- 19 case rate +1$)$ & $\begin{array}{c}-0.030 \\
{[-0.040,-0.020]}\end{array}$ & $\begin{array}{c}-0.027 \\
{[-0.041,-0.012]}\end{array}$ & $\begin{array}{c}-0.021 \\
{[-0.036,-0.006]}\end{array}$ & $\begin{array}{c}-0.022 \\
{[-0.038,-0.006]}\end{array}$ \\
\hline Sep-Mar ${ }^{*} \log ($ Stringency index +1$)$ & $\begin{array}{c}0.078 \\
{[0.062,0.094]}\end{array}$ & $\begin{array}{c}0.031 \\
{[-0.035,0.098]}\end{array}$ & $\begin{array}{c}0.032 \\
{[-0.035,0.099]}\end{array}$ & $\begin{array}{c}0.029 \\
{[-0.039,0.097]}\end{array}$ \\
\hline Sep-Mar* $\log ($ Income support index +1$)$ & $\begin{array}{c}-0.010 \\
{[-0.017,-0.003]}\end{array}$ & $\begin{array}{c}-0.009 \\
{[-0.015,-0.002]}\end{array}$ & $\begin{array}{c}-0.006 \\
{[-0.013,0.001]}\end{array}$ & $\begin{array}{c}-0.005 \\
{[-0.013,0.002]}\end{array}$ \\
\hline $\begin{array}{l}\text { State/province FE } \\
\text { Year FE }\end{array}$ & $\begin{array}{l}\text { YES } \\
\text { YES }\end{array}$ & YES & YES & YES \\
\hline $\begin{array}{l}\text { Month FE } \\
\text { Week-of-vear FE }\end{array}$ & & YES & $\begin{array}{l}\text { YES } \\
\text { YFS }\end{array}$ & \\
\hline $\begin{array}{l}\text { Week-of-year FE } \\
\text { Week FE }\end{array}$ & & & YES & YES \\
\hline \# States/provinces & 51 & 51 & 51 & 51 \\
\hline \# Observations & 5,909 & 5,909 & 5,909 & 5,909 \\
\hline
\end{tabular}

Note: Sub-national panel model including state and week fixed effects, dependent variable is $\log ($ Lifeline calls +1$)$ and independent variables are measured in logs as well. Estimated coefficients with $95 \%$ confidence intervals, standard errors are clustered at the state-month level. See Methods and materials, equation 6. 
a) Disaster Distress Helpline
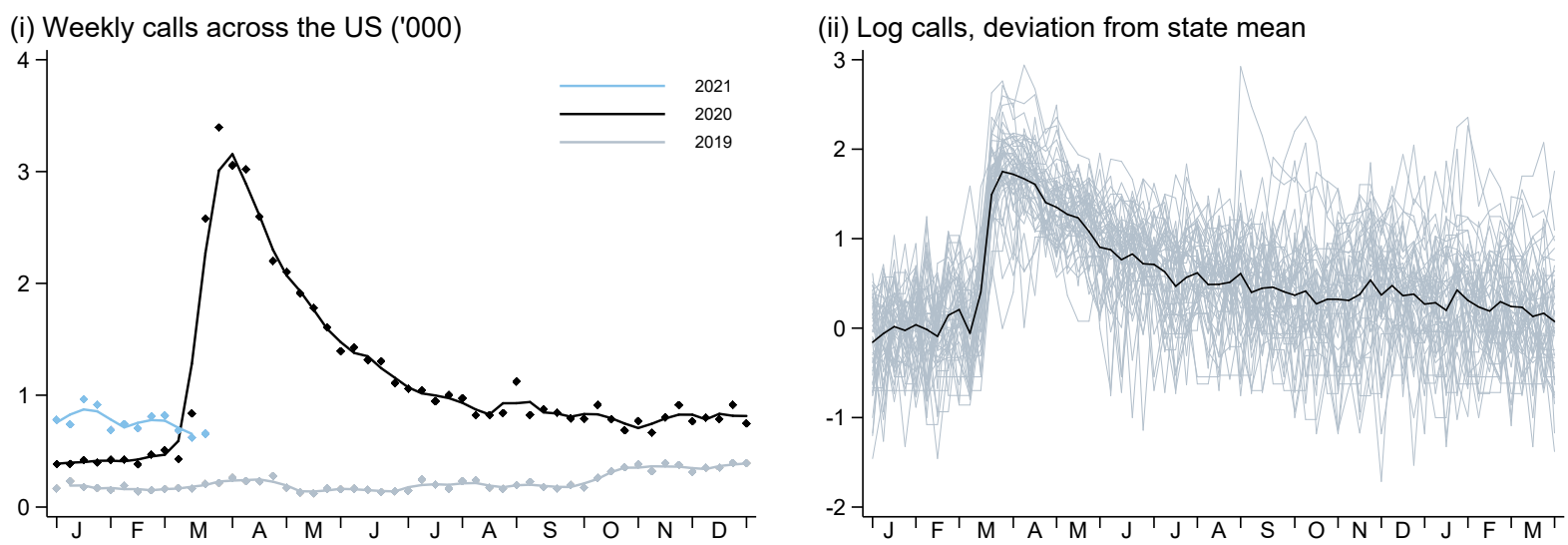

b) Estimation results: Log-log model with state and week fixed effects

(i) Baseline model

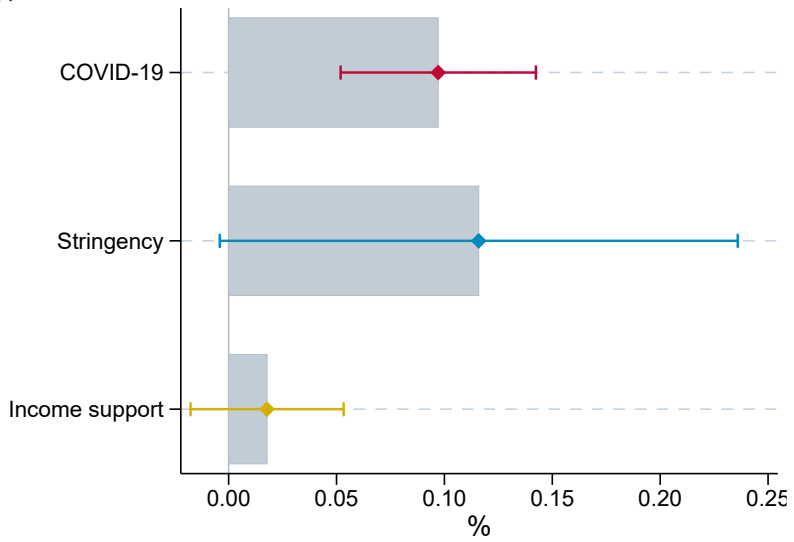

(ii) Time-varying effects: Interacted model

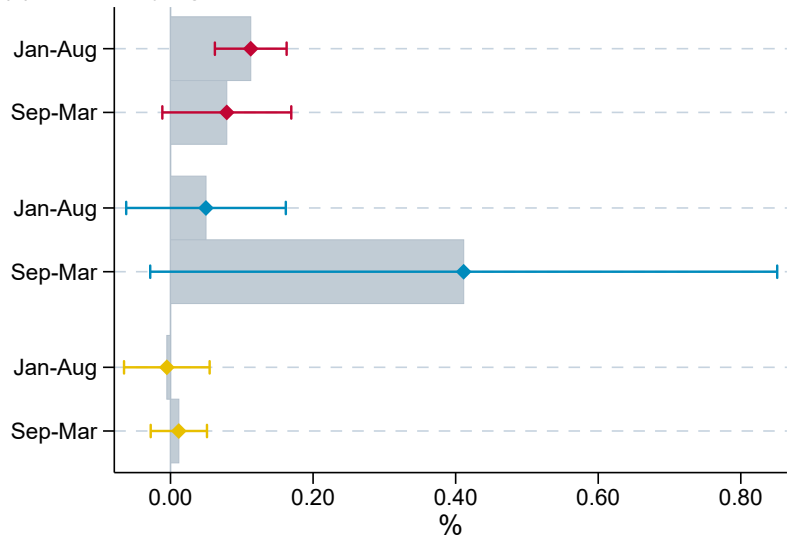

Figure S2: Calls to the Disaster Distress Helpline, COVID-19, and policy in the United States

a) Disaster Distress Helpline, (i) overall sum of weekly calls routed to centers by year, with 3-week moving average; (ii) deviation of log calls from state mean (gray), with overall weekly average (black). b) Sub-national panel model including state and week fixed effects, dependent variable is $\log ($ calls +1$)$ and independent variables are measured in logs as well. Estimated coefficients with 95\% confidence intervals, standard errors are clustered at the state-month level. See Methods, equation 5. 
Table S10: Disaster Distress Helpline calls across US states

\begin{tabular}{|c|c|c|c|c|}
\hline & (1) & (2) & (3) & (4) \\
\hline $\log ($ COVID -19 case rate +1$)$ & $\begin{array}{c}-0.057 \\
{[-0.082,-0.033]}\end{array}$ & $\begin{array}{c}0.158 \\
{[0.120,0.196]}\end{array}$ & $\begin{array}{c}0.139 \\
{[0.099,0.179]}\end{array}$ & $\begin{array}{c}0.097 \\
{[0.052,0.142]}\end{array}$ \\
\hline $\log ($ Stringency index +1$)$ & $\begin{array}{c}0.203 \\
{[0.159,0.247]}\end{array}$ & $\begin{array}{c}0.254 \\
{[0.160,0.348]}\end{array}$ & $\begin{array}{c}0.219 \\
{[0.119,0.318]}\end{array}$ & $\begin{array}{c}0.116 \\
{[-0.004,0.236]}\end{array}$ \\
\hline $\log ($ Income support index +1$)$ & $\begin{array}{c}0.135 \\
{[0.109,0.161]}\end{array}$ & $\begin{array}{c}0.055 \\
{[0.023,0.088]}\end{array}$ & $\begin{array}{c}0.046 \\
{[0.012,0.080]}\end{array}$ & $\begin{array}{c}0.018 \\
{[-0.018,0.053]}\end{array}$ \\
\hline State/province FE & $\begin{array}{ll}\text { YES } \\
\text { YES }\end{array}$ & YES & YES & YES \\
\hline $\begin{array}{l}\text { Month FE } \\
\text { Week-of-vear FE }\end{array}$ & & YES & $\begin{array}{l}\text { YES } \\
\text { YES }\end{array}$ & \\
\hline $\begin{array}{l}\text { Week-ot-year FE } \\
\text { Week FE }\end{array}$ & & & & YES \\
\hline \# States/provinces & 51 & 51 & 51 & 51 \\
\hline \# Observations & 5,909 & 5,909 & 5,909 & 5,909 \\
\hline
\end{tabular}

Note: Sub-national panel model including state and week fixed effects, dependent variable is $\log ($ Disaster Distress calls +1$)$ and independent variables are measured in logs as well. Estimated coefficients with 95\% confidence intervals, standard errors are clustered at the state-month level. See Methods and materials, equation 5.

Table S1 1: Disaster Distress Helpline calls across US states: Interacted model

\begin{tabular}{|c|c|c|c|c|}
\hline & (1) & (2) & (3) & (4) \\
\hline Jan-Aug* $\log ($ COVID-19 case rate +1$)$ & $\begin{array}{c}-0.040 \\
{[-0.092,0.011]}\end{array}$ & $\begin{array}{c}0.155 \\
{[0.110,0.201]}\end{array}$ & $\begin{array}{c}0.149 \\
{[0.104,0.195]}\end{array}$ & $\begin{array}{c}0.113 \\
{[0.062,0.163]}\end{array}$ \\
\hline Jan-Aug* $\log ($ Stringency index +1$)$ & $\begin{array}{c}0.125 \\
{[0.082,0.168]}\end{array}$ & $\begin{array}{c}0.096 \\
{[0.006,0.186]}\end{array}$ & $\begin{array}{c}0.107 \\
{[0.011,0.204]}\end{array}$ & $\begin{array}{c}0.050 \\
{[-0.062,0.162]}\end{array}$ \\
\hline Jan-Aug*log(Income support index+1) & $\begin{array}{c}0.204 \\
{[0.153,0.255]}\end{array}$ & $\begin{array}{c}0.189 \\
{[0.133,0.244]}\end{array}$ & $\begin{array}{c}0.146 \\
{[0.086,0.207]}\end{array}$ & $\begin{array}{c}-0.005 \\
{[-0.065,0.055]}\end{array}$ \\
\hline Sep-Mar $* \log ($ COVID- 19 case rate +1$)$ & $\begin{array}{c}0.014 \\
{[-0.041,0.068]}\end{array}$ & $\begin{array}{c}0.069 \\
{[-0.011,0.150]}\end{array}$ & $\begin{array}{c}0.069 \\
{[-0.018,0.156]}\end{array}$ & $\begin{array}{c}0.079 \\
{[-0.011,0.169]}\end{array}$ \\
\hline Sep-Mar*log $($ Stringency index +1$)$ & $\begin{array}{c}0.126 \\
{[0.045,0.207]}\end{array}$ & $\begin{array}{c}0.424 \\
{[-0.005,0.852]}\end{array}$ & $\begin{array}{c}0.415 \\
{[-0.020,0.850]}\end{array}$ & $\begin{array}{c}0.411 \\
{[-0.028,0.851]}\end{array}$ \\
\hline Sep-Mar* $\log ($ Income support index +1$)$ & $\begin{array}{c}0.010 \\
{[-0.027,0.047]}\end{array}$ & $\begin{array}{c}0.008 \\
{[-0.029,0.046]}\end{array}$ & $\begin{array}{c}0.013 \\
{[-0.027,0.052]}\end{array}$ & $\begin{array}{c}0.012 \\
{[-0.028,0.051]}\end{array}$ \\
\hline $\begin{array}{l}\text { State/province FE } \\
\text { Year FE }\end{array}$ & $\begin{array}{l}\text { YES } \\
\text { YES }\end{array}$ & YES & YES & YES \\
\hline $\begin{array}{l}\text { Month FE } \\
\text { Week-of-year FE }\end{array}$ & & YES & $\begin{array}{l}\text { YES } \\
\text { YES }\end{array}$ & \\
\hline Week FE & & & & YES \\
\hline \# States/provinces & 51 & 51 & 51 & 51 \\
\hline \# Observations & 5,909 & 5,909 & 5,909 & 5,909 \\
\hline
\end{tabular}

Note: Sub-national panel model including state and week fixed effects, dependent variable is $\log ($ Disaster Distress calls +1$)$ and independent variables are measured in logs as well. Estimated coefficients with $95 \%$ confidence intervals, standard errors are clustered at the state-month level. See Methods and materials, equation 5. 
Table S12: Daily calls by conversation topic, COVID-19, and policy in Germany and France

\begin{tabular}{|c|c|c|c|c|c|c|c|c|}
\hline & (1) Fear & (2) Loneliness & (3) Suicide & (4) Addiction & (5) Violence & (6) Phys. Health & (7) Livelihood & (8) Relationships \\
\hline $\log ($ COVID- 19 case rate +1$)$ & $\begin{array}{c}0.012 \\
{[-0.001,0.026]}\end{array}$ & $\begin{array}{c}0.012 \\
{[0.001,0.023]}\end{array}$ & $\begin{array}{c}-0.024 \\
{[-0.035,-0.014]}\end{array}$ & $\begin{array}{c}-0.005 \\
{[-0.019,0.009]}\end{array}$ & $\begin{array}{c}-0.006 \\
{[-0.017,0.006]}\end{array}$ & $\begin{array}{c}0.023 \\
{[0.013,0.033]}\end{array}$ & $\begin{array}{c}0.012 \\
{[0.001,0.022]}\end{array}$ & $\begin{array}{c}0.003 \\
{[-0.006,0.011]}\end{array}$ \\
\hline $\log ($ Stringency index +1$)$ & $\begin{array}{c}0.093 \\
{[0.057,0.128]}\end{array}$ & $\begin{array}{c}0.039 \\
{[0.010,0.067]}\end{array}$ & $\begin{array}{c}0.035 \\
{[0.011,0.060]}\end{array}$ & $\begin{array}{c}0.019 \\
{[-0.011,0.048]}\end{array}$ & $\begin{array}{c}-0.014 \\
{[-0.038,0.010]}\end{array}$ & $\begin{array}{c}0.011 \\
{[-0.013,0.035]}\end{array}$ & $\begin{array}{c}0.003 \\
{[-0.018,0.025]}\end{array}$ & $\begin{array}{c}-0.007 \\
{[-0.024,0.010]}\end{array}$ \\
\hline $\log ($ Income support index +1$)$ & $\begin{array}{c}-0.042 \\
{[-0.061,-0.024]}\end{array}$ & $\begin{array}{c}-0.024 \\
{[-0.040,-0.008]}\end{array}$ & $\begin{array}{c}-0.020 \\
{[-0.033,-0.006]}\end{array}$ & $\begin{array}{c}-0.004 \\
{[-0.023,0.015]}\end{array}$ & $\begin{array}{c}0.002 \\
{[-0.018,0.022]}\end{array}$ & $\begin{array}{c}-0.026 \\
{[-0.041,-0.011]}\end{array}$ & $\begin{array}{c}-0.016 \\
{[-0.030,-0.002]}\end{array}$ & $\begin{array}{c}-0.009 \\
{[-0.021,0.004]}\end{array}$ \\
\hline \# Observations & 1,631 & 1,631 & 1,631 & 1,631 & 1,631 & 1,631 & 1,631 & 1,631 \\
\hline
\end{tabular}

Note: Coefficients from separate models by topic with 95\% confidence interval. Dependent variable is the natural logarithm of the respective number of calls plus 1 . COVID-19 infections per 100,000 population, government response stringency, and income support are defined as logarithmic measures as well. All models include helpline indicators, interacted with year, week-of-year, and day-of-week fixed effects. The sample includes all calls featuring at least one recorded conversation topic to Telefonseelsorge (Germany) and S.O.S. Amitié (France), from January 1, 2019 to March 31, 2021, aggregated to 1,631 daily totals. Standard errors are clustered at the helpline-week level. See Methods, equation (7). 

into 46 finer categories.

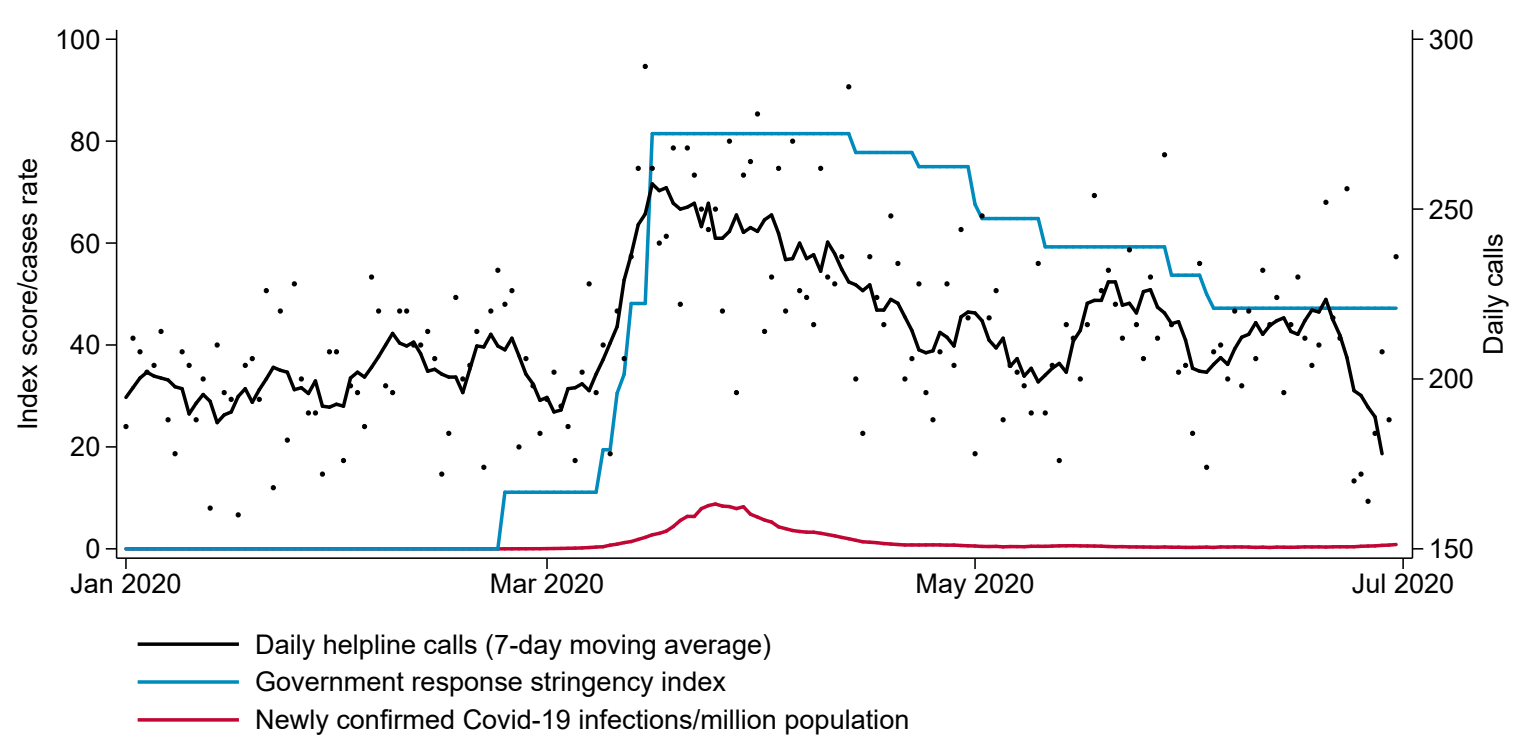

Figure S3: Daily calls to Telefonseelsorge, Covid-19 incidence and government response in Austria

\section{Austria}

Telefonseelsorge Österreich is an Austria-wide organization with nine counseling centers that can be reached free of charge, 24 hours a day. The first helpline center was established 1966 in Linz as an offshoot of Telefonseelsorge Germany, sponsors are the Catholic and Protestant churches, as well as a private association in Vorarlberg. The team consists of around 25 full-time and 800 trained volunteer counselors. Originally founded with a focus on suicide prevention, today the helpline deals more broadly with acute crisis intervention and coping with everyday crises. Further information is available online at www.telefonseelsorge.at.

We received data on calls answered at the helpline center in Vienna, for the time from January 1, 2019 to June 30, 2020. The collected information includes the sex and age group of callers, as well as the primary conversation topic. Note that, in contrast to most other helplines included in this study, only one exclusive topic is recorded for each call. Overall, topics are classified into 10 broad groups, and further distinguished

\section{Supplementary materials: Individual helplines, by country}


Table S13: Classification of conversation topics: Telefonseelsorge, Austria

\begin{tabular}{ll}
\hline Topic & Helpline-specific topic definitions \\
\hline Fears & Ängste/Zwänge \\
Loneliness & Einsamkeit/Isolation/Alltag \\
Suicide & Suizid; Suizidgefährdete; Sorge um Suizidgefährde \\
Addiction & Sucht; Alkohohl; andere Suchterkrankung; Sorge um Suchtkranke \\
Violence & Gewalt/Missbrauch gegen Erwachsene; gegen Kinder \\
Physical health & Krankheit/Gesundheit (körperlich) \\
Livelihood & Arbeitslos/Arbeitssuche; Probleme in Ausbildung/Beruf \\
Relationships & Partnerschaft; Erziehung; Schwangerschaft/Abtreibung \\
\hline
\end{tabular}


a) Daily calls by age and sex of caller (seven-day moving average)

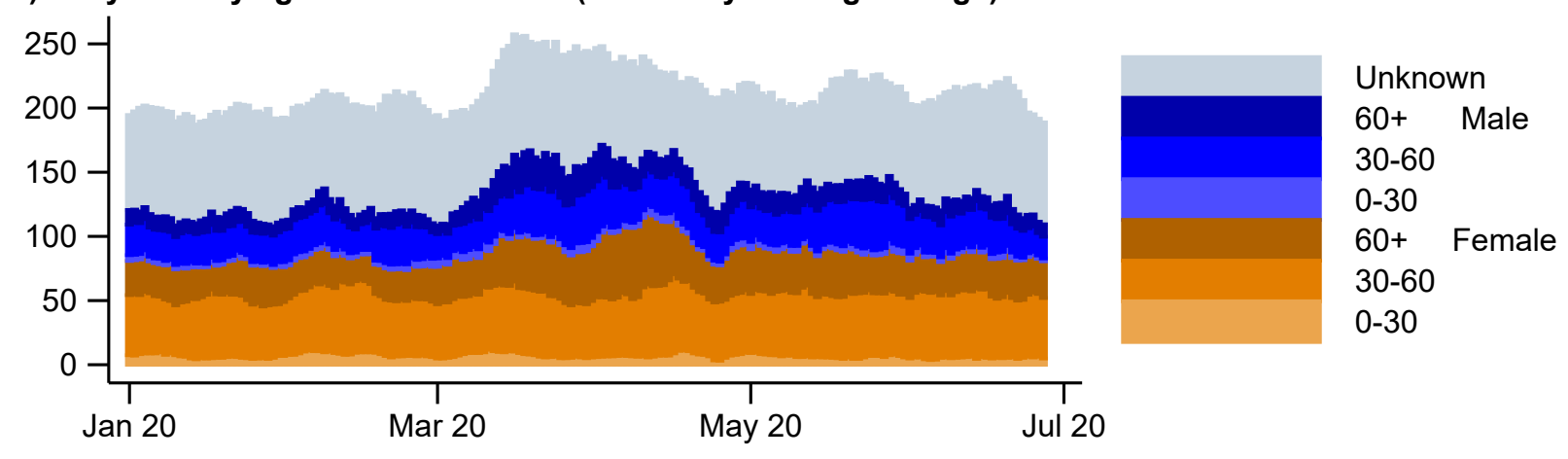

b) Daily calls by topic (seven-day moving average)

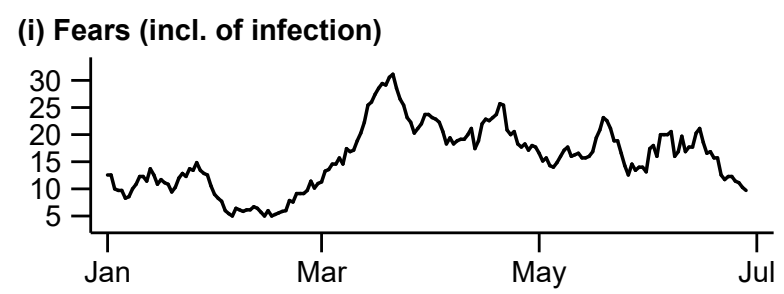

(ii) Loneliness

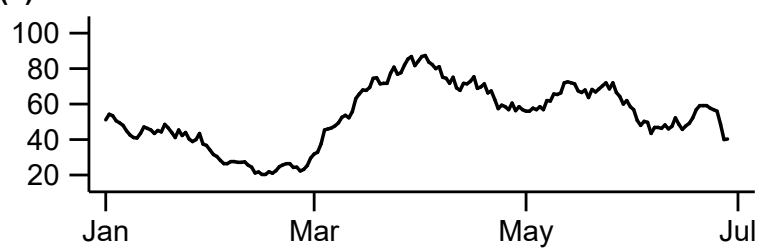

(iii) Suicide

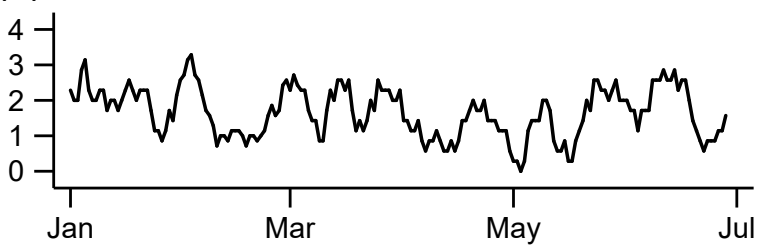

(iv) Addiction

(v) Violence
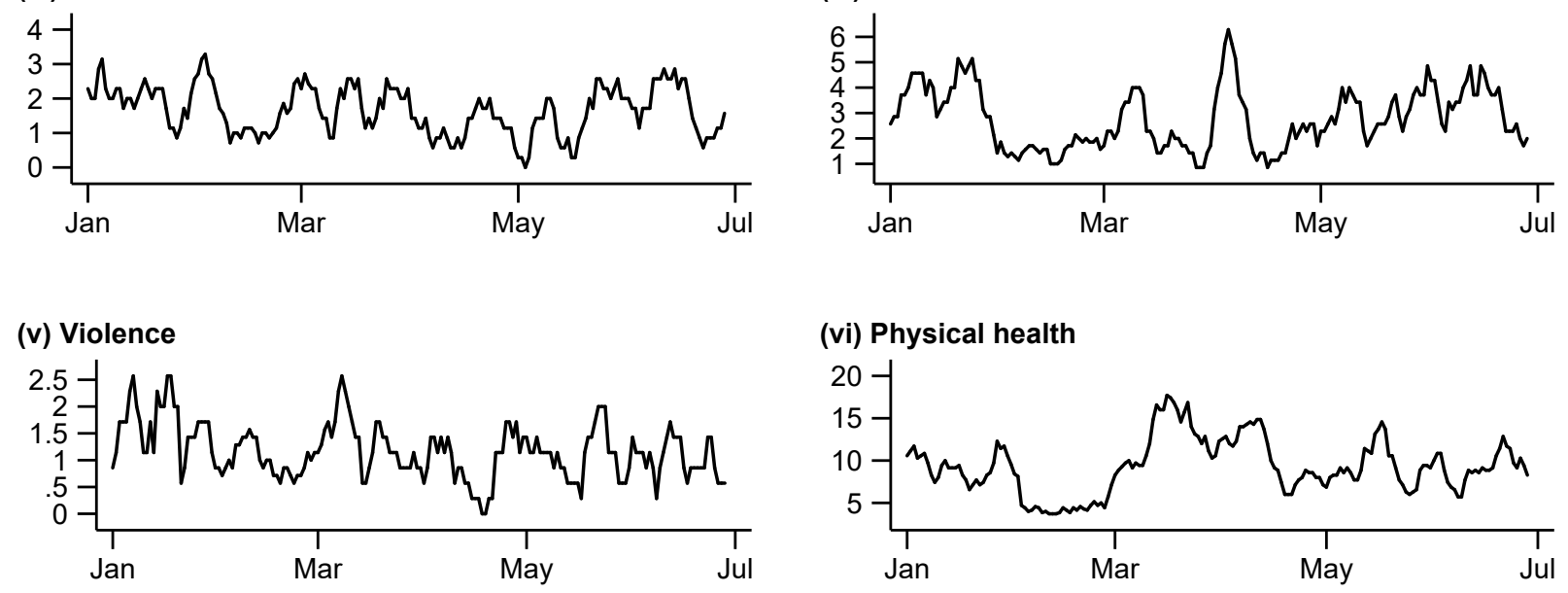

(vi) Physical health

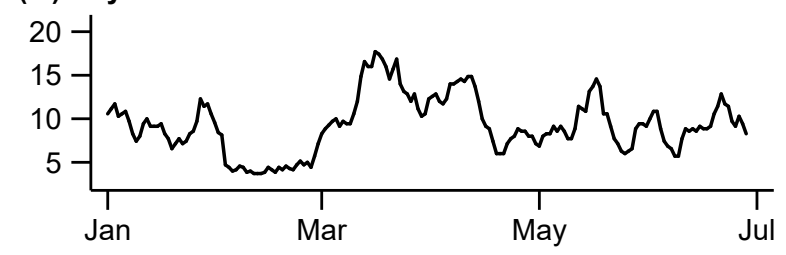

(vii) Livelihood

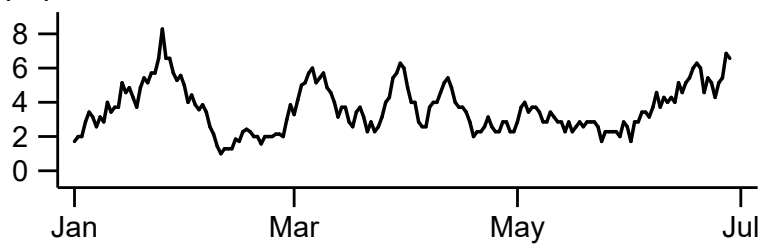

(viii) Relationships

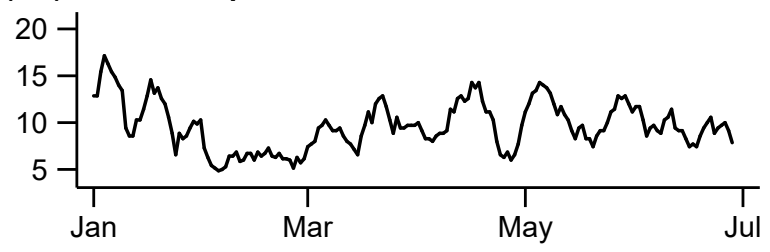

Figure S4: Caller characteristics and conversation topics, Telefonseelsorge Austria 


\section{Belgium}

Tele-Onthaal has a tele-reception service in every Flemish province and in Brussels and the services work together within the Federation of Tele Reception Services in Flanders (Federatie van tele-onthaaldiensten Vlaanderen). The five centers are Verband der Fernempfangsdienste in Flandern, Tele-Empfang Limburg (Limburg), Teleempfang Ostflandern (East Flanders), Teleempfang Flemisch Brabant und Brüssel (Flemish Brabant \& Brussels Capital Region), Tele-Welcome West Flanders, and Teleempfang Antwerpen. Each service has its own legal structure (non-profit organization). The service is subsidized by the Flemish government (Decree General Welfare Work). Tele-Onthaal offers 24/7 telephone advice anonymously. Chatting is possible 7 days every evening from 6 p.m. to 11 p.m. and on Wednesday and Sunday afternoons from 3 p.m. Further information is available online at www.tele-onthaal.be.

We received data on individual calls received during the time from January 1, 2019 to June 30, 2020, including information on caller's sex, age group, and up to 3 non-exclusive conversation topics. Additionally, counselors collect information on up to 4 psychological disorders.

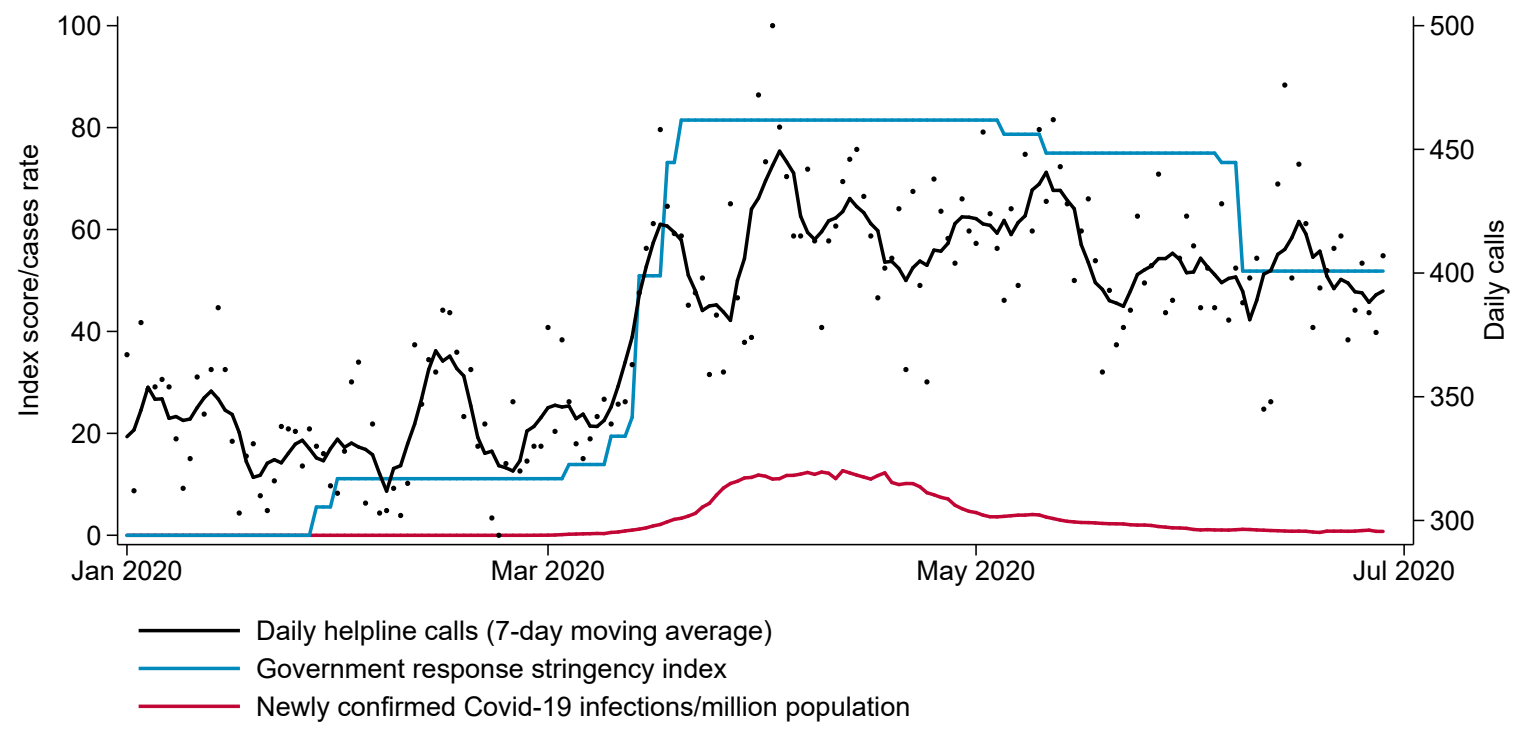

Figure S5: Daily calls to Tele-Onthaal, Covid-19 incidence and government response in Belgium 
Table S14: Classification of conversation topics: Tele-Onthaal, Belgium

\begin{tabular}{ll}
\hline Topic & Helpline-specific topic definitions \\
\hline Fears & Disorder: Angsten/fobieën \\
Loneliness & Eenzaamheid \\
Suicide & Zelfdoding \\
Addiction & Afhankelijkheid/Verslaving; Disorder: Verslaving \\
Violence & Slachtofferbeleving \\
Physical health & Gezondheid \\
Livelihood & \\
Relationships & Relaties \\
\hline
\end{tabular}




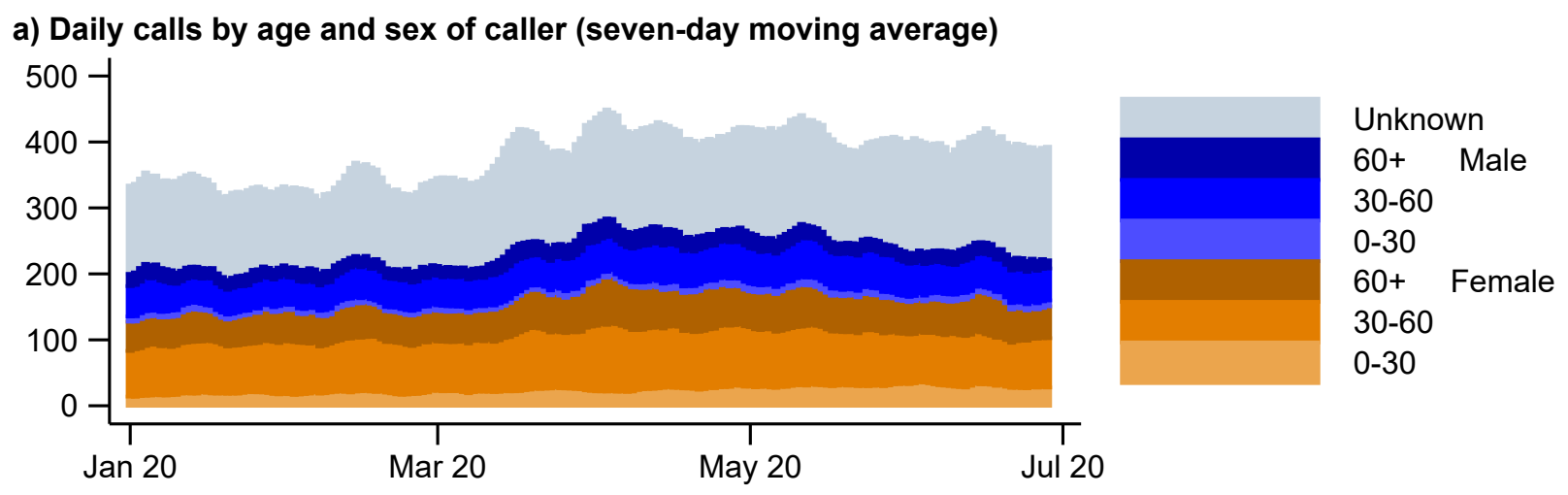

b) Daily calls by topic (seven-day moving average)

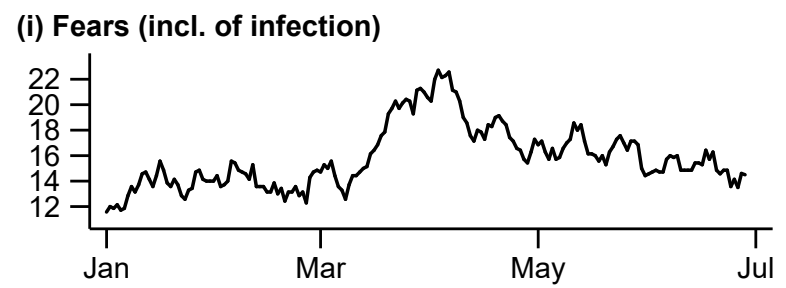

(ii) Loneliness

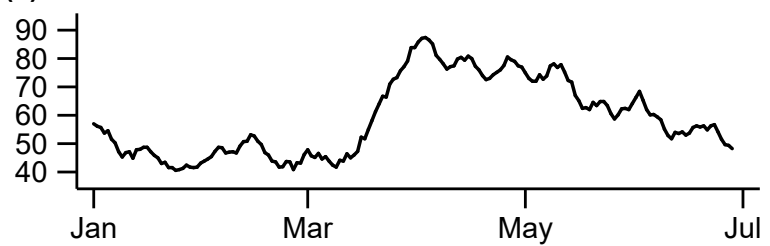

(iii) Suicide

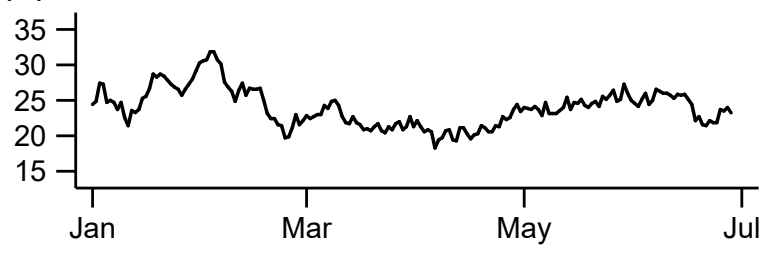

(iv) Addiction

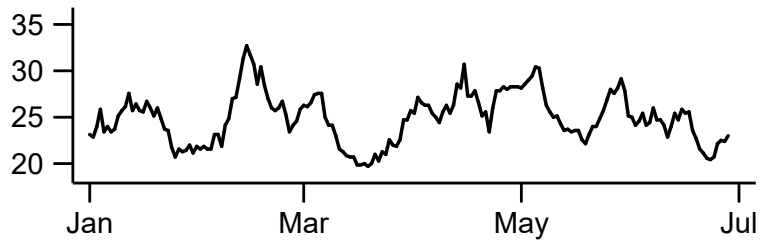

(v) Violence

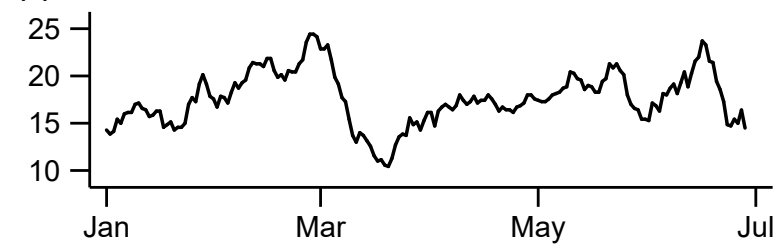

(vi) Physical health

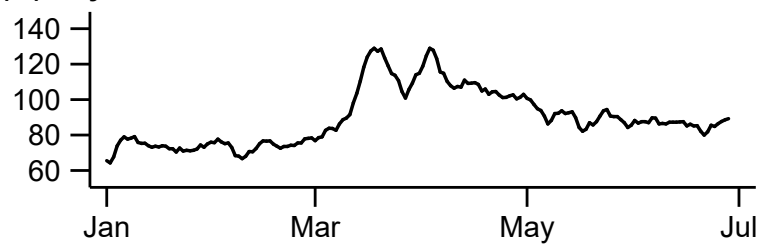

(vii) Livelihood

(viii) Relationships
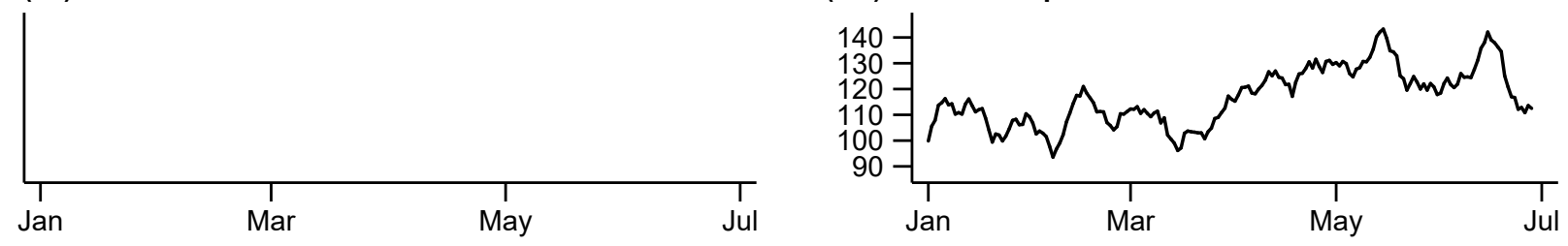

Figure S6: Caller characteristics and conversation topics, Tele-Onthaal, Belgium 


\section{Bosnia and Herzegovina}

Plavi Telefon was established in 1990 and is part of the Blue Phone Association. The helpline is connected to the Croatian Plavi Telefon and consists of two employees and at least 4 volunteers each day. The helpline did not change their services during the pandemic but built up psychotherapist supervision for volunteers and consultations with clients led by psychotherapists. Further information is available online at www.facebook.com/PlaviTelefonBanjaluka.

We received data on individual calls, covering the time from January 1, 2019 to October 23, 2020.

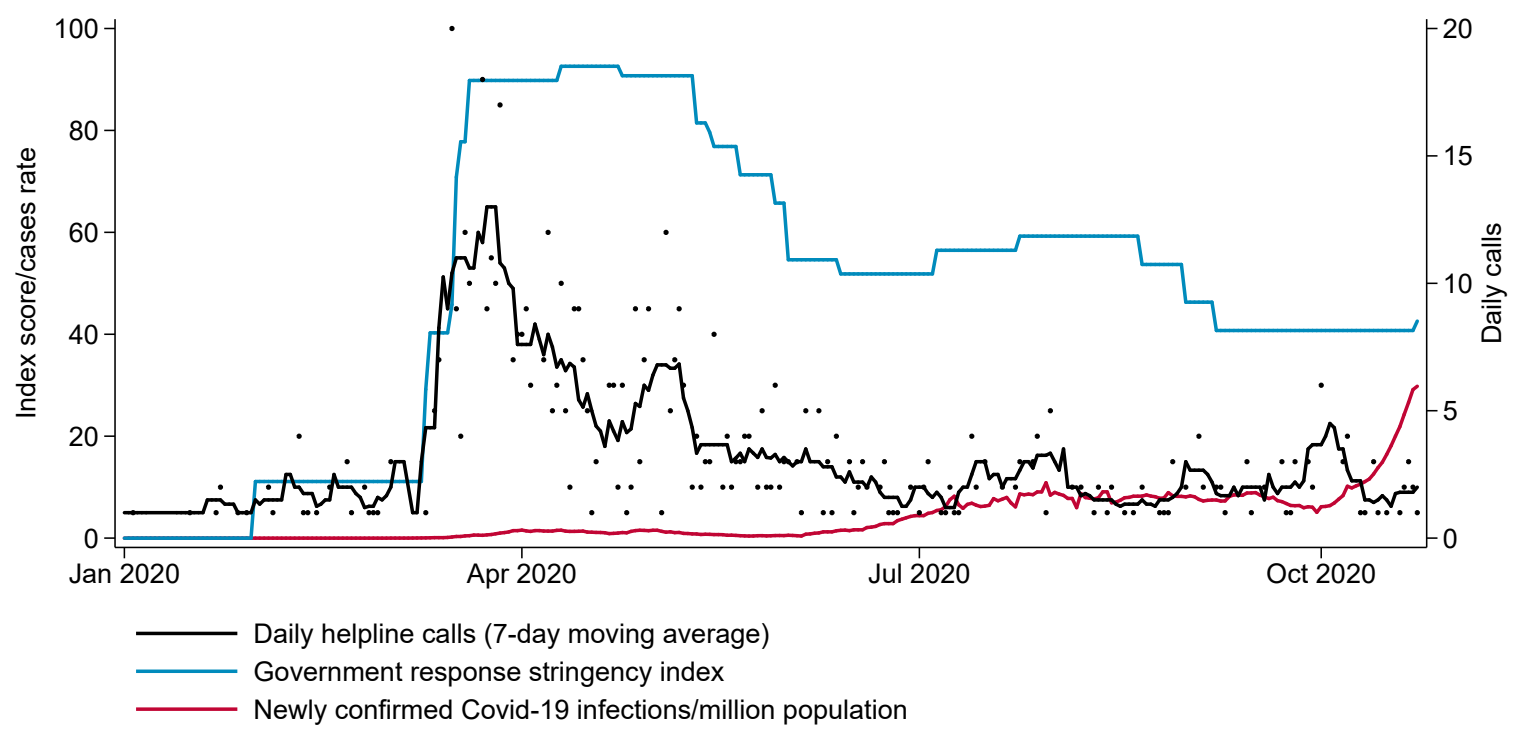

Figure S7: Helpline calls, COVID-19, and government response in Bosnia 


\section{China}

The Chinese helpline Hope 24 was officially launched in Shanghai in December 2012. From December 2013, the line started to cover all of China, and as of today, there are 21 switch rooms waiting for calls. An average of 20 volunteers answer calls every day on the toll free number. The helpline belongs to the Public Welfare Department of Beijing Daguan Institute of Psychosomatic Medicine. During the pandemic, an additional line was opened as the number of calls was increasing during March, April and May in 2020. Similar hotlines were opened throughout the country during the epidemic. For additional information, visit www.hope9995.com.

We received data on individual calls, covering the time from January 1, 2019 to June 25, 2020. The recorded information includes caller sex and age group, as well as the main reason for consultation and the psychological trauma level, where one exclusive reason and level is selected by counselors for each call.

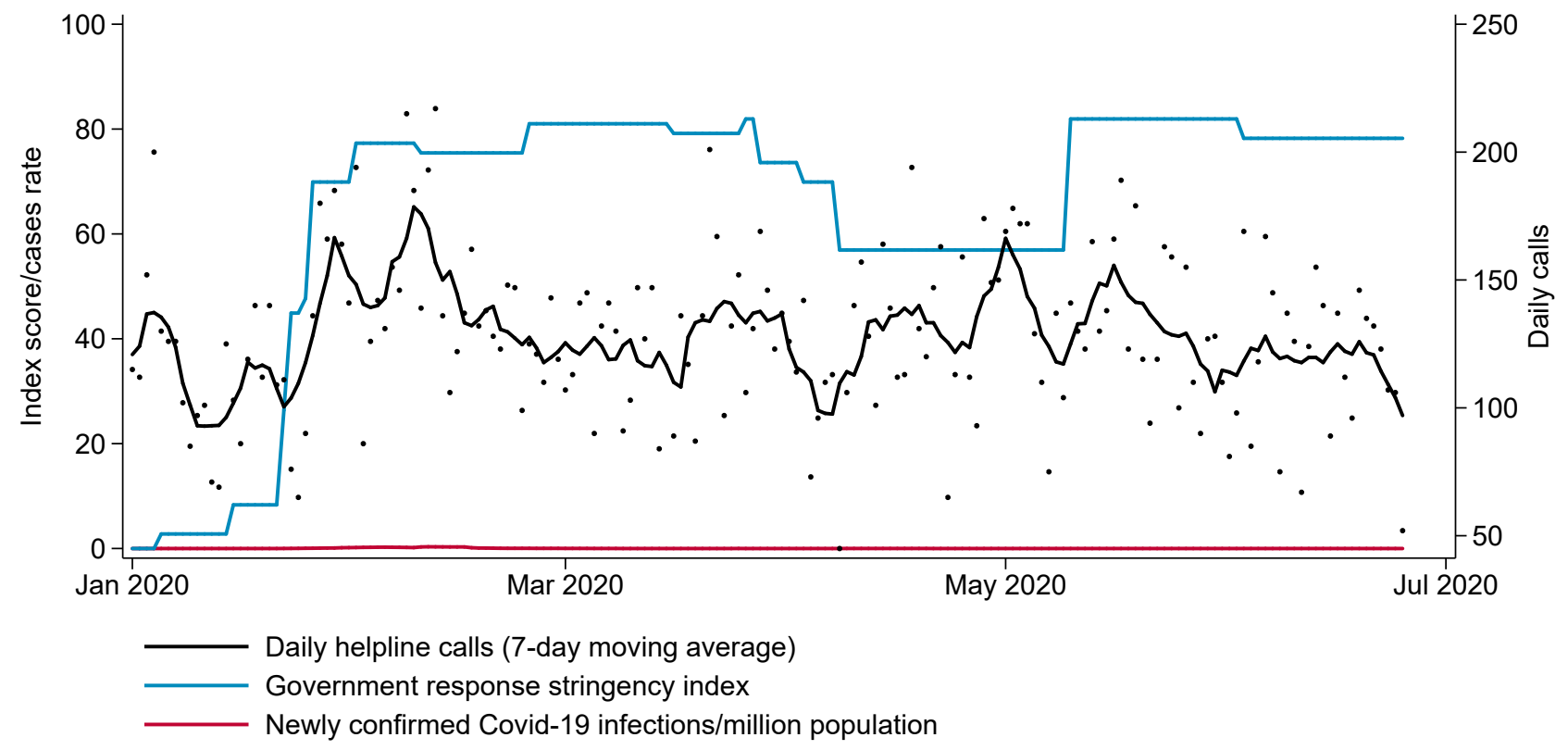

Figure S8: Daily calls to the Hope 24 Line, COVID-19, and government response in China 
Table S15: Classification of conversation topics: Hope 24 Line, China

\begin{tabular}{ll}
\hline Topic & Helpline-specific topic definitions (translated from Mandarin) \\
\hline $\begin{array}{l}\text { Fears } \\
\text { Loneliness } \\
\text { Suicide } \\
\begin{array}{l}\text { Addiction } \\
\text { Violence }\end{array}\end{array}$ & Pychological trauma level: Suicidal ideation \\
$\begin{array}{l}\text { Physical health } \\
\text { Livelihood }\end{array}$ & $\begin{array}{l}\text { Reason for consultation: Disease and disability } \\
\text { Relationships }\end{array}$ \\
& $\begin{array}{l}\text { Reason for consultation: Job-related; Financial issues } \\
\text { Reason for consultation: Relationship; Friendship; Marriage; Issues with children; }\end{array}$ \\
\hline
\end{tabular}


a) Daily calls by age and sex of caller (seven-day moving average)
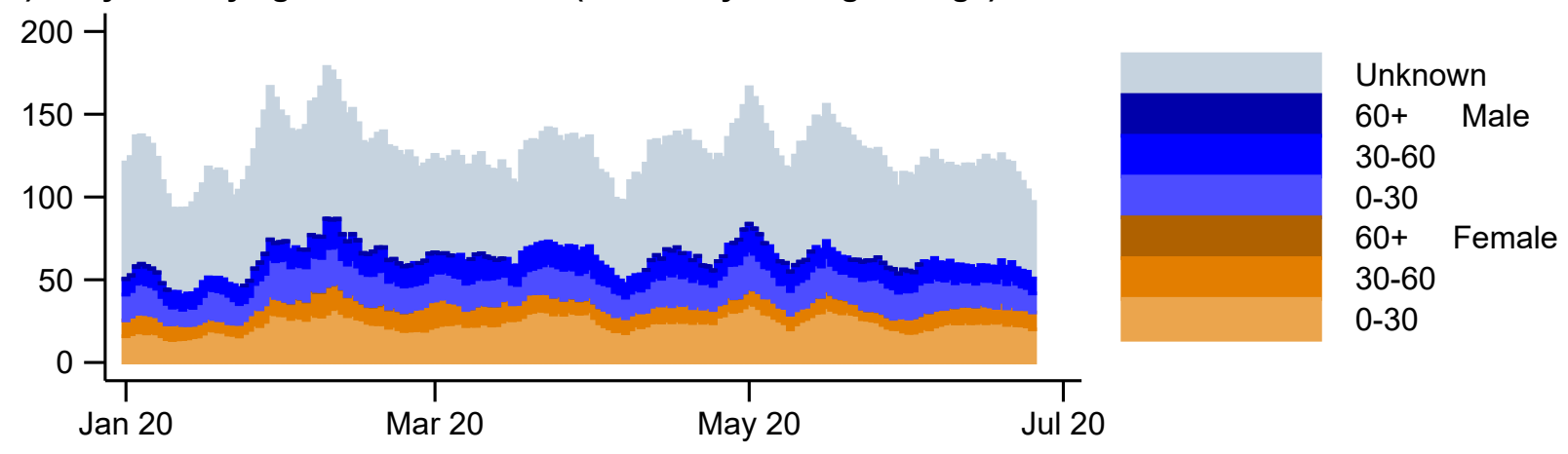

b) Daily calls by topic (seven-day moving average)

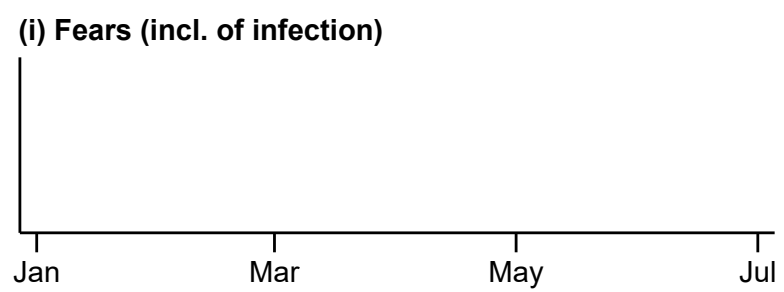

(ii) Loneliness

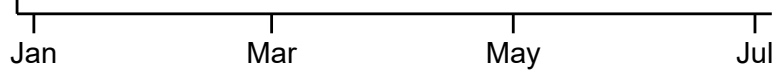

(iii) Suicide

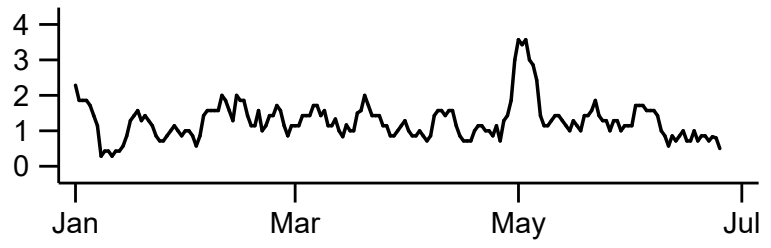

(iv) Addiction

(v) Violence
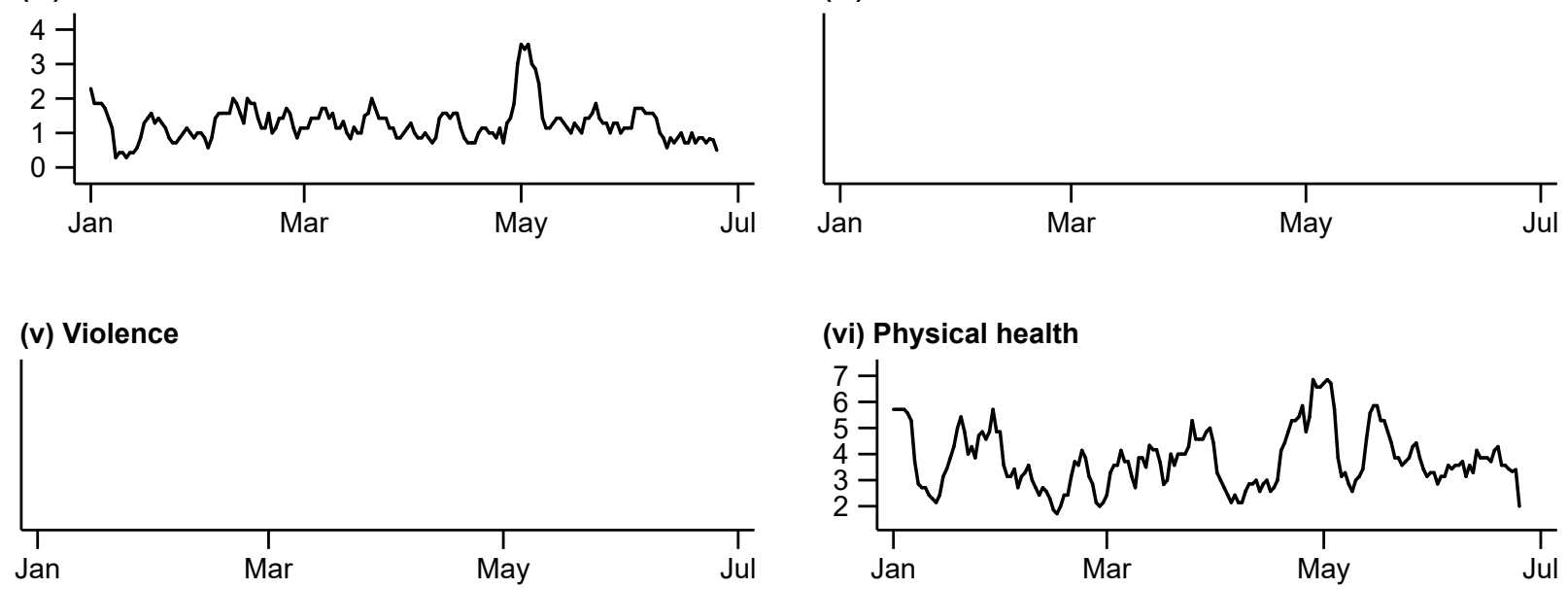

(vi) Physical health

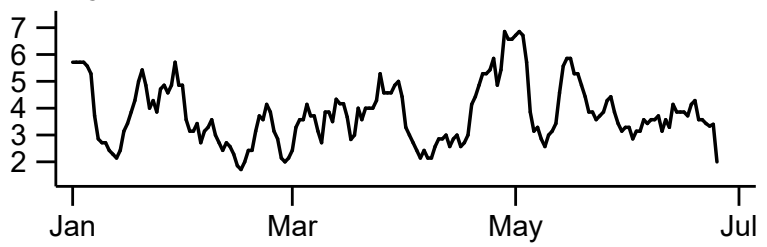

(vii) Livelihood

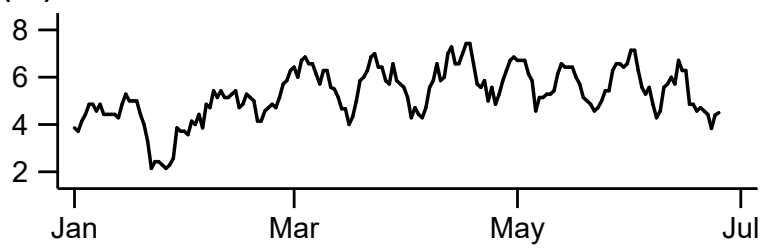

(viii) Relationships

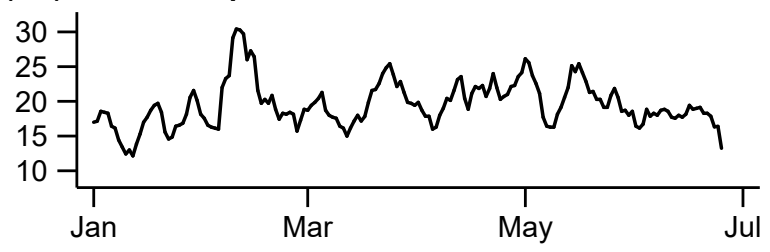

Figure S9: Caller characteristics and conversation topics, Hope 24 Line, China 


\section{Czech Republic}

The helpline Modrá linka started in December 1994. There is no specific focus, and everyone in crisis can call. Five full time employees and 21 part time employees offer mail, chat, skype and classical phone counseling from 9 am to 9 pm every day. Employees are trained in crisis assistance trainings (minimum 100 hours) or have obtained a university degree (psychologists, educators, or social workers). Modrá linka further offers accredited courses aimed at crisis assistance for other organizations. Callers pay only the own tariff. Modrá linka is an Ifotes member.

We have detailed information on answered contacts, covering the time from January 1, 2019 to June 28, 2020. Around the outbreak of the pandemic, capacity was extended and the helpline started to operate 24 hours a day. Conversation topics and characteristics are available only for selected calls, the sex of callers is not recorded. Further information is available online at www.modralinka.cz.

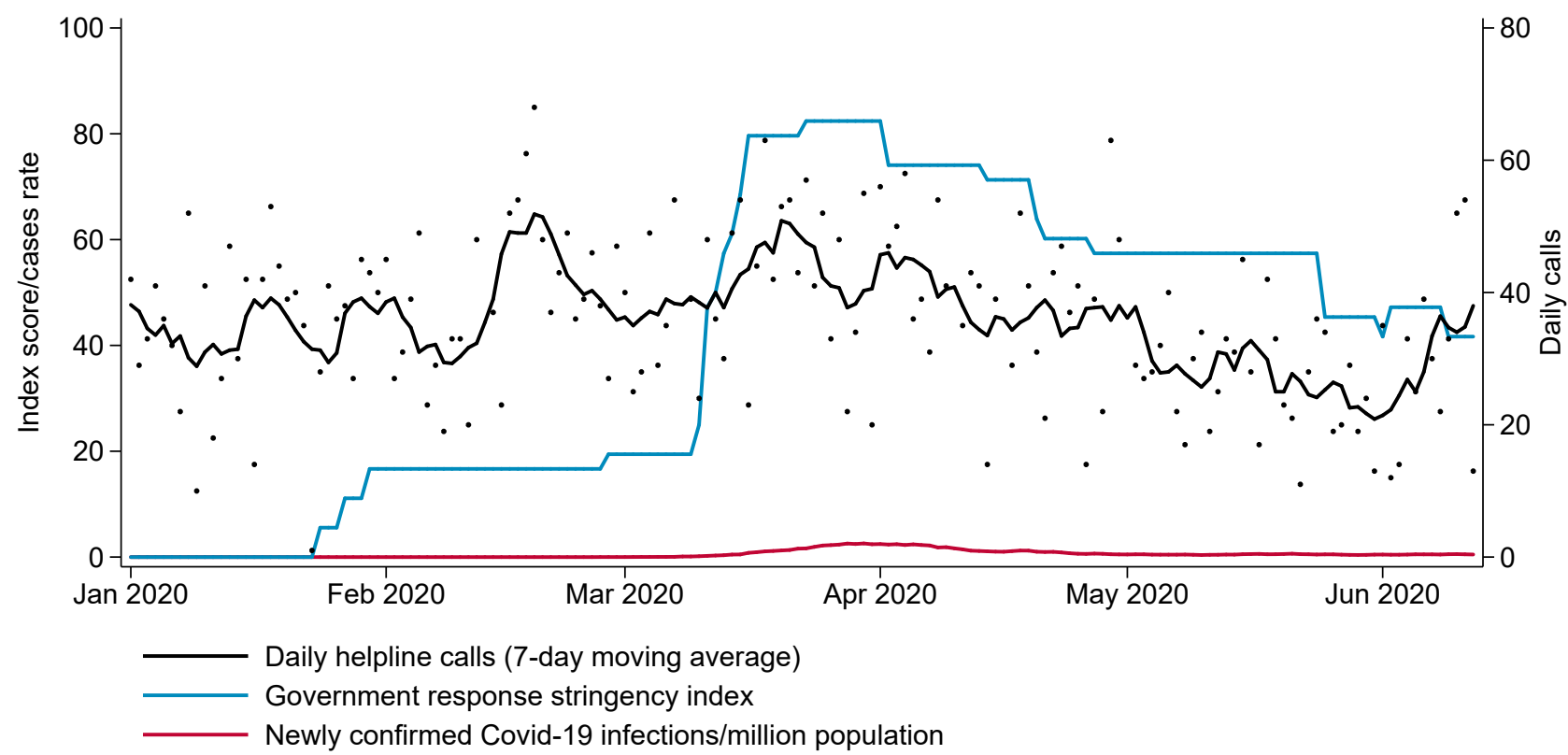

Figure S10: Modrá linka , COVID-19, and government response in Czech Republic 


\section{Finland}

MIELI Mental Health Finland is operating 24/7 each day, providing help for people in crisis with a special focus in preventing suicide. Established in 1897, MIELI is the oldest non-profit mental health organisation in the world. Since April 2019, the service is offered on a new, cheaper number where callers pay only the regular phone operator fees. MIELI's operations are primarily financed by the Finnish State, and the amount of crisis workers and volunteers depends on the time of the day: just one or two crisis workers in the early morning hours, eight or more people in the evening, which are the most active hours. With the start of the pandemic mid-march), higher capacity adjustment was implemented and the helpline has been enabling remote work for both professional crisis workers and volunteer incl. acquiring about 200 SIM cards. Crisis workers' working hours shifted from face-to-face counselling to helpline, resulting in a higher amount of answered calls and extra hours in the helpline (between March 16 and June 20, 1,372 extra hours by volunteers and 1,054 hours by employees). In addition, they received a lot of publicity in February 2020 with the connection of Crisis Helpline to the public emergency number 112 application, which has been downloaded by almost 1/3 of Finns. The record of call attempts in 2019 was approximately 212,000 calls. Call volumes increased by $42 \%$ in early October 2020, which amounts to a $42 \%$ increase compared to the same period 2019. Calls from young women (18-29 years old) have increased most noticeably. For further information, visit www.mieli.fi

We have obtained daily series of call volumes for the period January 1, 2019 to June 12, 2020, as well as separate series by caller sex and conversation topic.

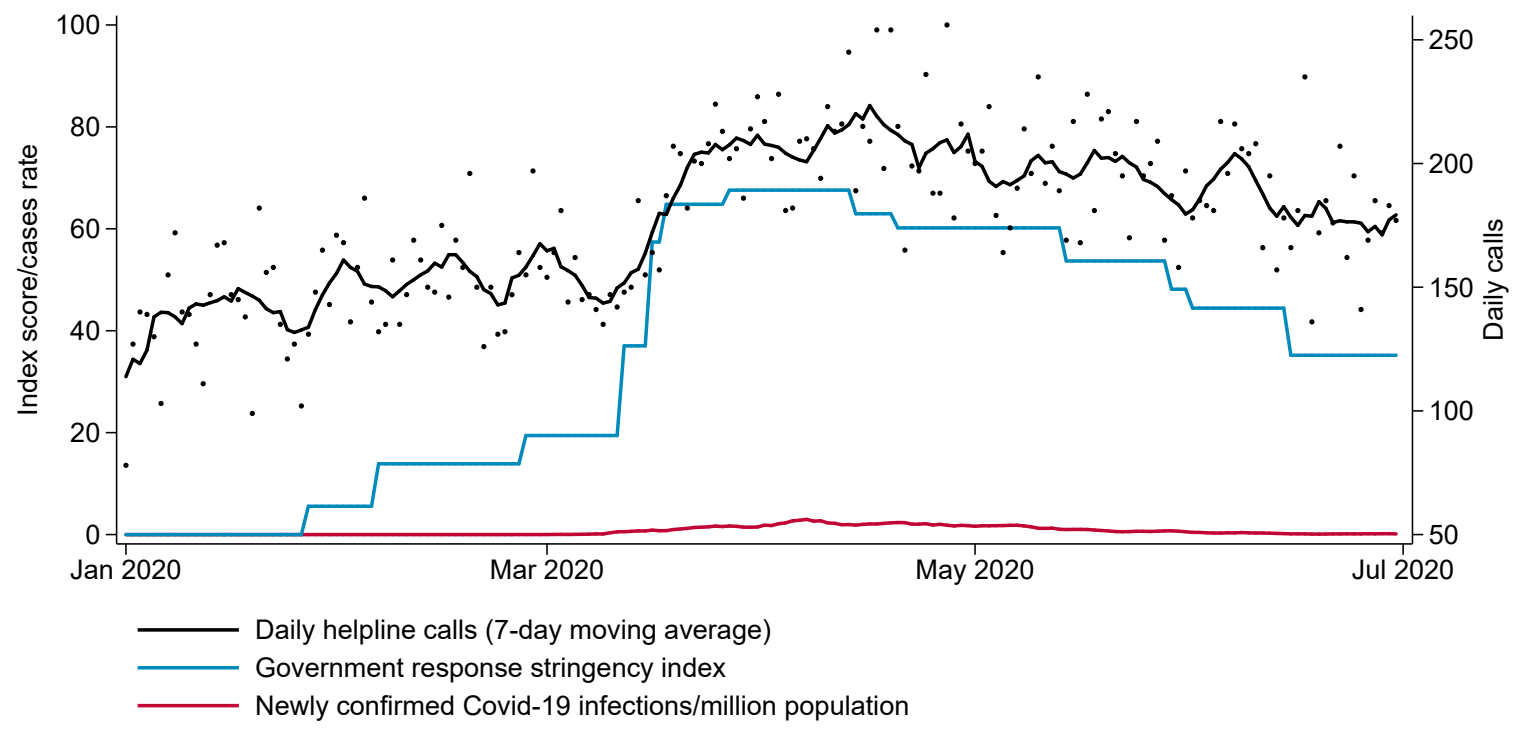

Figure S1 1: Daily calls to MIELI, COVID-19, and government response in Finland 


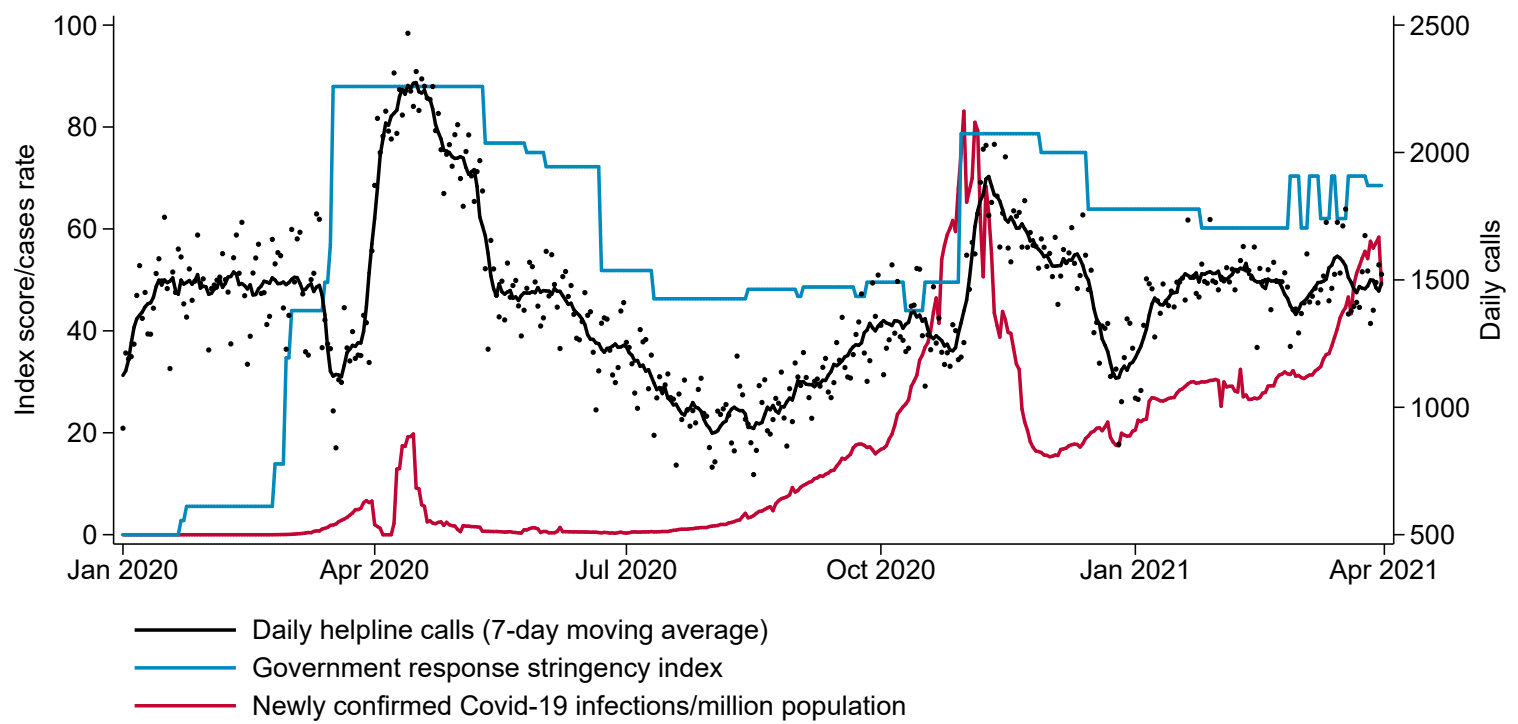

Figure S12: Daily calls to S.O.S. Amitié, Covid-19 incidence and government response in France 
Table S16: Classification of conversation topics: S.O.S. Amitié, France

\begin{tabular}{ll}
\hline Topic & Helpline-specific topic definitions \\
\hline Fears & Peur Anxiété; Peur de la mort; Crise Angoisse \\
Loneliness & Sentiment de solitude; Isolement social; Autre (Solitude) \\
Suicide & Suicidaire; Suicidant; Conduite suicidaire \\
Addiction & Alcool; Drogue; Tabaco; Poly addiction; Autre (Addiction) \\
Violence & Violence; Maltraitance; Harcèlement exclusion/sexuel; Autre (Abus sex- \\
& uel/Violence) \\
Physical health & Maladie; Longue maladie; Physique; Handicap physique; Autre (Physique) \\
Livelihood & Emploi protégé; Emploi précaire; Sans logement; Mal logé; Surendettement; Autre \\
& (travail; logement; finances) \\
Relationships & Relations parents enfants; Conflit entre personnes; Fratrie; Curatelle, tutelle; Voisi- \\
& nage; Famille recomposée; Familiale; Couple; Conjugale; Problèmes sentimentaux; \\
& Divorce Séparation; Autre (difficulté de relation) \\
\hline
\end{tabular}


a) Daily calls by age and sex of caller (seven-day moving average)

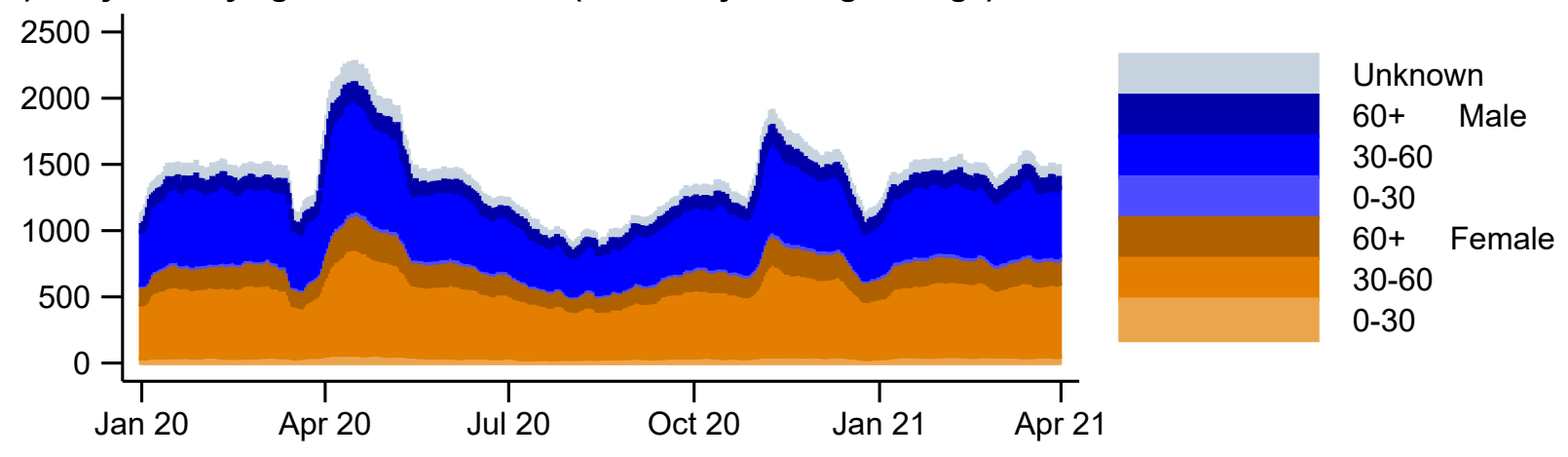

b) Daily calls by topic (seven-day moving average)

(i) Fears (incl. of infection)

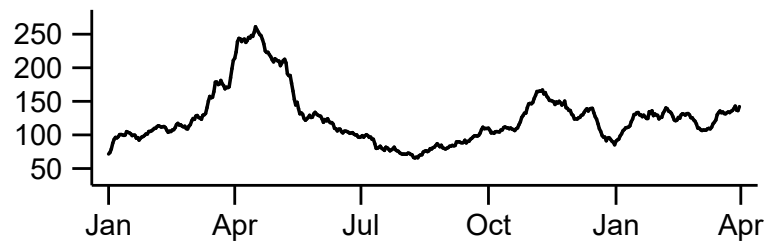

(iii) Suicide

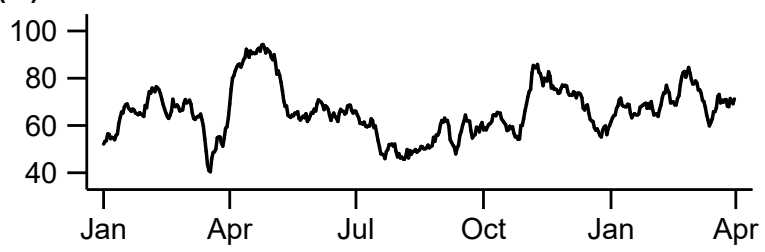

(v) Violence

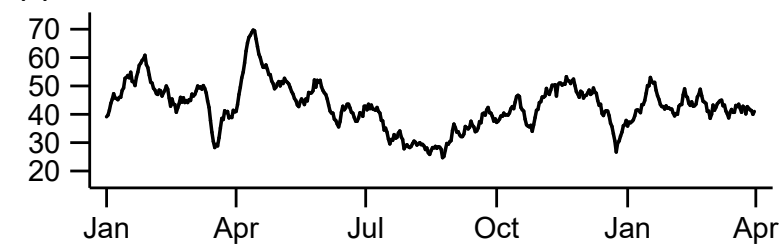

(vii) Livelihood

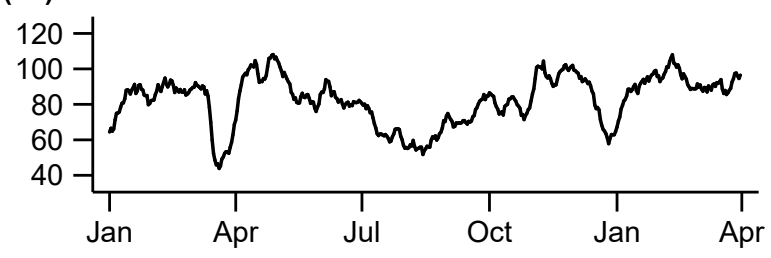

(ii) Loneliness

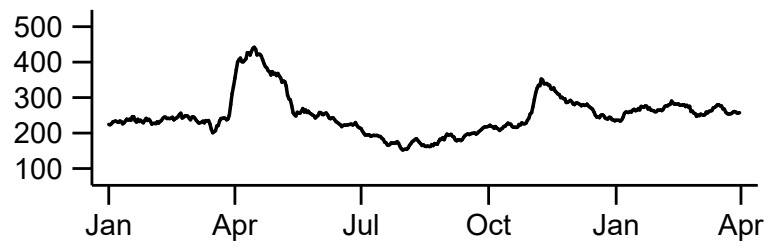

(iv) Addiction

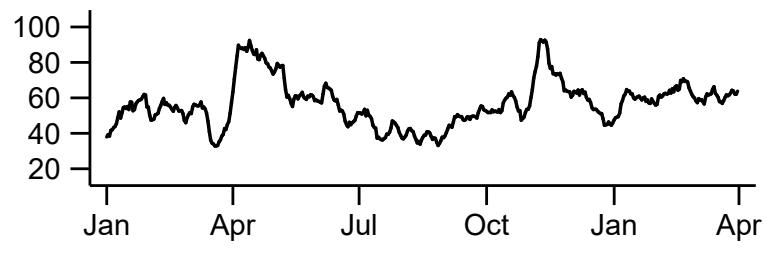

(vi) Physical health

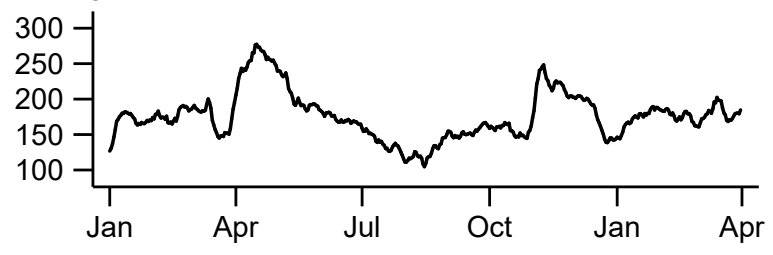

(viii) Relationships

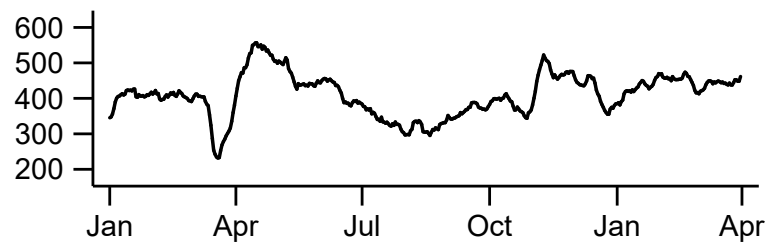

Figure S13: Caller characteristics and conversation topics, S.O.S. Amitié, France 


\section{Germany I}

The Telefonseelsorge is the by far the largest telephone and online emergency helpline in Germany, with over 100 centers in Germany. It is nationally well known, free, anonymous, partly government-funded, and the only facility in Germany to offer telephone conversations both day and night ( 24 hours). The Telefonseelsorge is under responsibility of the Protestant and the Catholic church and can be reached via phone, as well as online via mail and chat on the central website. Further information is available online at www.telefonseelsorge.de ) We received a data on individual calls from January 1, 2019 to March 31, 2021, including the sex and age group of callers, as well as their living situation, occupational status, and call duration. For each call, counselors also record conversation topics and caller issues, with no limit to the number of selected topics. From 1 March 2020 onwards, an additional variable on the 'current topic' records whether calls are related to the COVID-19 pandemic.

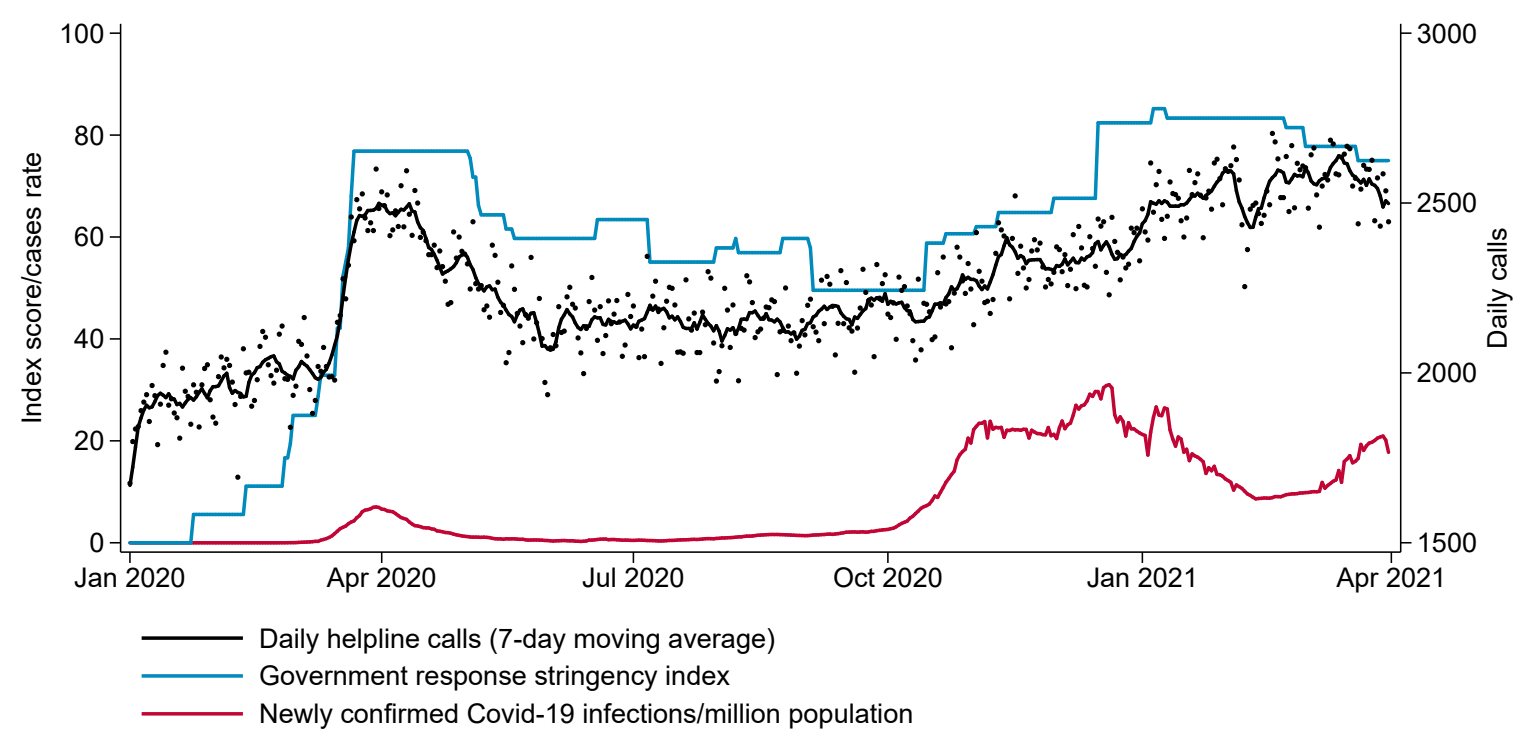

Figure S14: Daily calls to Telefonseelsorge, COVID-19, and government response in Germany 
Table S17: Classification of conversation topics: Telefonseelsorge, Germany

\begin{tabular}{ll}
\hline Topic & Helpline-specific topic definitions \\
\hline Fears & Ängste \\
Loneliness & Einsamkeit/Isolation \\
Suicide & Suizidgedanken; Suizidabsichten; Suizidversuche; Suizidalität des Ratsuchenden; \\
& Suizidalität einer anderen Person \\
Addiction & Sucht \\
Violence & Körperliche/Seelische Gewalt; Sexualisierte Gewalt \\
Physical health & Körperliches Befinden/Beschwerden \\
Livelihood & Arbeitssituation; Arbeitslosigkeit/Arbeitssuche; Wohnung/Wohnumfeld; Armut; \\
& Finanzfragen/Erbschaft/Unterhalt \\
Relationships & Leben in Partnerschaft; Partnersuche/Partnerwahl; Trennung; Familiäre Beziehun- \\
& gen; Schwangerschaft/Kinderwunsch; Elternschaft/Erziehung; Virtuelle Beziehun- \\
& gen; Alltagsbeziehungen/Nachbarn \\
\hline
\end{tabular}


a) Daily calls by age and sex of caller (seven-day moving average)

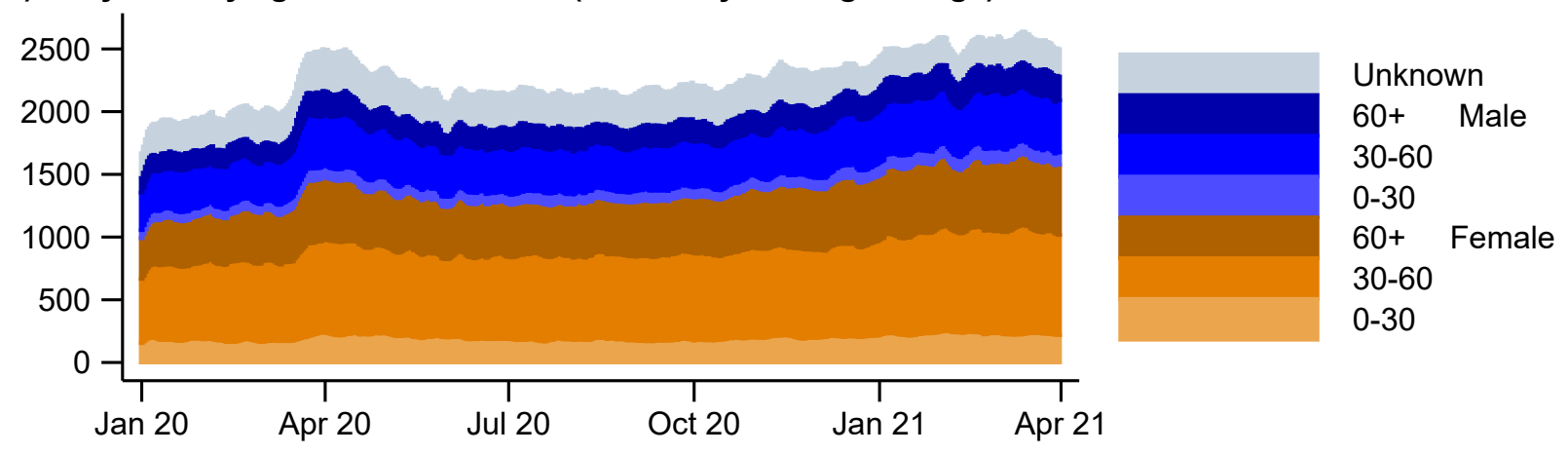

b) Daily calls by topic (seven-day moving average)

(i) Fears (incl. of infection)

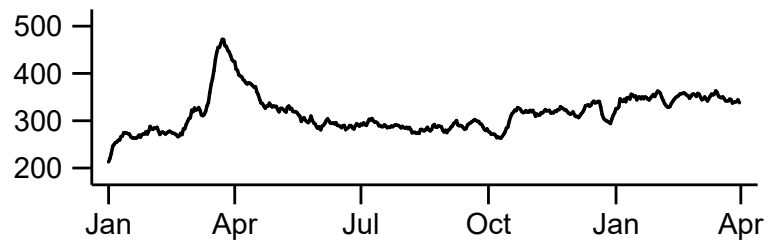

(iii) Suicide

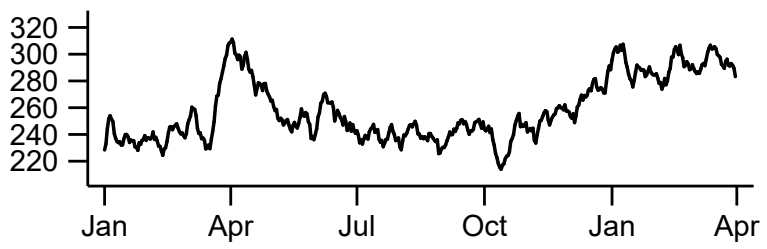

(v) Violence

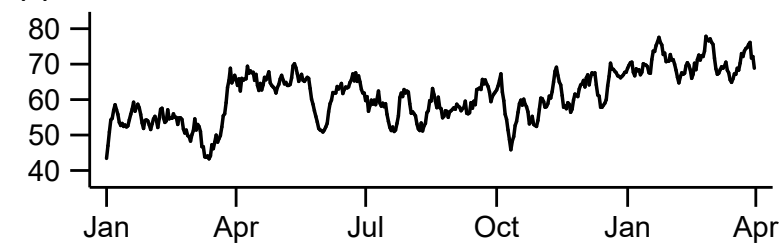

(vii) Livelihood

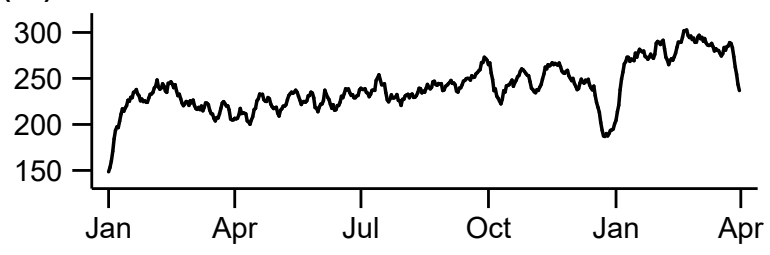

(ii) Loneliness

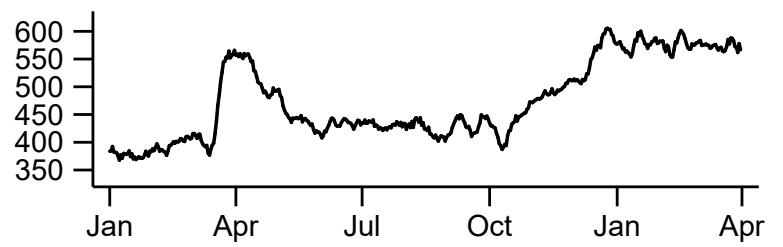

(iv) Addiction

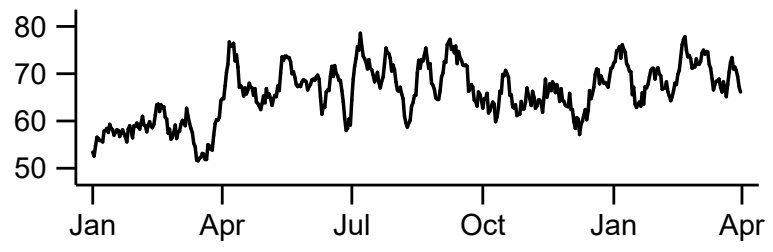

(vi) Physical health

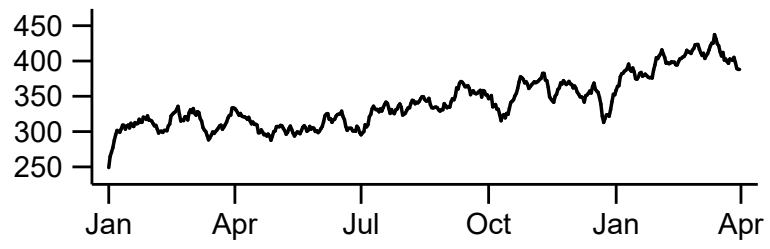

(viii) Relationships

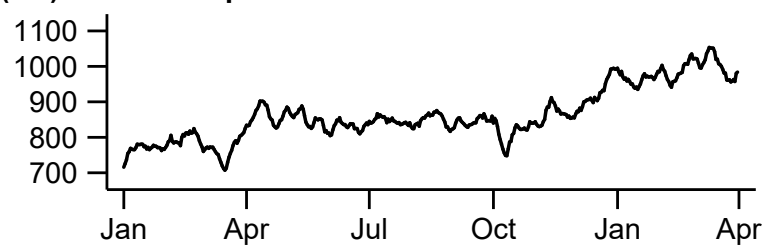

Figure S15: Caller characteristics and conversation topics, Telefonseelsorge, Germany 


\section{a) Daily calls related to COVID-19 (seven-day moving average)}

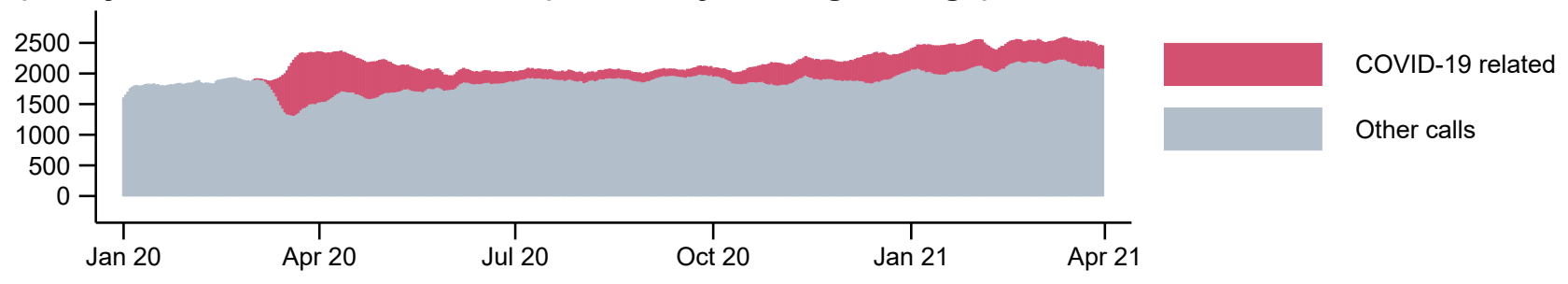

\section{b) COVID-19 related calls by topic}
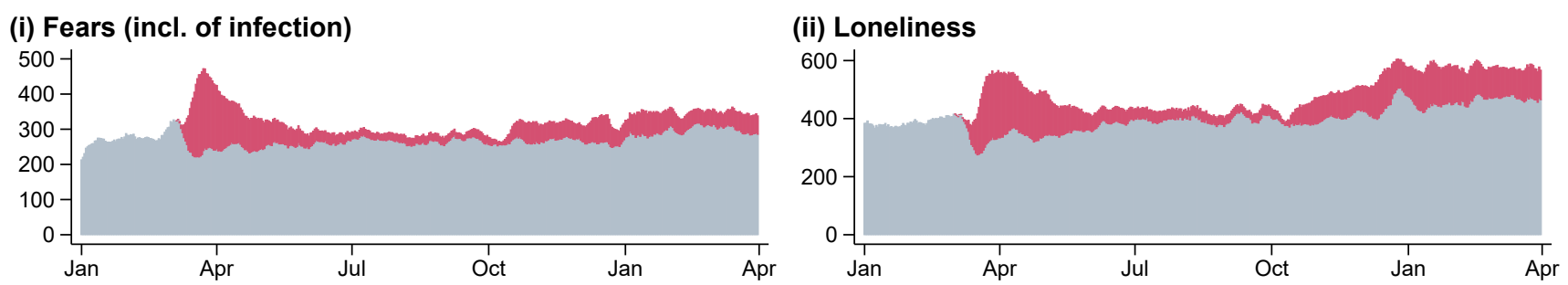

(iii) Suicide

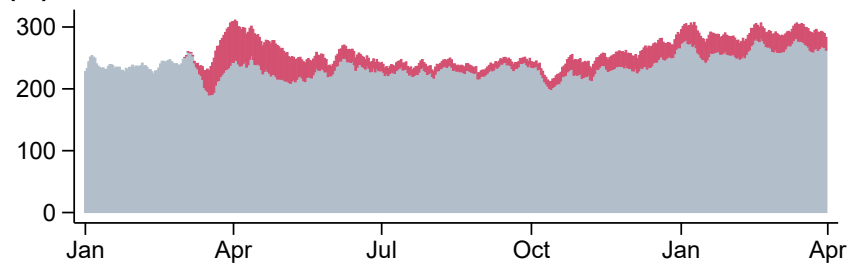

(iv) Addiction

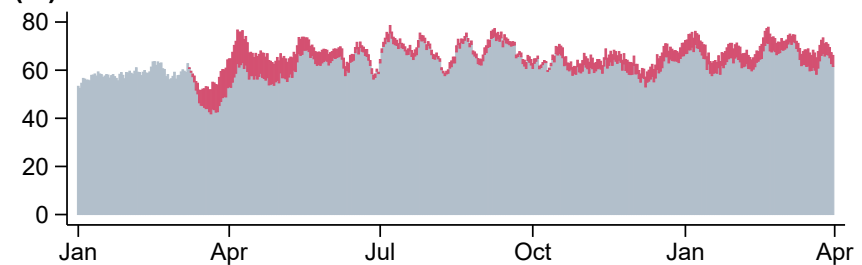

(v) Violence

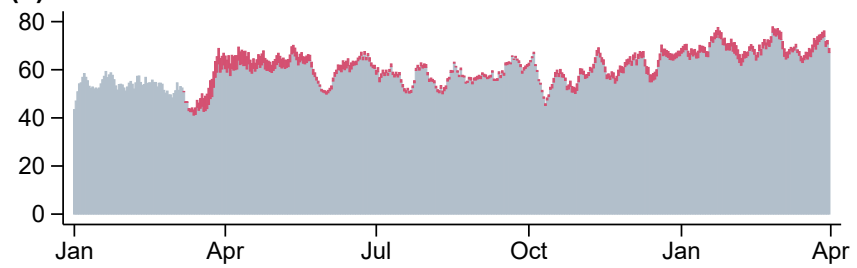

(vi) Physical health

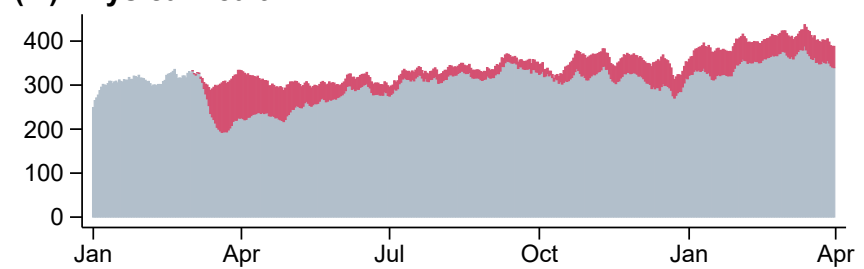

(vii) Livelihood

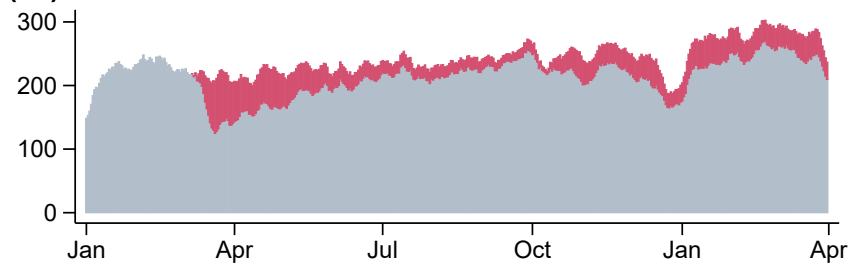

(viii) Relationships

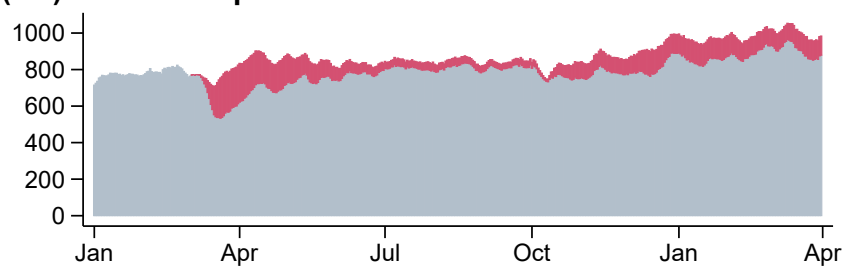

Figure S16: Helpline calls related to COVID-19, overall and by topic

Helpline calls in 2020 and 2021, Telefonseelsorge... 
a) State of receiving helpline center

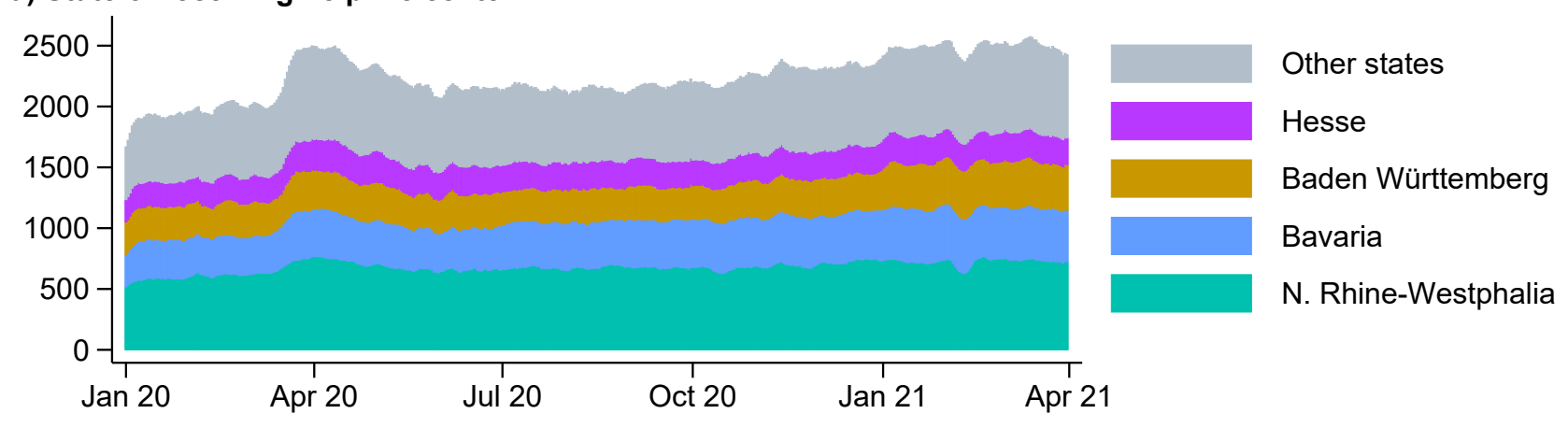

b) Living situation

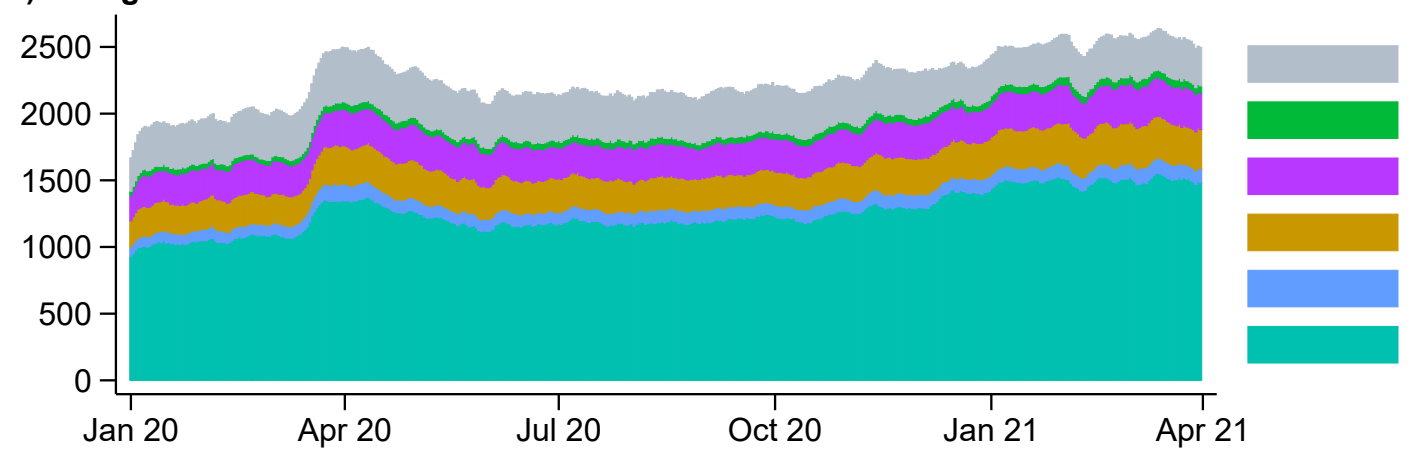

Other/unknown

With others

With partner

With family

Institution

Alone

c) Occupational status

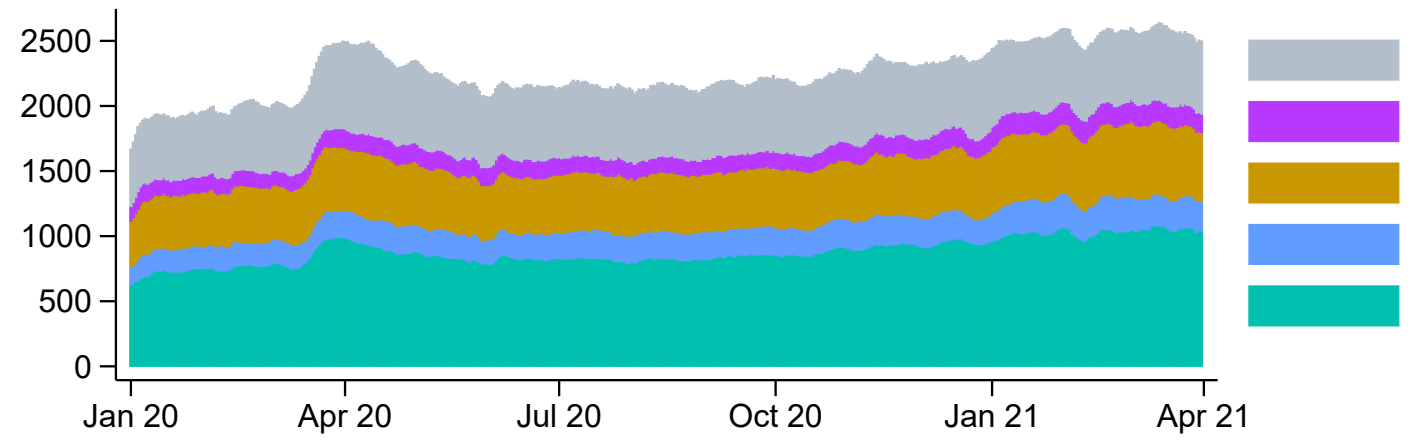

Other/unknown

Education

Payed work

Unemployed

Retired/disability

Figure S17: Helpline calls by state, living situation, and occupational status

Helpline calls in 2020 and 2021, Telefonseelsorge... 


\section{Germany II}

The Muslimisches Seelsorgetelefon (MuTes) was founded 2009 with the help of the Telefonseelsorge Germany and is operated by Islamic Relief Germany as the sole provider. Volunteer pastors guarantee a 24-hour service every day of the year.They receive a theoretical and practical training by an experienced team, lasting about 160 hours. Further information is available online at www.mutes.de.

We have received data on individual calls received during the time from 1 January 2020 to 8 December 2020. Data collection on conversation topics follows the classification of Telefonseelsorge, see Table S17.

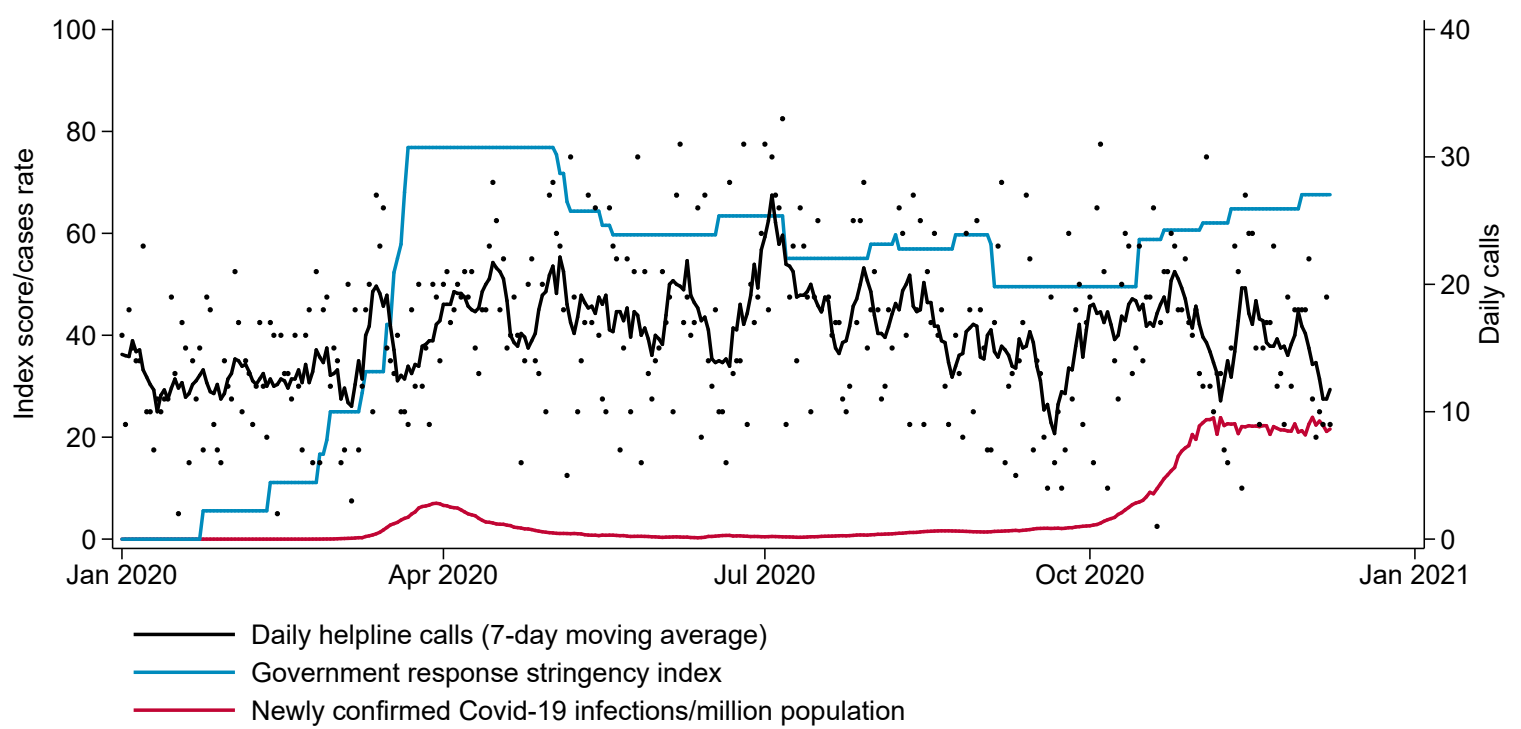

Figure S18: Daily calls to Muslimisches Seelsorgetelefon, COVID-19, and government response in Germany 
a) Daily calls by age and sex of caller (seven-day moving average)

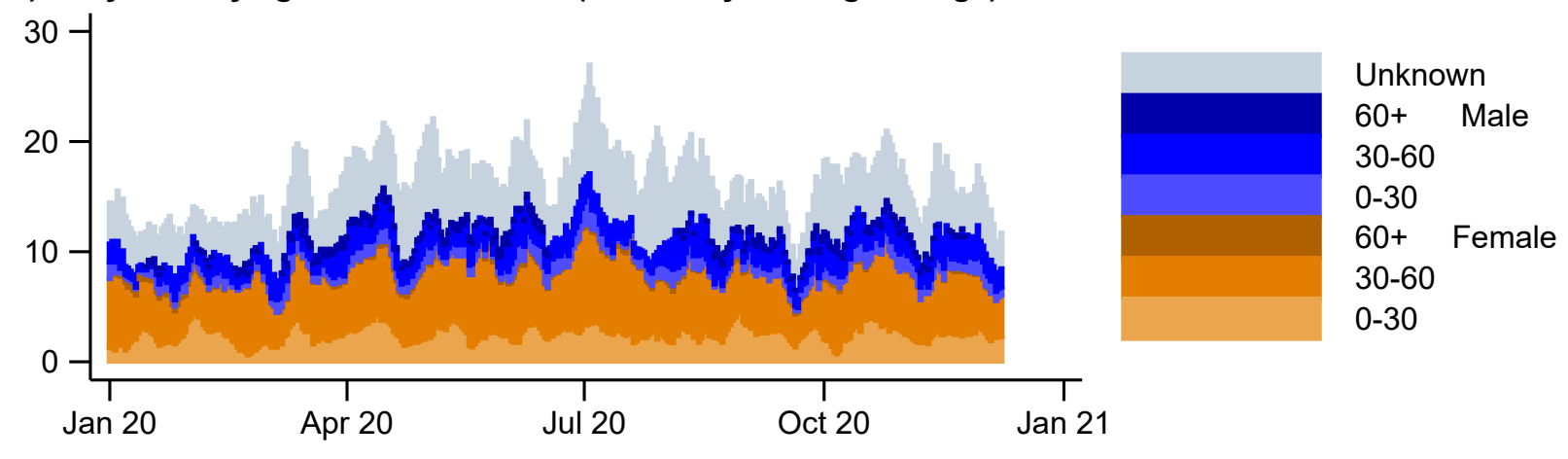

b) Daily calls by topic (seven-day moving average)

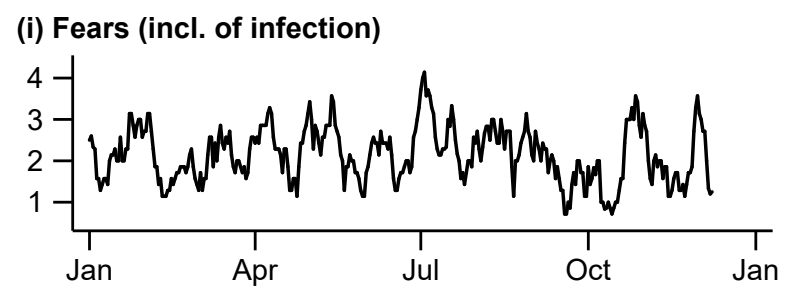

(ii) Loneliness

(iii) Suicide
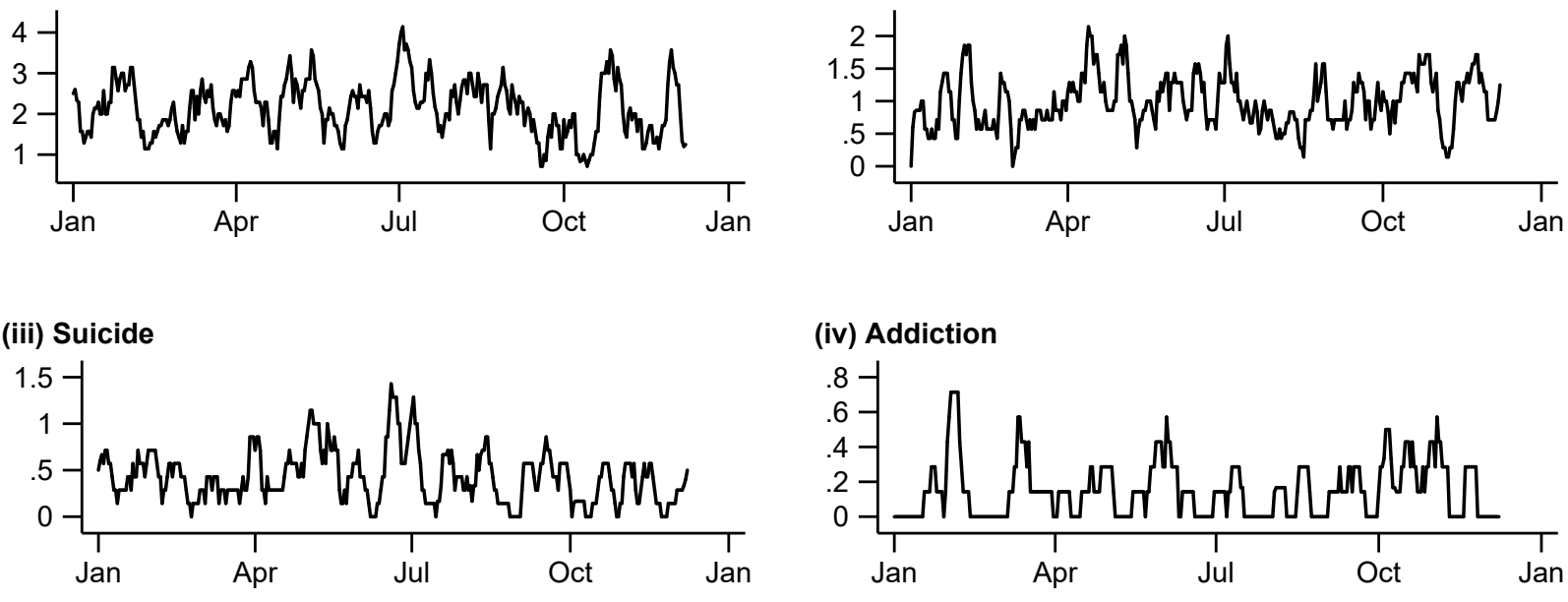

(iv) Addiction

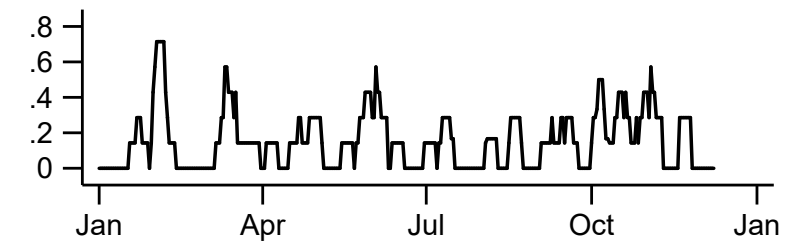

(v) Violence
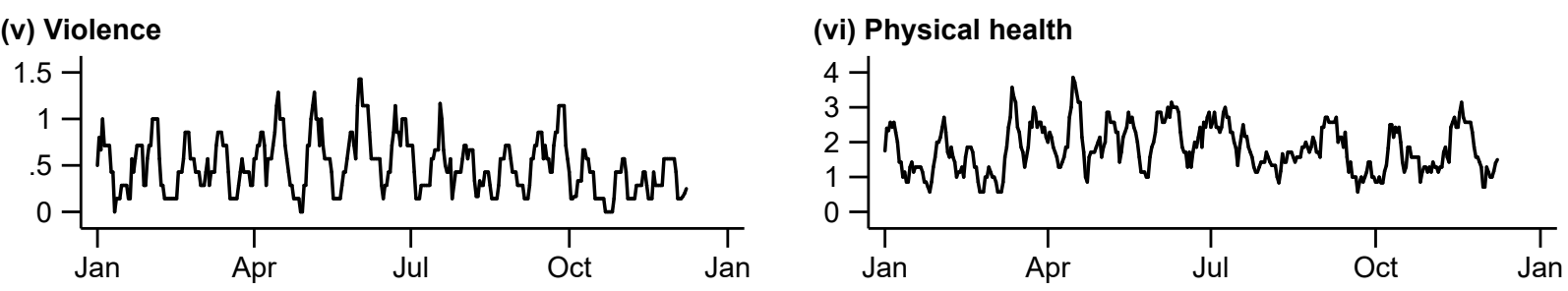

(vii) Livelihood

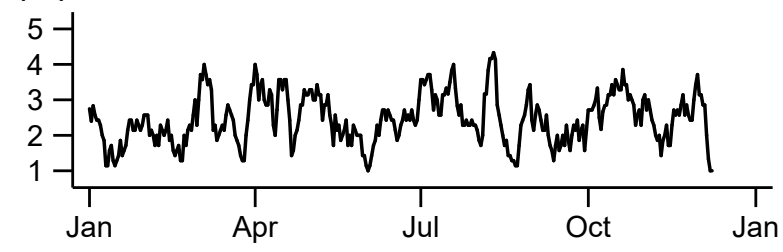

(viii) Relationships

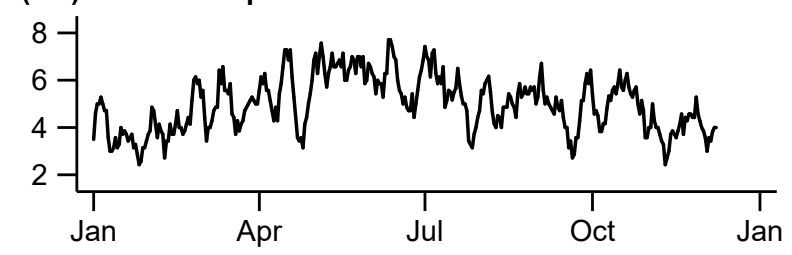

Figure S19: Caller characteristics and conversation topics, Muslimisches Seelsorgetelefon, Germany 


\section{Germany III}

The Nummer gegen Kummer e.V. (engl.: Number against worries) is the umbrella organization of the largest telephone advisory service dedicated to children, young people, and parents in Germany. The association was founded in 1980 and has been a registered non-profit association based in Wuppertal since 1994. Nummer gegen Kummer consists of two specific helpline, one for children and young people and one for parents, operating anonymous and free of charge from mobile phones and landlines from Monday to Saturday from 2pm to 8pm (children) and Monday to friday from 9 am to $5 \mathrm{pm}$ as well as Thuesday and Thursday from $5 \mathrm{pm}$ to $7 \mathrm{pm}$ (parents). The helpline has 94 local associations that maintain a location for the child and youth telephone and/or a location for the parent telephone across Germany. Further information is available online at www.nummergegenkummer.de.

Nummer gegen Kummer provided us with a detailed data on individual calls to both helplines, covering the time from January 1, 2019 to February 18, 2021. The information includes the location, problem, age, family situation and status and the number of children in family.

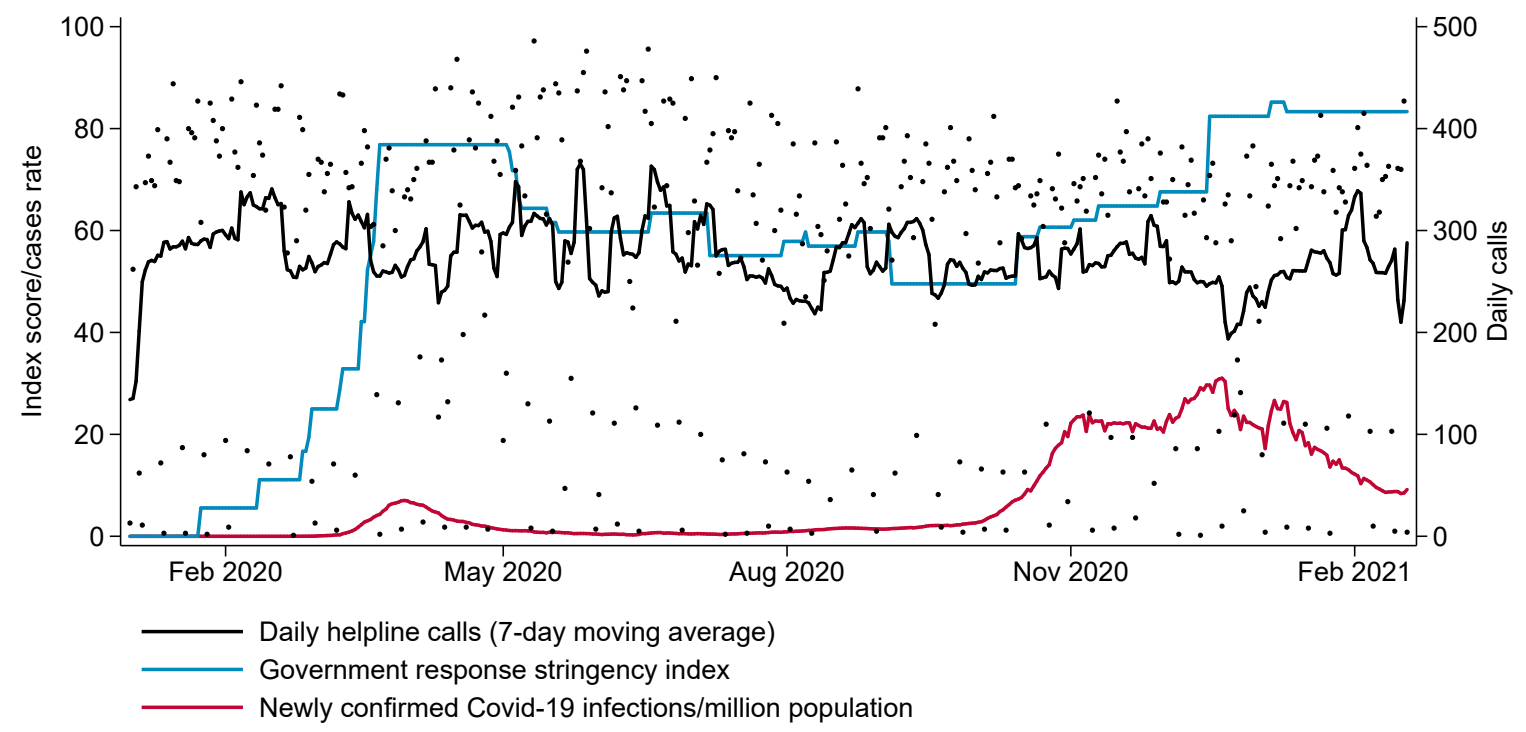

Figure S20: Daily calls to Nr. gg. Kummer (children line), COVID-19, and government response in Germany 


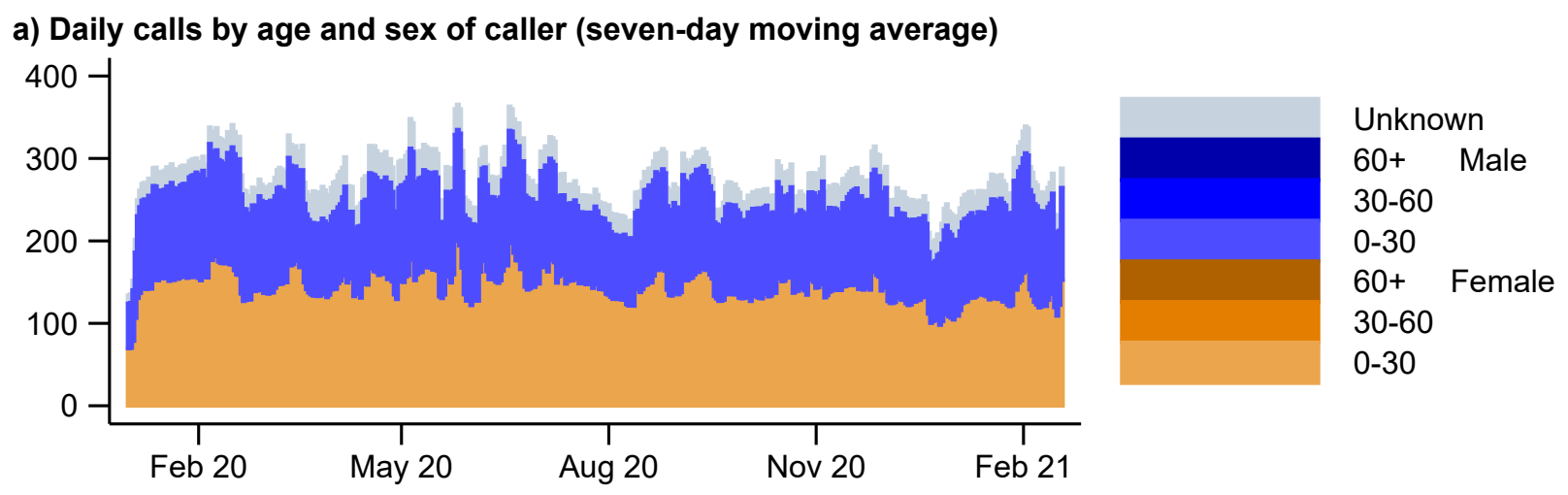

b) Daily calls by topic (seven-day moving average)

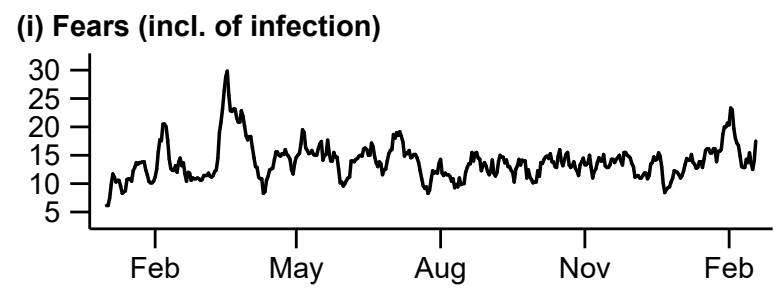

(ii) Loneliness

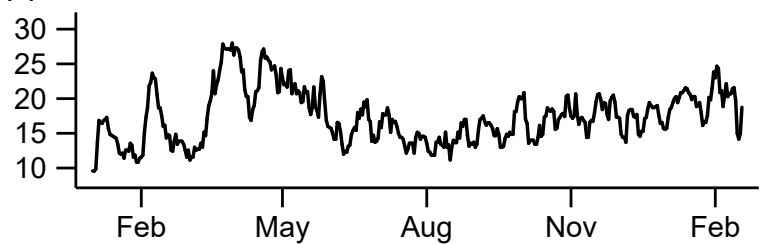

(iii) Suicide

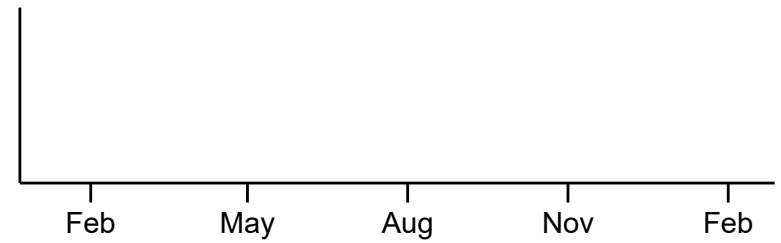

(iv) Addiction
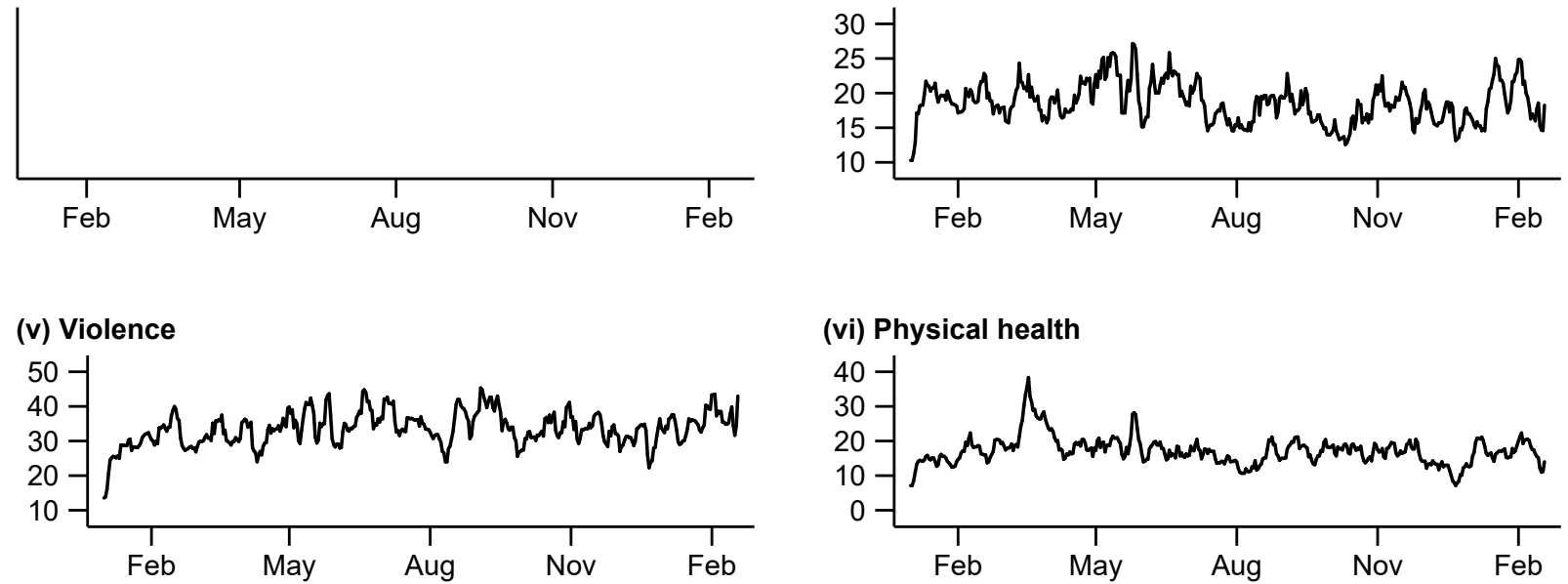

(vii) Livelihood

(viii) Relationships
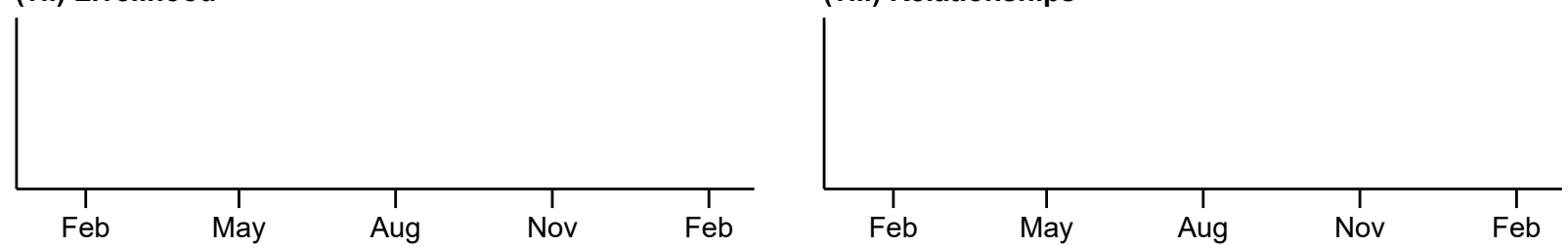

Figure S21: Caller characteristics and conversation topic, Nummer gegen Kummer (children line), Germany 


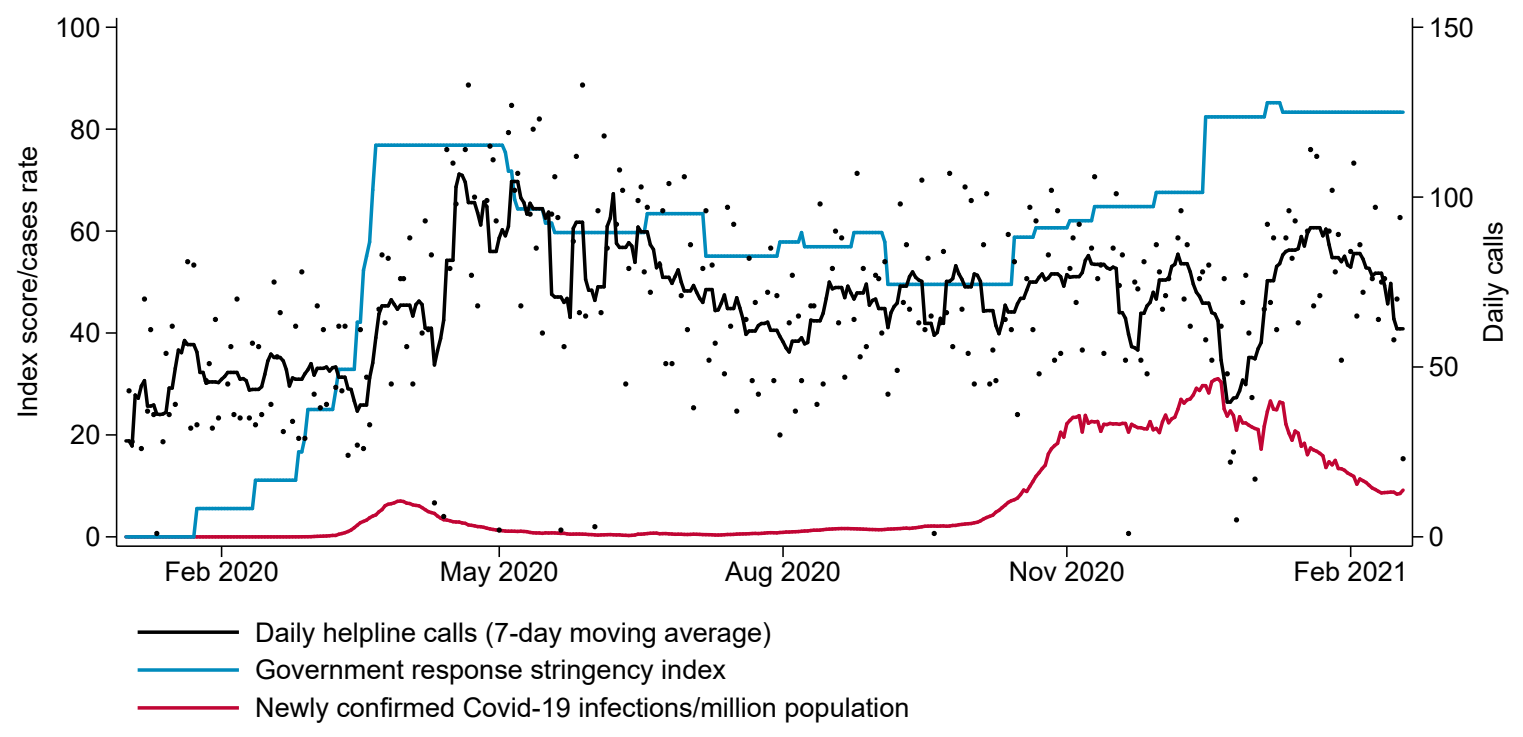

Figure S22: Daily calls to Nr. gg. Kummer (parent line), COVID-19, and government response in Germany 
a) Daily calls by age and sex of caller (seven-day moving average)

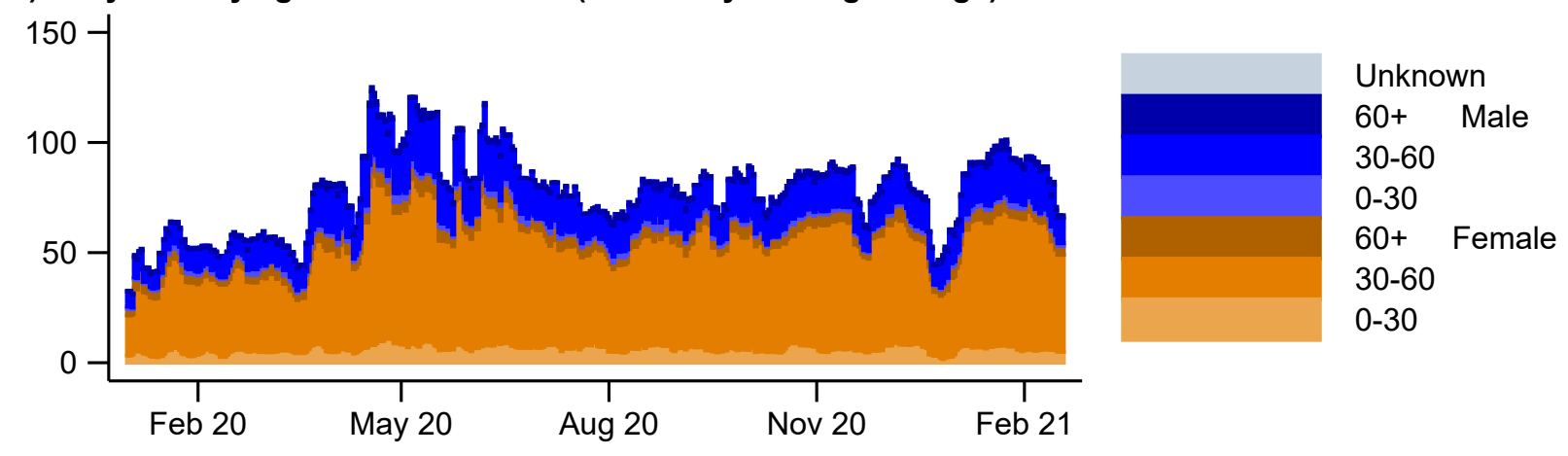

b) Daily calls by topic (seven-day moving average)

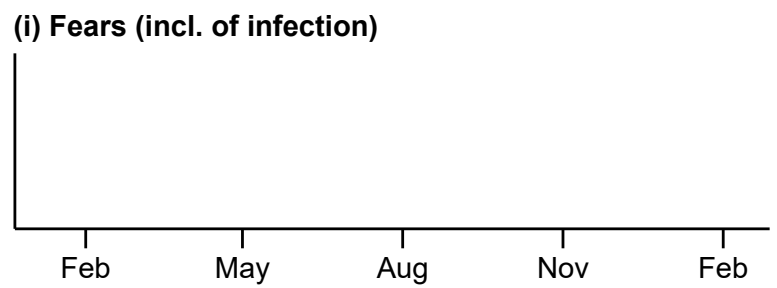

(ii) Loneliness

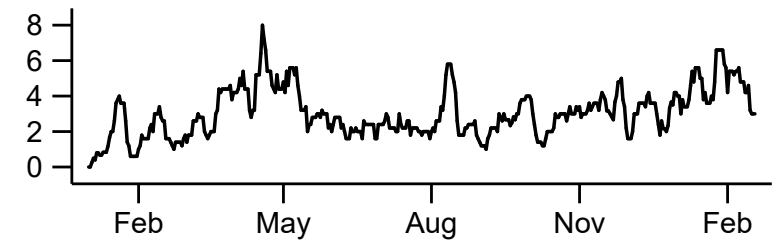

(iii) Suicide

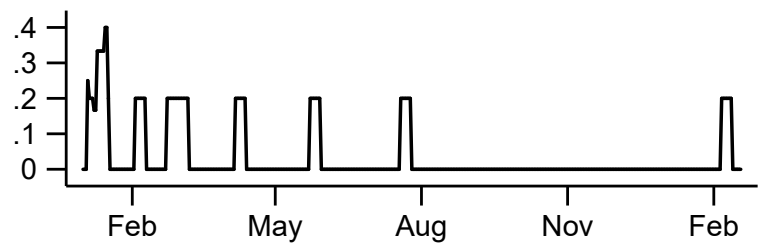

(iv) Addiction

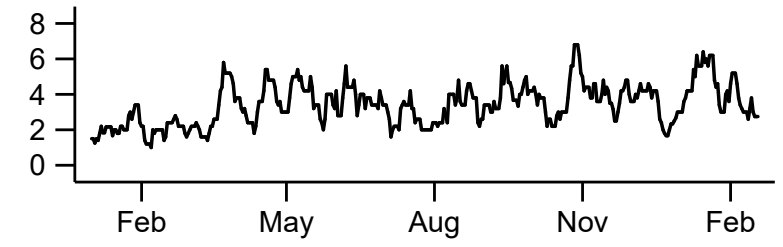

(v) Violence

(vi) Physical health
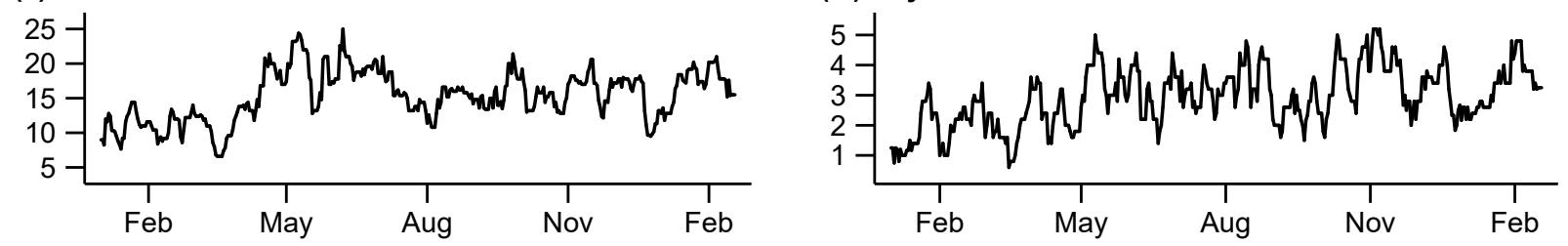

(vii) Livelihood

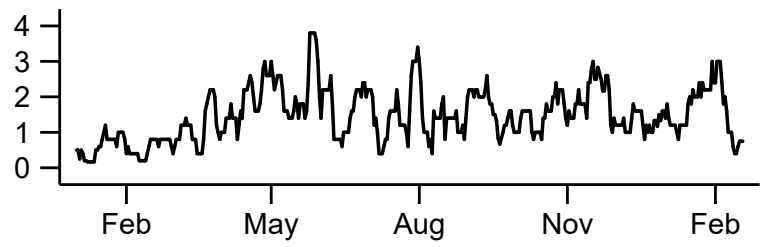

(viii) Relationships

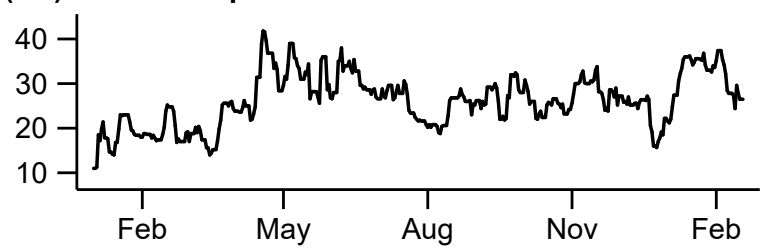

Figure S23: Caller characteristics and conversation topic, Nummer gegen Kummer (parent line), German 


\section{Hong Kong}

The Samaritan Befrienders Hong Kong was officially registered 1963 as the Hong Kong Samaritans, which they later renamed the Samaritan Befrienders Hong Kong in December 1976. The organisation, despite its name, has no religious affiliation. They have over 290 volunteers and their Suicide Crisis Intervention Centre provides immediate suicide intervention services, especially with the Emotional Support Hotline which is offered all-year-round 24 hours. For further information, visit www.sbhk.org.hk.

We have received data on indivudual calls, covering the time from 23 January 2020 to 6 October 2020, including the sex of callers.

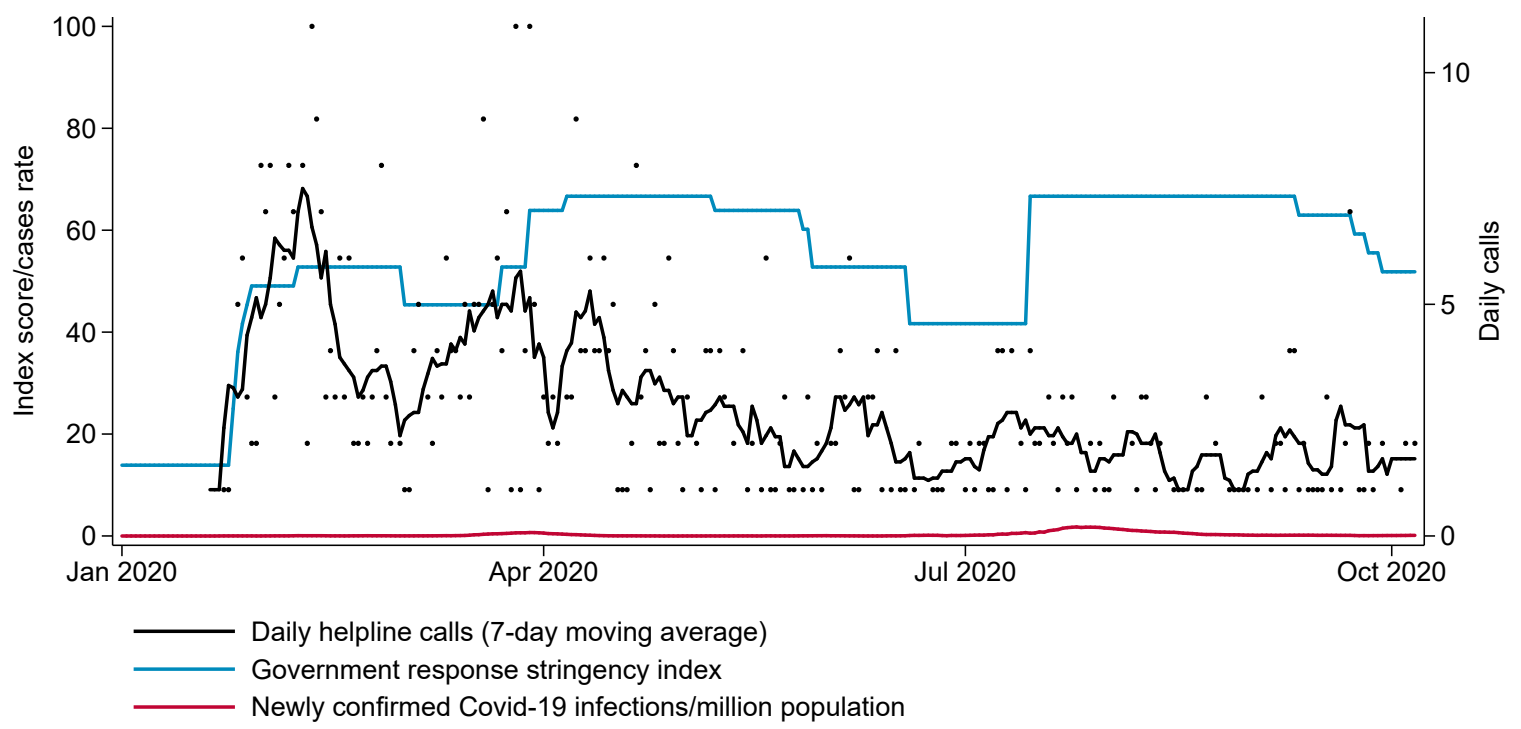

Figure S24: Daily calls to the Samaritan Befrienders, COVID-19, and government response in Hong Kong 


\section{Hungary}

The Hungarian Spiritual first aid telephone service LESZ was founded in 1970 and provides free and anonymous emotional helpline support with 400 volunteers in Hungary and approximately 25 counselors each day. LESZ overs usual training for volunteers and asks them to pass exams (written and verbal). During the COVID-19 outbreak, the capacity to answer calls was at first lowered due to working-from-home requirements, but then increased as an additional line was introduced. For further information, visit sos116-123.hu.

We received time series of daily call volumes, covering the time from January 1, 2019 to May 31, 2020.

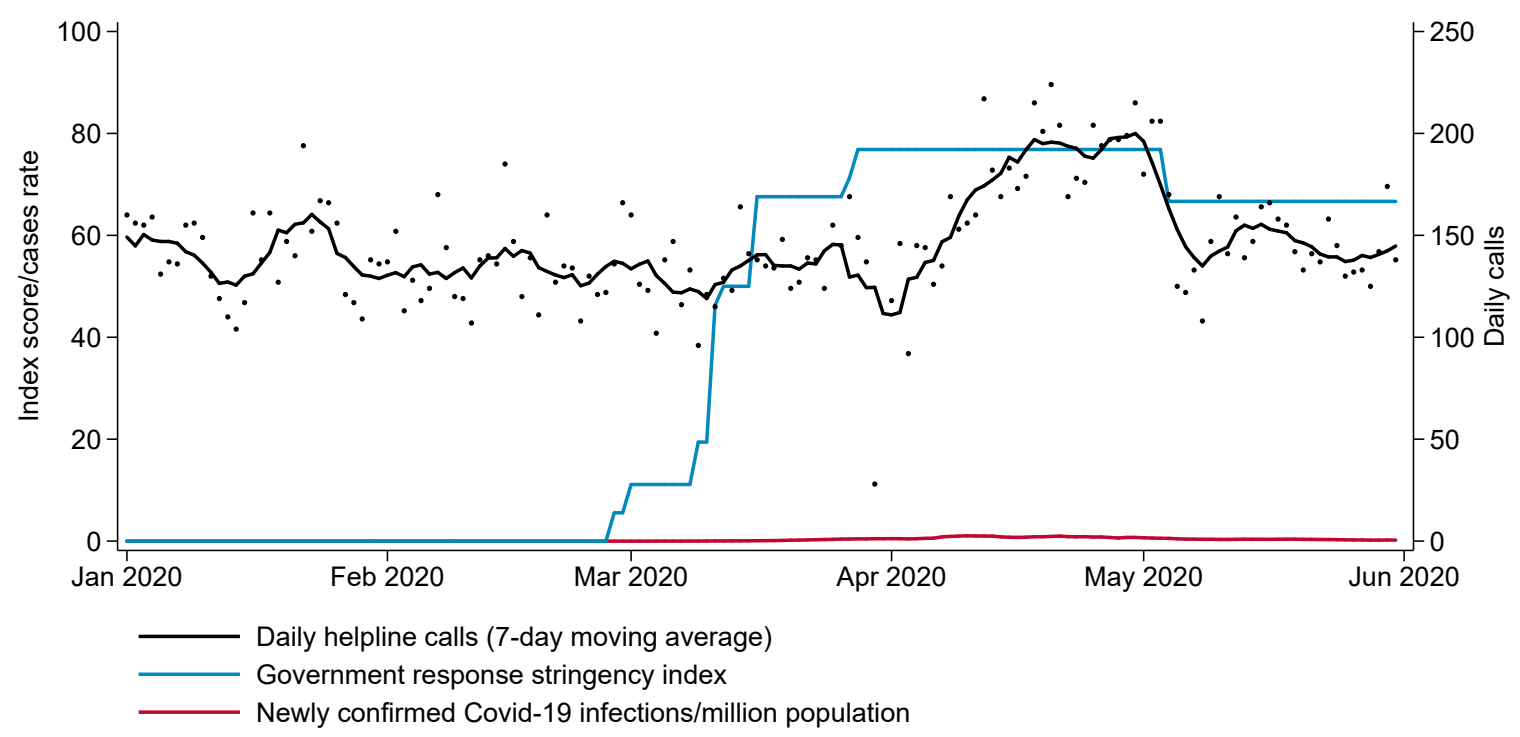

Figure S25: Daily calls to LESZ, COVID-19, and government response in Hungary 


\section{Israel}

Israel's emotional support helpline Sahar is a non-profit organization based in Israel, established in 2000, to provide anonymous, instantaneous, free-of-charge online assistance to people experiencing emotional distress. Sahar was among the first hotlines to provide emotional assistance through digital services only (no phone line), and offers a personal chat, support forums, and mail services provided by around 150 trained volunteers. As far as we know, there are no other projects that aim to identify distress messages to prevent suicide and ease severe emotional distress in Israel. Working hours are 8 hours a day (4 pm until midnight, 6 days a week) since 15 March 2020 - prior to the COVID-19 outbreak, they were working only 3 hours a day (from 9pm until midnight, 6 days a week). Further information can be found online at www.sahar.org.il.

We received anonymous chat data from with information on gender, age category, and the content that they raise in the chat. While the dataset covers calls from January 2019 to 24 December 2020, the data for 2019 are incomplete and we therefore consider only calls from 1 January 2020 onwards that are comparable to the post-outbreak time.

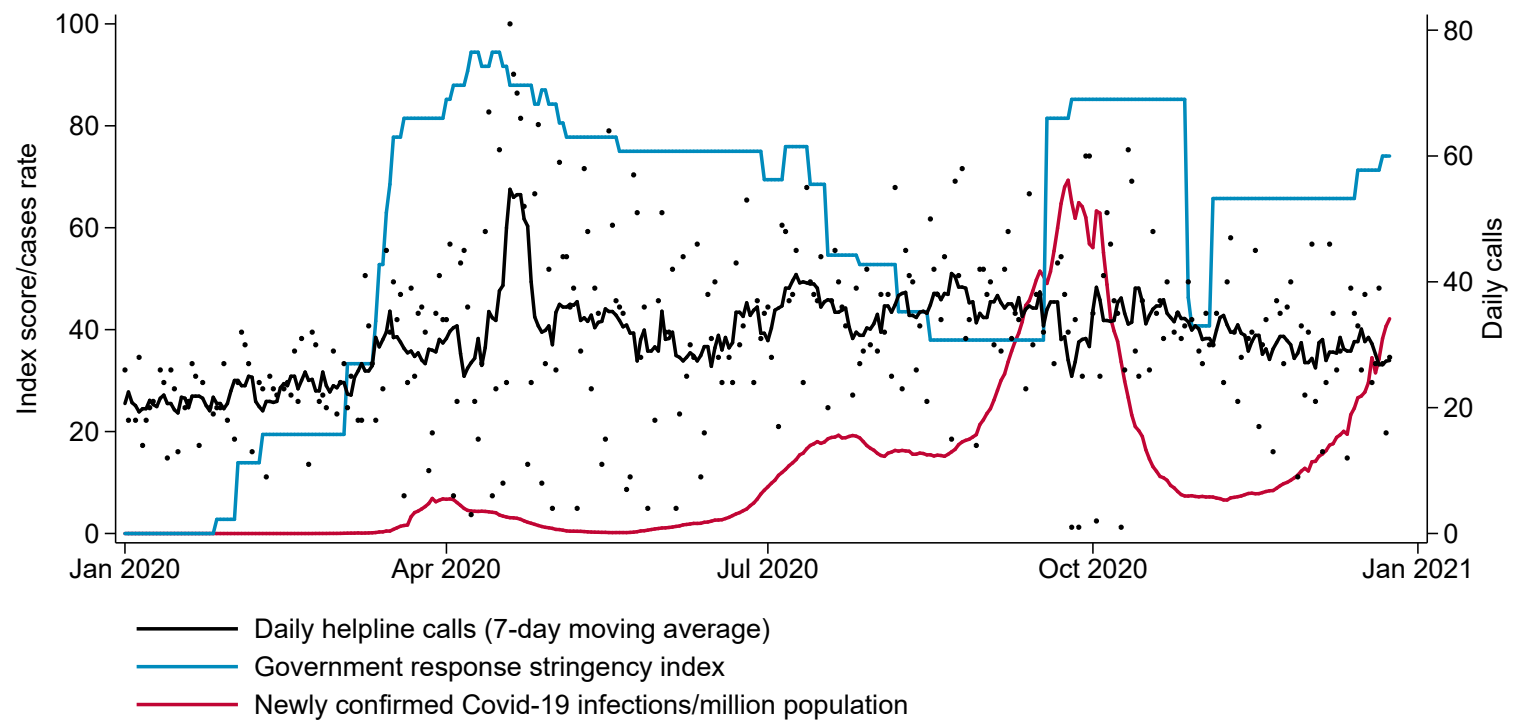

Figure S26: Daily calls to Sahar, Covid-19, and government response in Israel 
Table S18: Classification of conversation topics: Sahar, Israel

\begin{tabular}{ll}
\hline Topic & Helpline-specific topic definitions (translated from Hebrew original) \\
\hline Fears & Fear/anxiety \\
Loneliness & Loneliness \\
Suicide & Suicidal ideation, Danger of comitting suicide \\
Addiction & Addiction \\
Violence & Domestic violence \\
Physical health & \\
Livelihood & Economic difficulties, financials \\
Relationships & Social difficulties, problems in family, romantic relations \\
\hline
\end{tabular}


a) Daily calls by age and sex of caller (seven-day moving average)

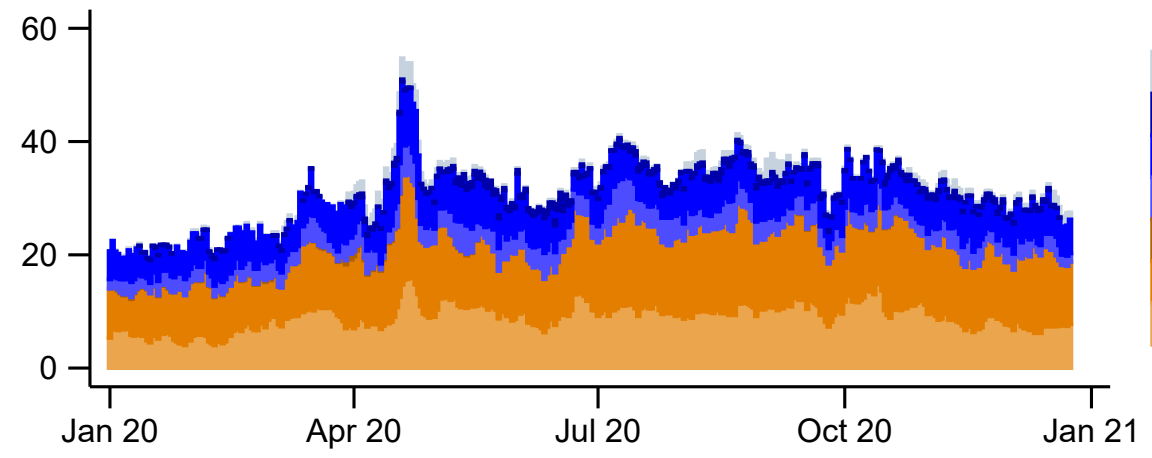

Unknown

$60+$ Male

$30-60$

$0-30$

$60+$ Female

$30-60$

$0-30$

b) Daily calls by topic (seven-day moving average)

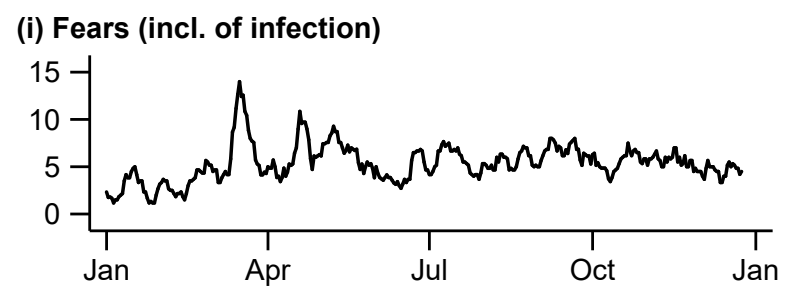

(ii) Loneliness

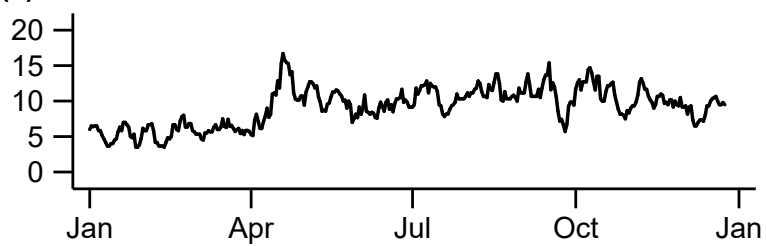

(iii) Suicide

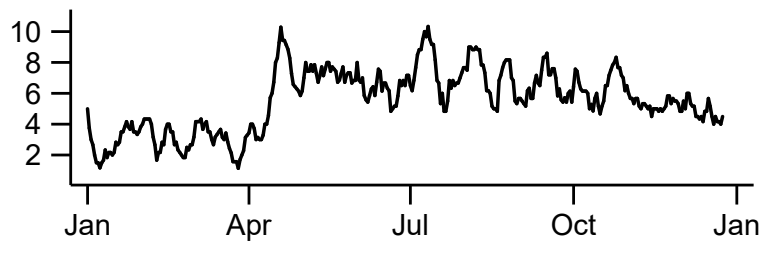

(iv) Addiction

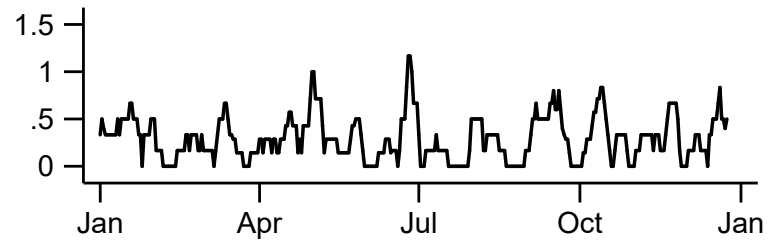

(v) Violence

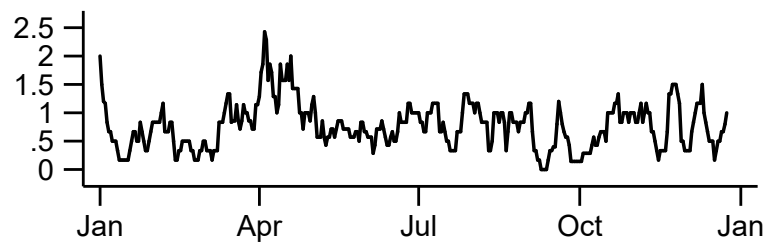

(vi) Physical health

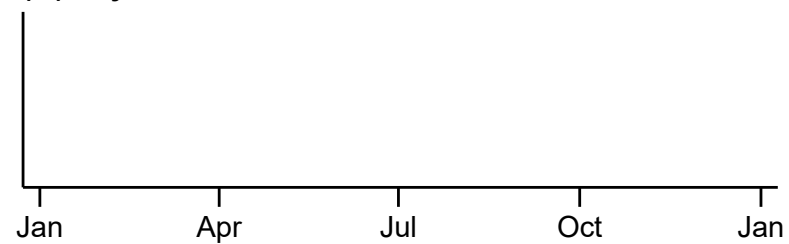

(vii) Livelihood

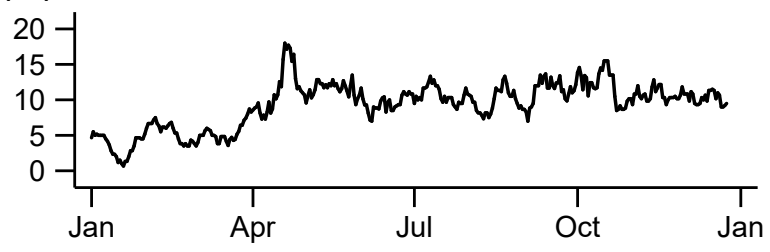

(viii) Relationships

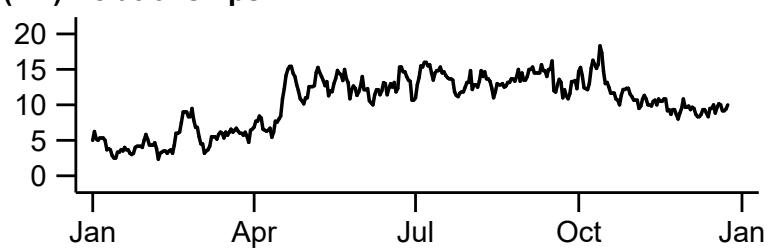

Figure S27: Caller characteristics and conversation topics, Sahar, Israel 


\section{Italy}

Telefono Amico was founded in the 1960s and 1967, the National Association of Telefono Amico Italia was established. There are 20 centers across Italy providing free and anonymous web, chat and telephone service from 10 am to 12 pm each day. Further information is available onlne at www.telefonoamico.it

We received data on individual calls (incl. chats) from January 1, 2019 to June 1, 2020, including information on callers' sex and age group, as well as problems of callers and conversation topics. Additionally, the data includes the occupational status, living situation, call duration, and the sub-national region of origin. Calls labeled as hoax (scherzo) are dropped.

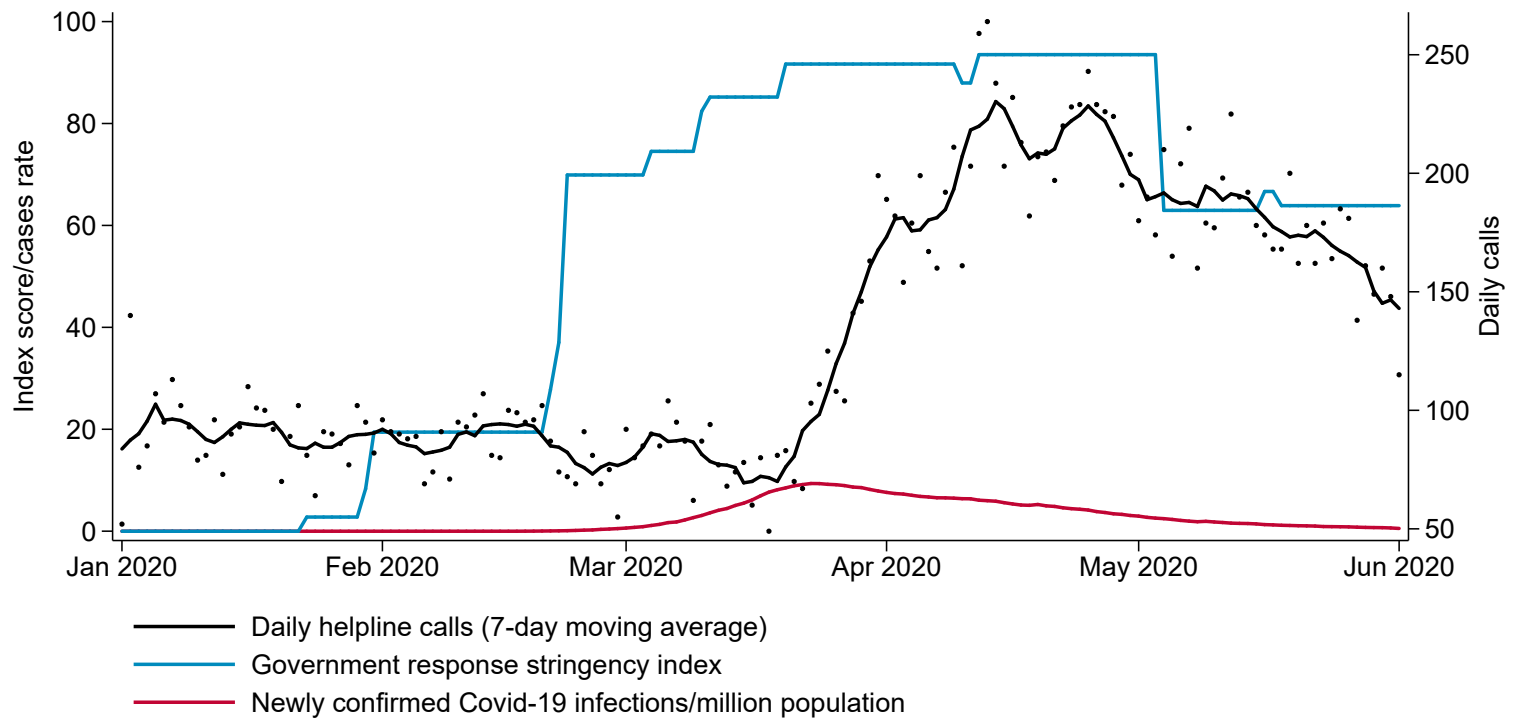

Figure S28: Daily calls to Telefono Amico, COVID-19, and government response in Italy

Table S19: Classification of conversation topics: Telefono Amico, Italy

\begin{tabular}{ll}
\hline Topic & Helpline-specific topic definitions (problems and additional counselor reporting) \\
\hline Fears & \\
Loneliness & Solitudine \\
Suicide & Suicidio \\
Addiction & Dipendenza sostanze \\
Violence & Violenza \\
Physical health & Malattia fisica \\
Livelihood & Abitative; lavorativi; economica; ins. lavorativo/sociale \\
Relationships & Amicali/altre relazioni; familiari; diff. rapporti e relazioni; bisogno di comp.; coppia \\
\hline
\end{tabular}


a) Daily calls by age and sex of caller (seven-day moving average)

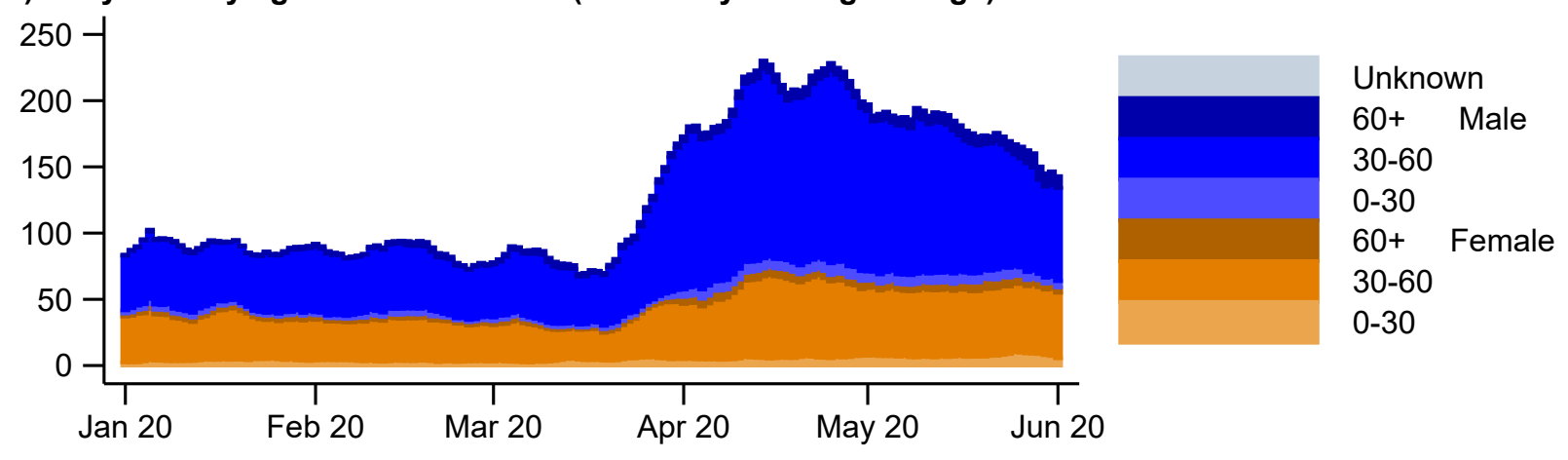

b) Daily calls by topic (seven-day moving average)

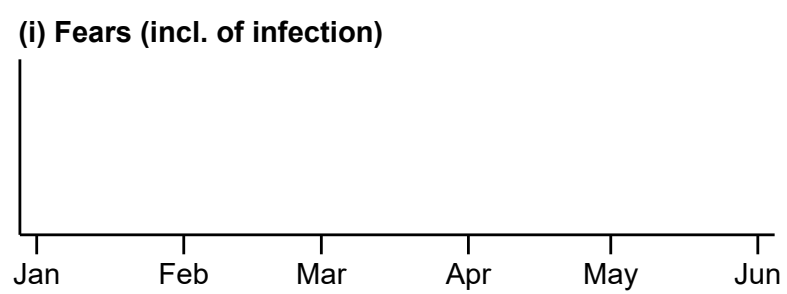

(ii) Loneliness
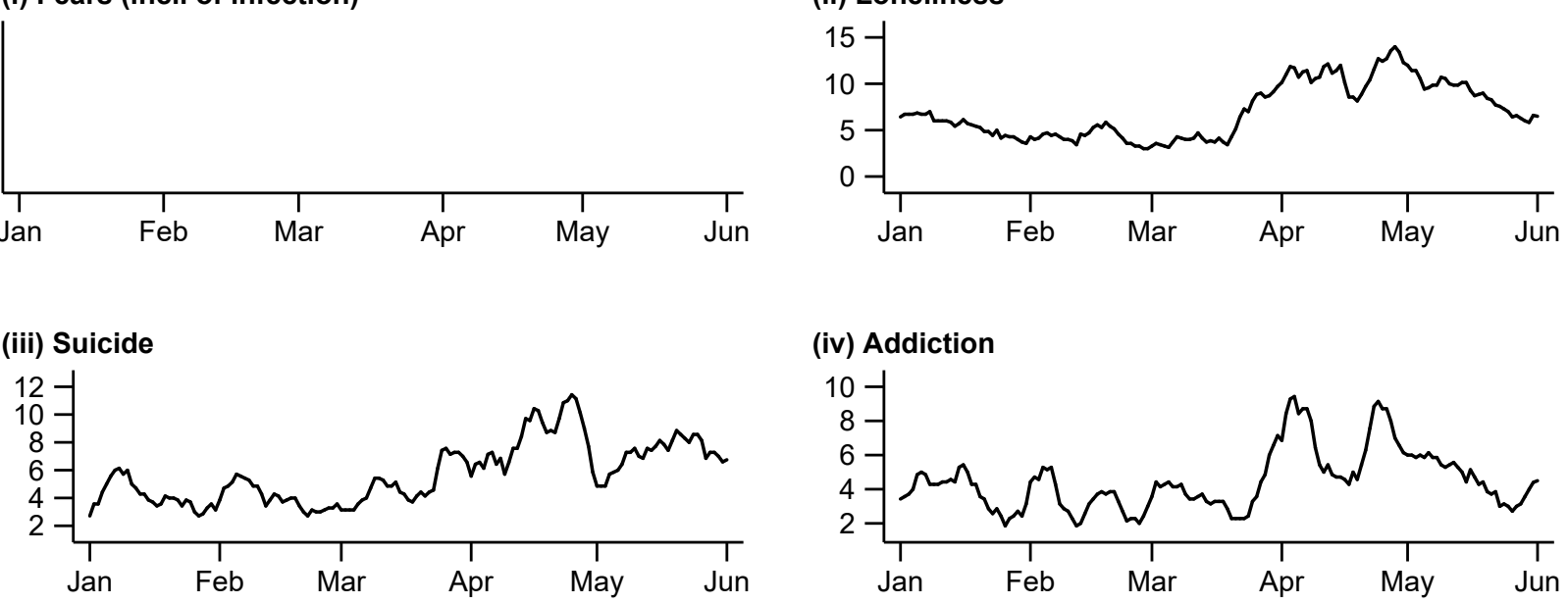

(iv) Addiction

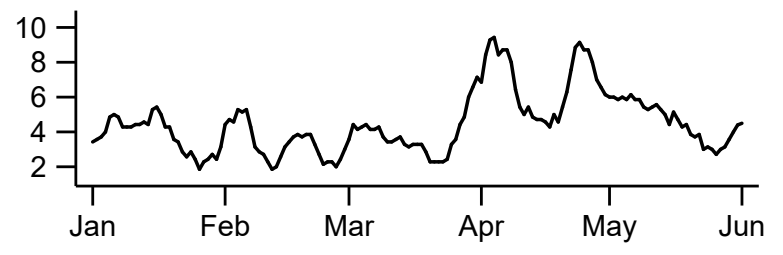

(v) Violence

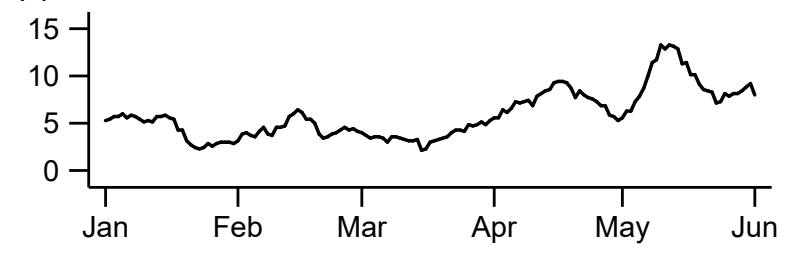

(vi) Physical health

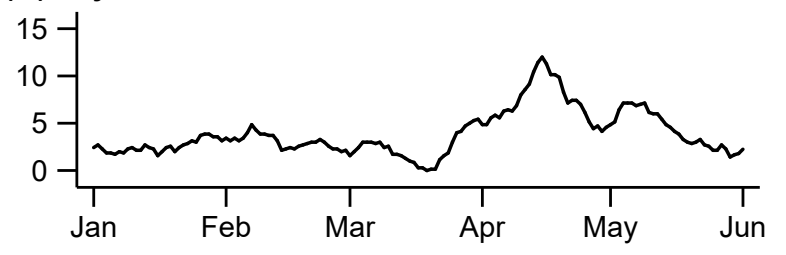

(vii) Livelihood

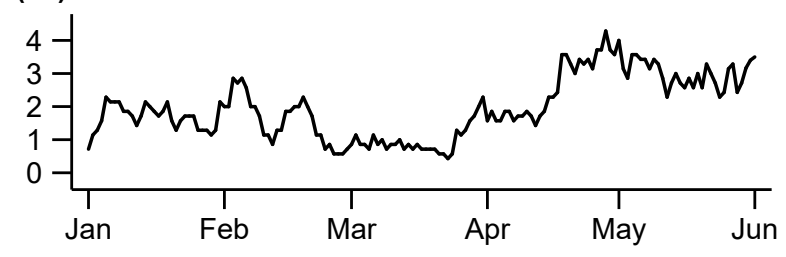

(viii) Relationships

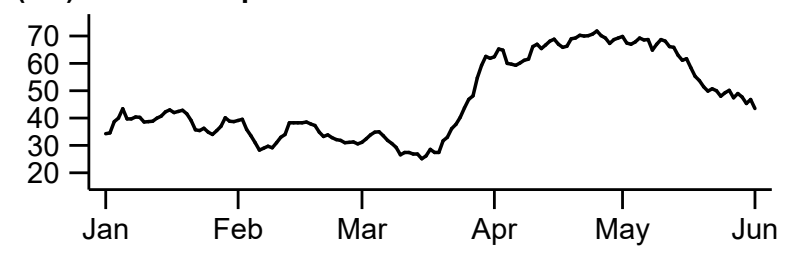

Figure S29: Caller characteristics and conversation topics, Telefono Amico, Italy 


\section{Lebanon}

Embrace is a non-profit organization (NGO) which works to raise awareness around mental health in Lebanon.

Embrace's largest accomplishment to date is the Embrace Lifeline: the national emotional support and suicide prevention helpline in Lebanon in collaboration with the National Mental Health Program of the Ministry of Public Health (MOPH). The Embrace LifeLine is the first and only National Emotional Support and Suicide Prevention Helpline in Lebanon which can be reached 24 hours each day. There are no other helplines in Lebanon or the middle east and around 60 trained volunteer work as emotional crisis and suicide prevention helpline operators. Capacity was not adjusted around the pandemic outbreak, but after the explosion in Beirut in August 2020 (not included in our analysis). Further information can be found online at www.embracelebanon.org.

We received data on individual calls from 2 January 2019 to 30 June 2020, with information on callers' sex, age group, and the severity of suicidal ideation (distress, suicide plans, acute attempt). While no other topics are collected, the data include occupational and marital status, living situation, and whether callers are international migrants.

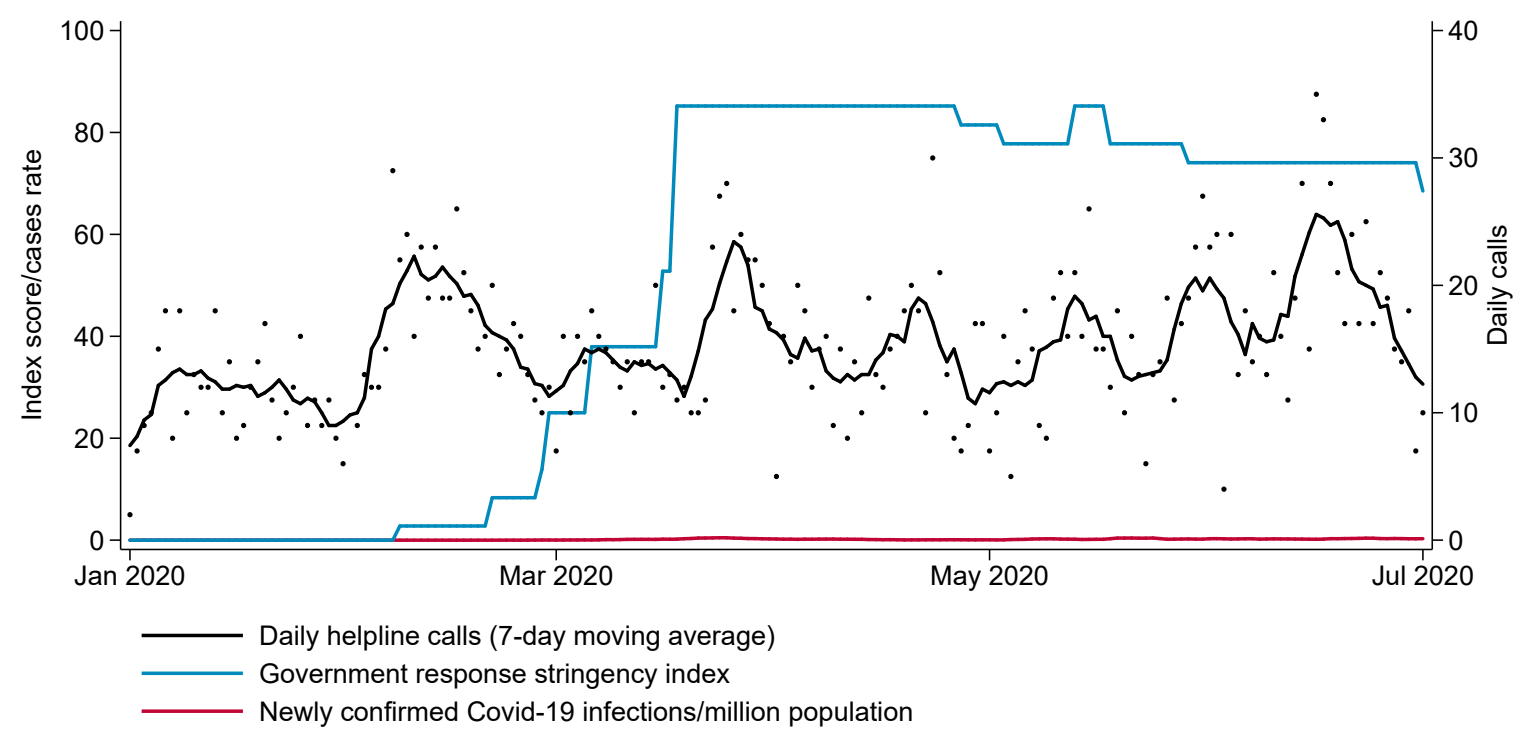

Figure S30: Daily calls to Embrace Lifeline, COVID-19, and government response in Lebanon 
a) Daily calls by age and sex of caller (seven-day moving average)

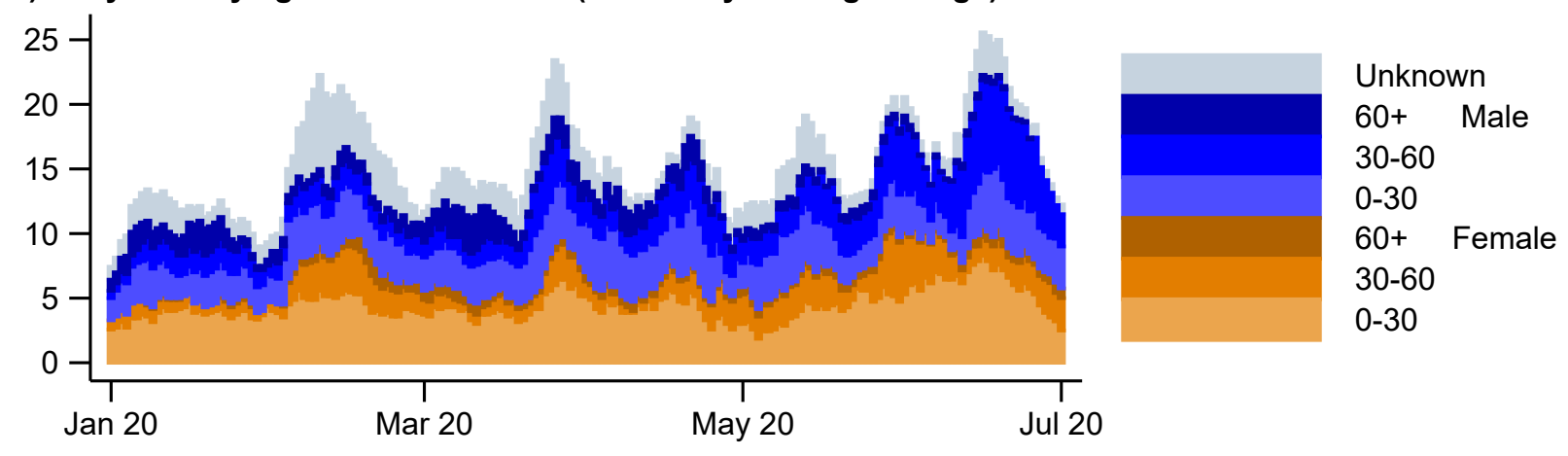

b) Daily calls by topic (seven-day moving average)

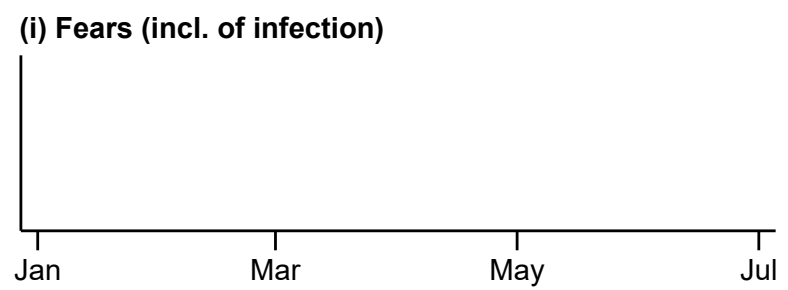

(ii) Loneliness

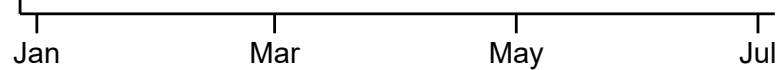

(iii) Suicide

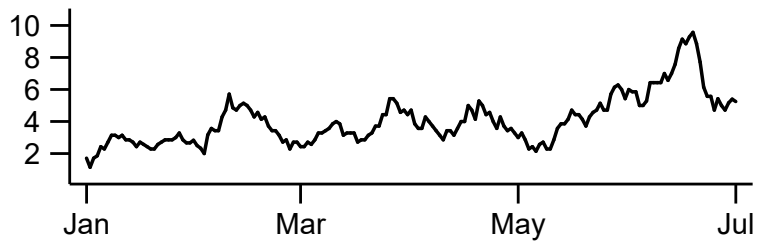

(iv) Addiction

(v) Violence

(vi) Physical health
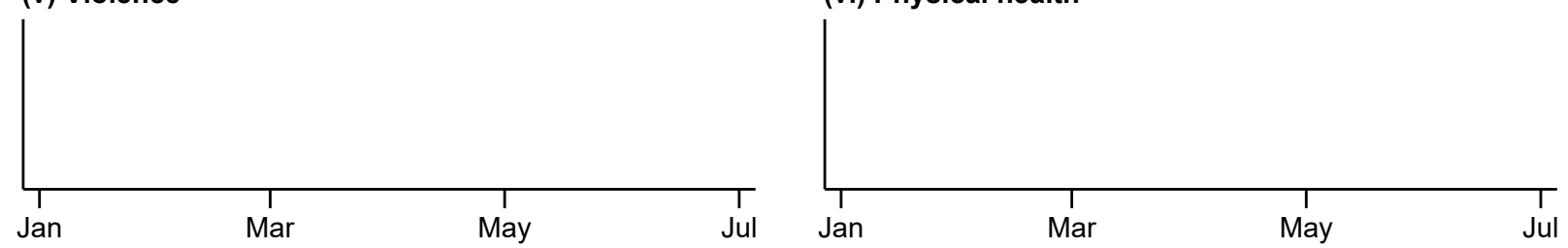

(vii) Livelihood

(viii) Relationships
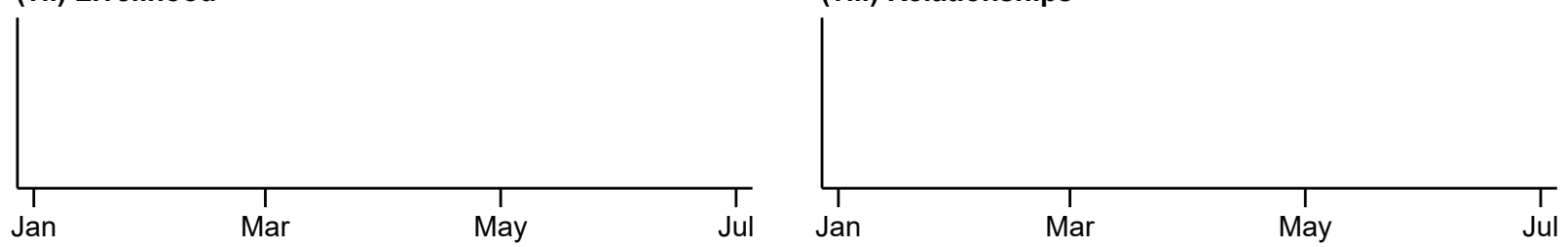

Figure S31: Caller characteristics and conversation topics, Embrace Lifeline, Lebanon 


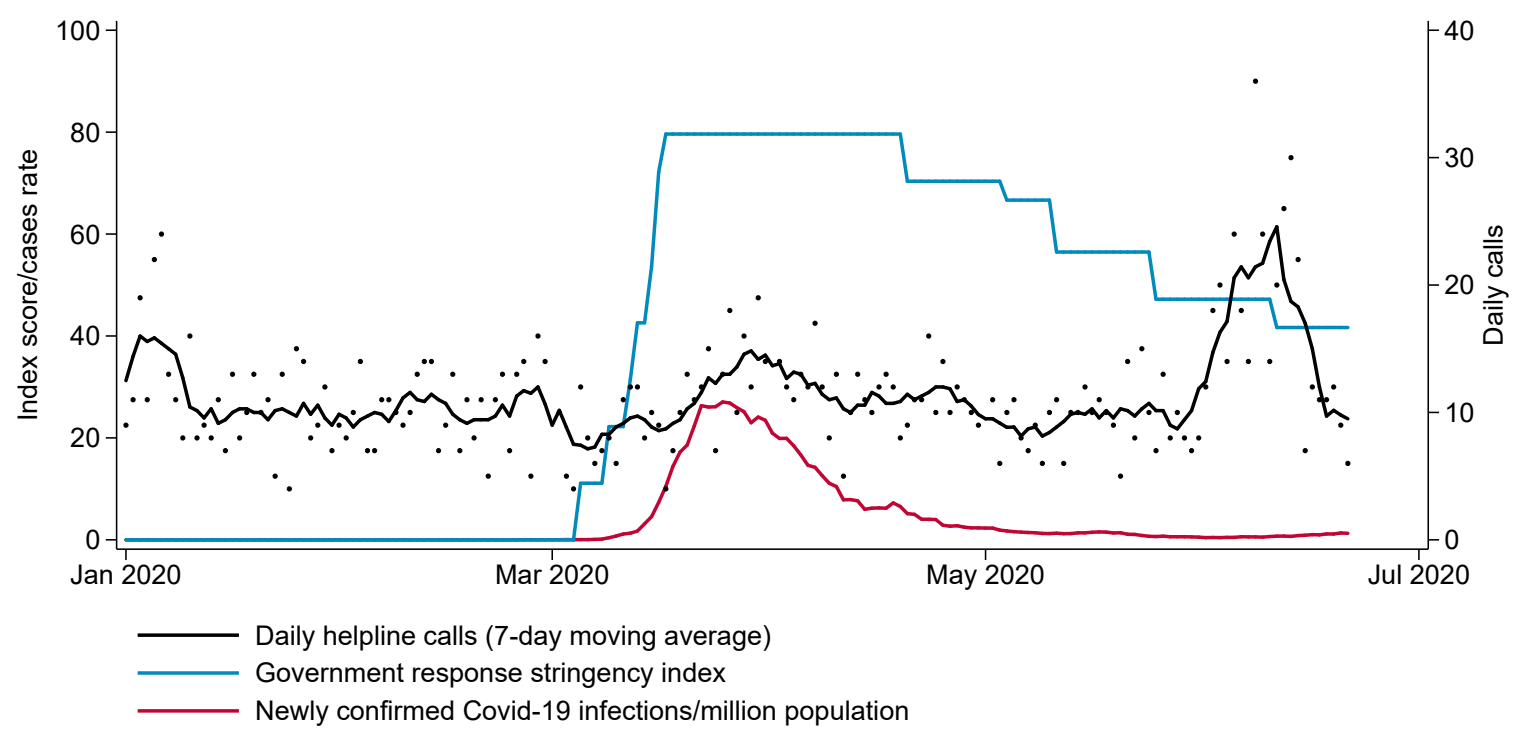

Figure S32: Daily calls to SOS Détresse, COVID-19, and government response in Luxembourg 


\section{Netherlands}

In 1958, the Rotterdam preacher Ds. Teutscher started the first telephone emergency service in the Netherlands under the name De Luisterlijn. At first the telephone service was only carried out from Protestant churches, later Catholic volunteers were added and at the end of the 1960s the humanists came to strengthen the work. Meanwhile there are over 1,500 volunteers at De Luisterlijn providing phone counseling day and night, all year round, for people who need a confidential conversation. They further offer counselling by email, every day of the week and by chat 24/7. For more information, visit www.deluisterlijn.nl.

We received data on individual calls from January 1, 2019 toJune 30, 2020, including information on caller's sex, age group, as well as up to 21 non-exclusive conversation topics and up to 14 caller feelings.

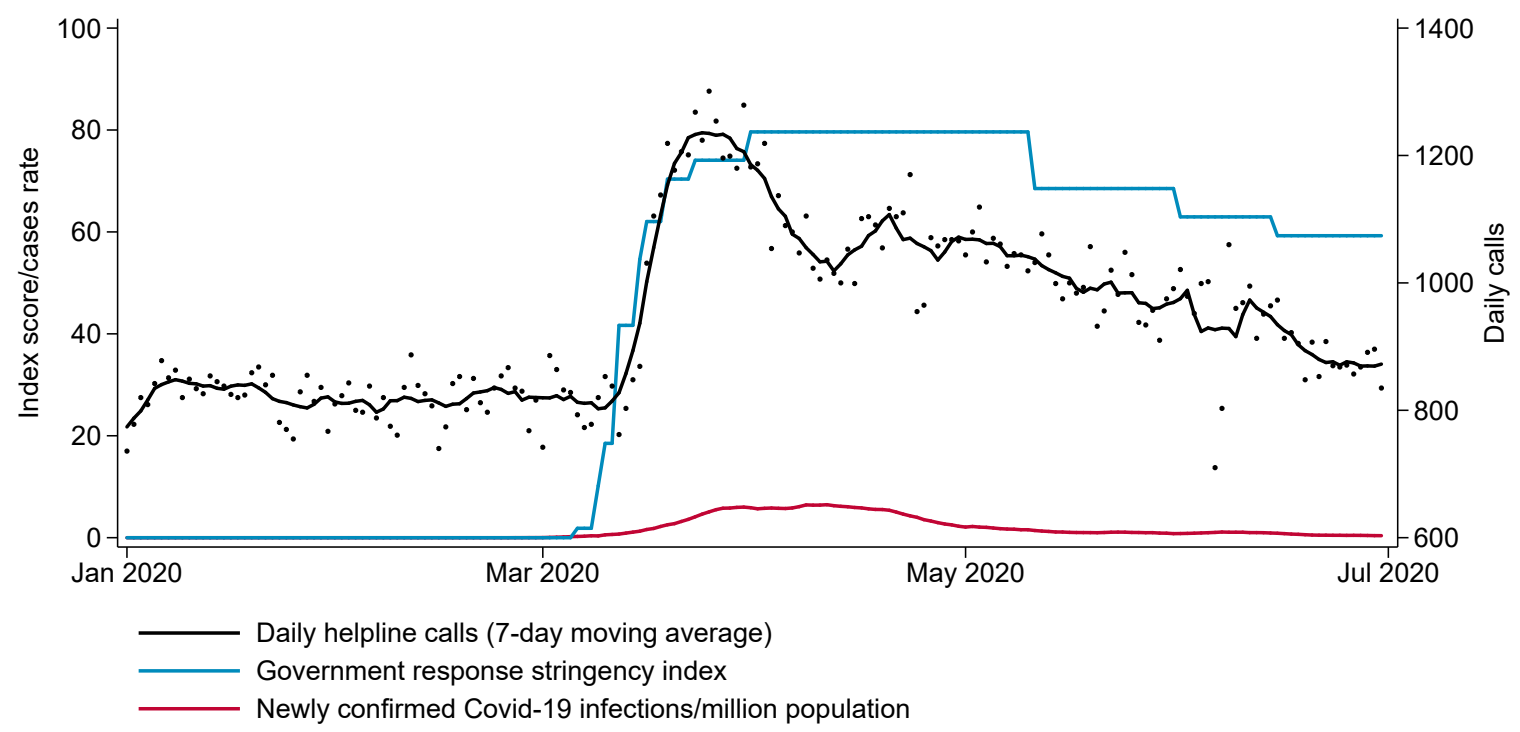

Figure S33: Daily calls to De Luisterlijn, COVID-19, and government response in the Netherlands

Table S20: Classification of conversation topics: De Luisterlijn, Netherlands

\begin{tabular}{ll}
\hline Topic & Helpline-specific topic definitions \\
\hline Fears & Feeling: Bang; Bezorgd; Paniek \\
Loneliness & Eenzaam; Feeling: Alleen voelen \\
Suicide & Zelfmoord \\
Addiction & Verslaving \\
Violence & Huiselijk geweld; Geweld/veiligheid; Seksueel misbruik; Ouderenmishandeling; \\
& Pesten; Verwaarlozing \\
Physical health & Lichamelijke gezondheid \\
Livelihood & Werk; Werkloosheid; Financ; Huisvesting \\
Relationships & Relaties; Burenoverlast/ruzie \\
\hline
\end{tabular}


a) Daily calls by age and sex of caller (seven-day moving average)

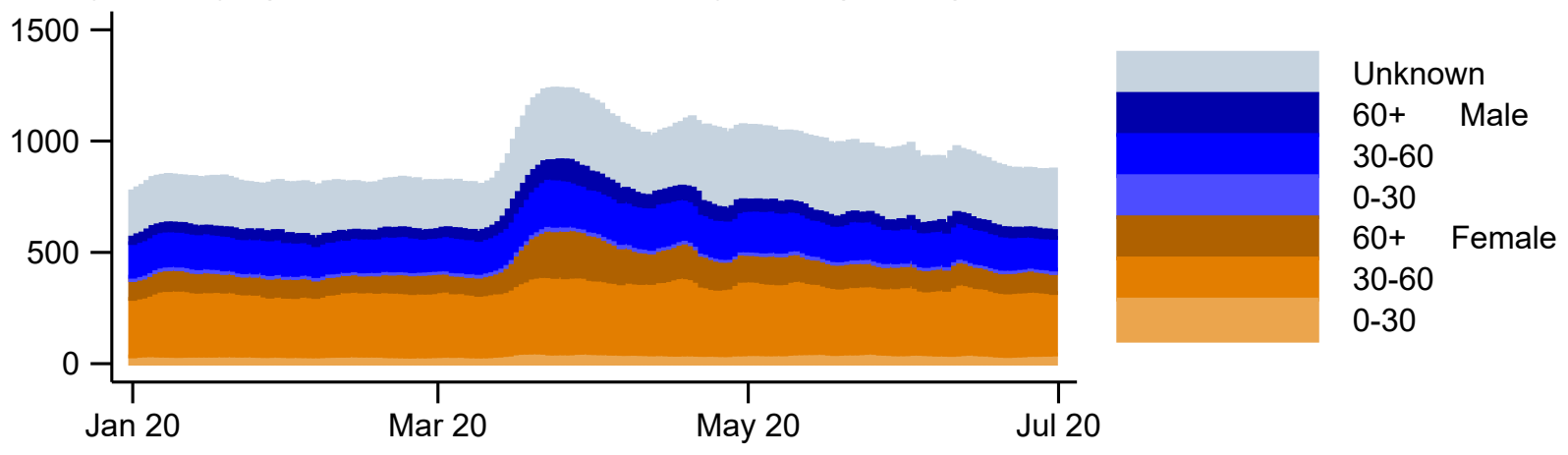

b) Daily calls by topic (seven-day moving average)

(i) Fears (incl. of infection)

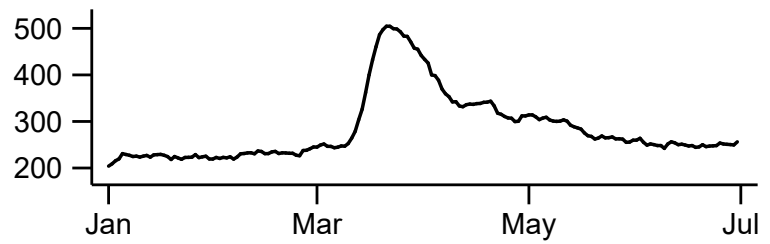

(iii) Suicide

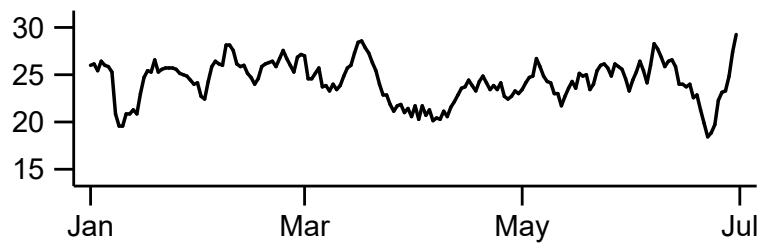

(v) Violence

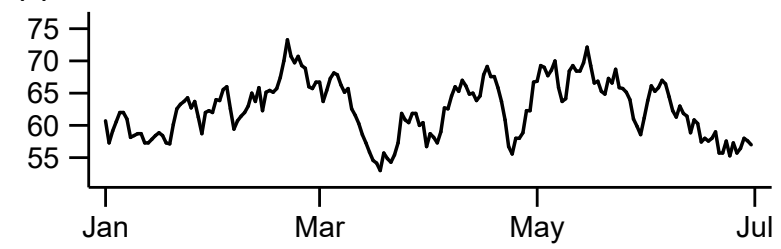

(vii) Livelihood

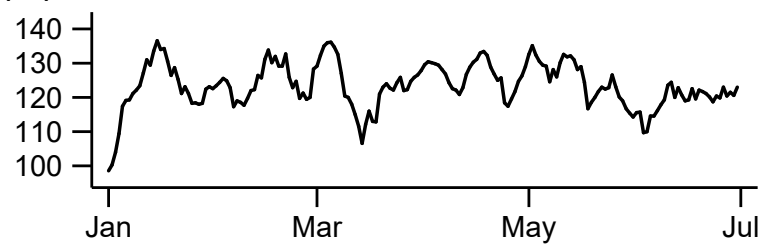

(ii) Loneliness

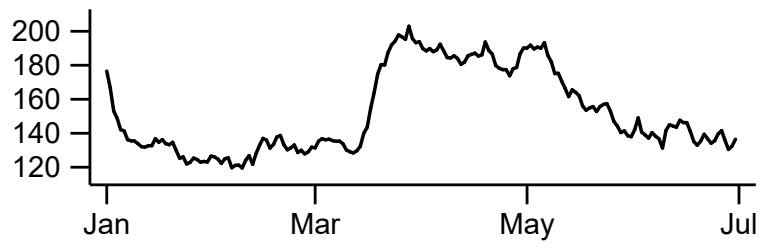

(iv) Addiction

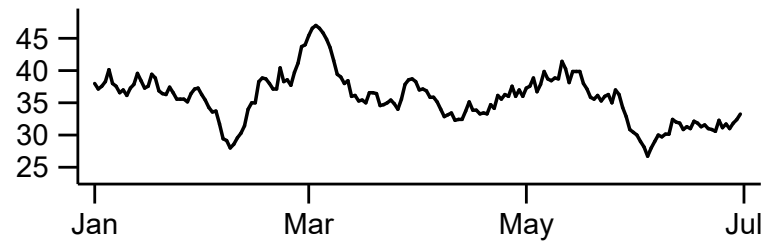

(vi) Physical health

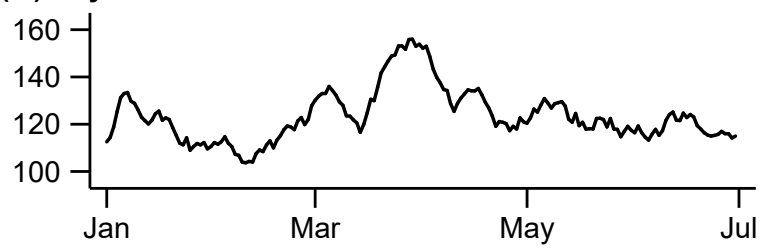

(viii) Relationships

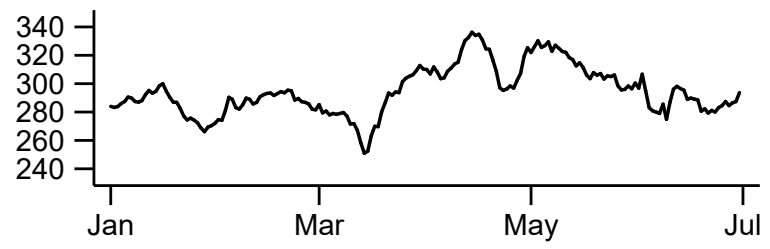

Figure S34: Caller characteristics and conversation topics, De Luisterlijn, Netherlands 


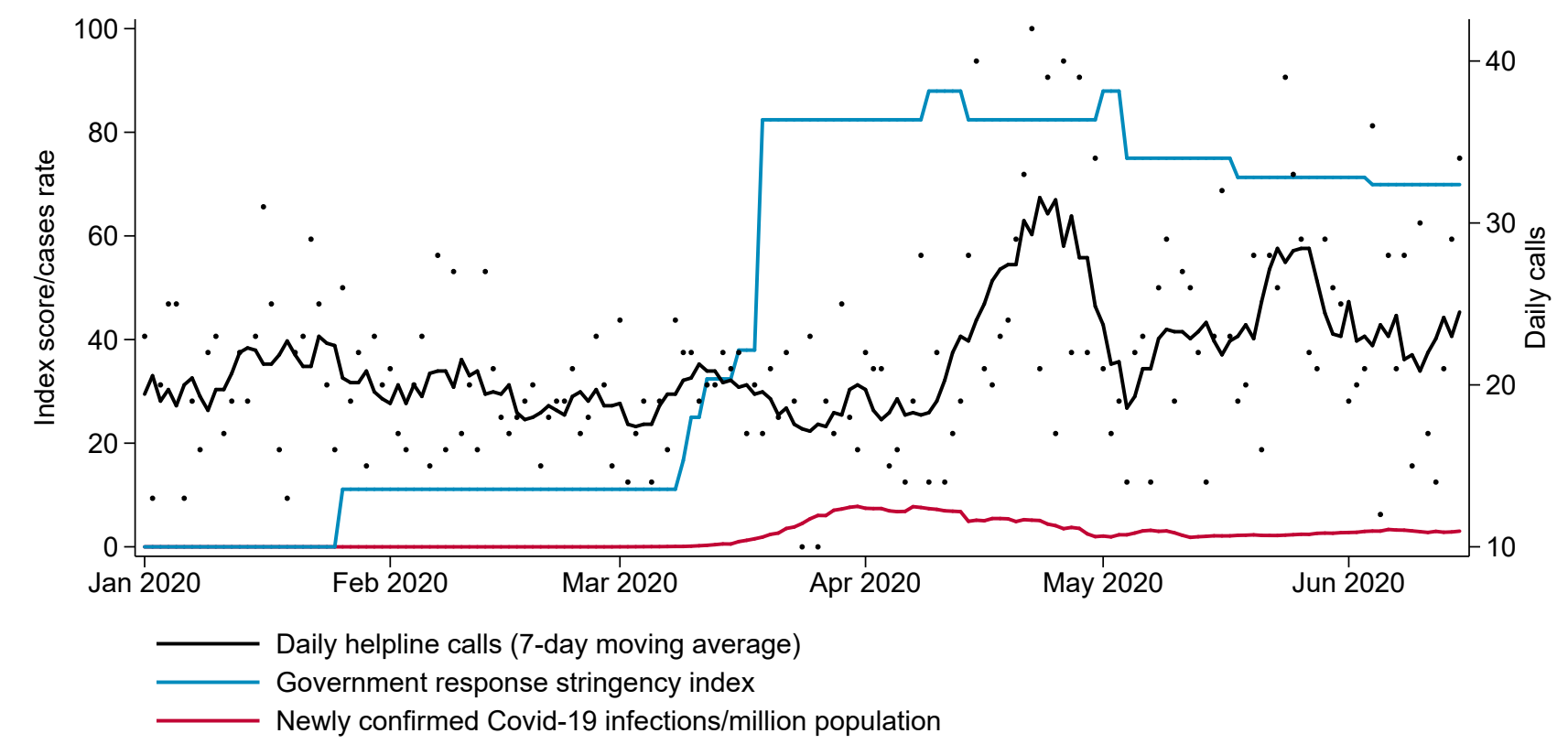

Figure S35: Daily calls to SOS Voz Amiga, COVID-19, and government response in Portugal 
a) Daily calls by age and sex of caller (seven-day moving average)

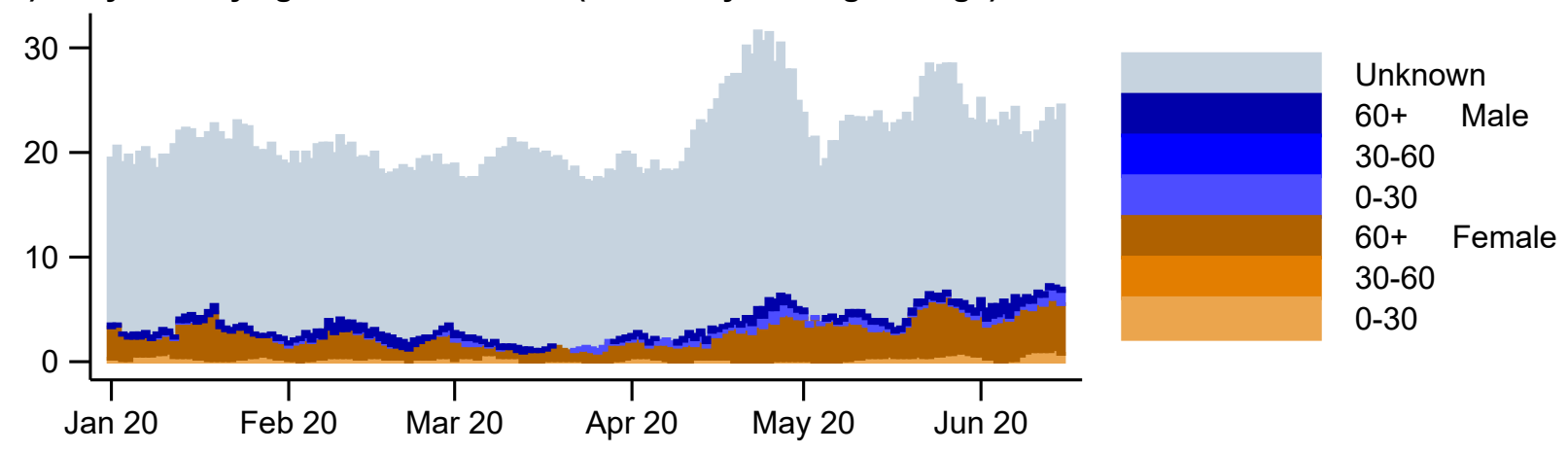

b) Daily calls by topic (seven-day moving average)

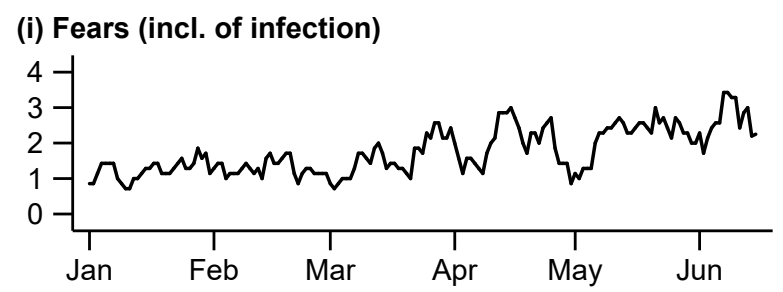

(ii) Loneliness

(iii) Suicide
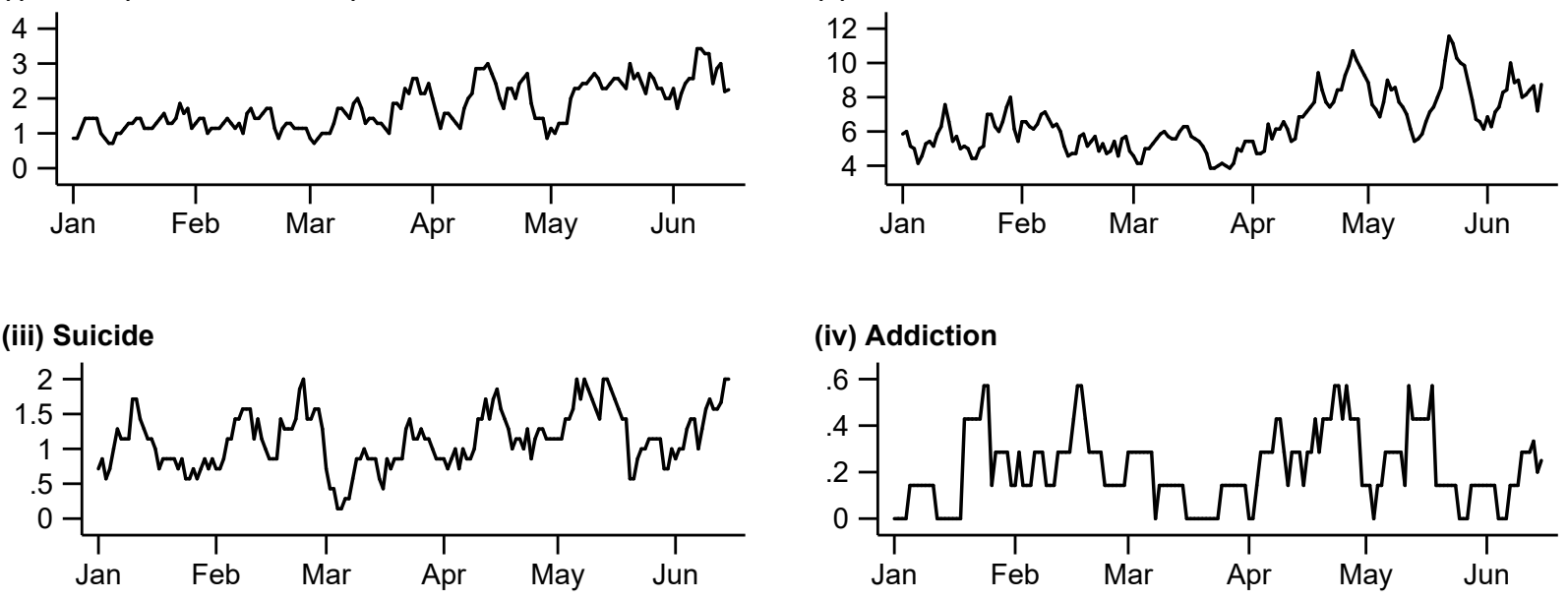

(iv) Addiction

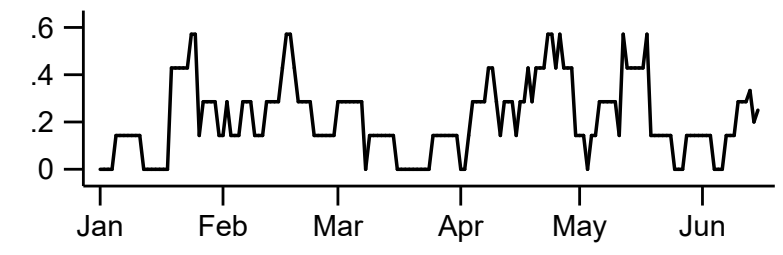

(v) Violence

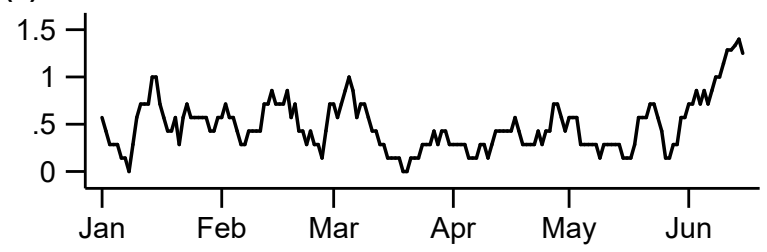

(vi) Physical health

(vii) Livelihood
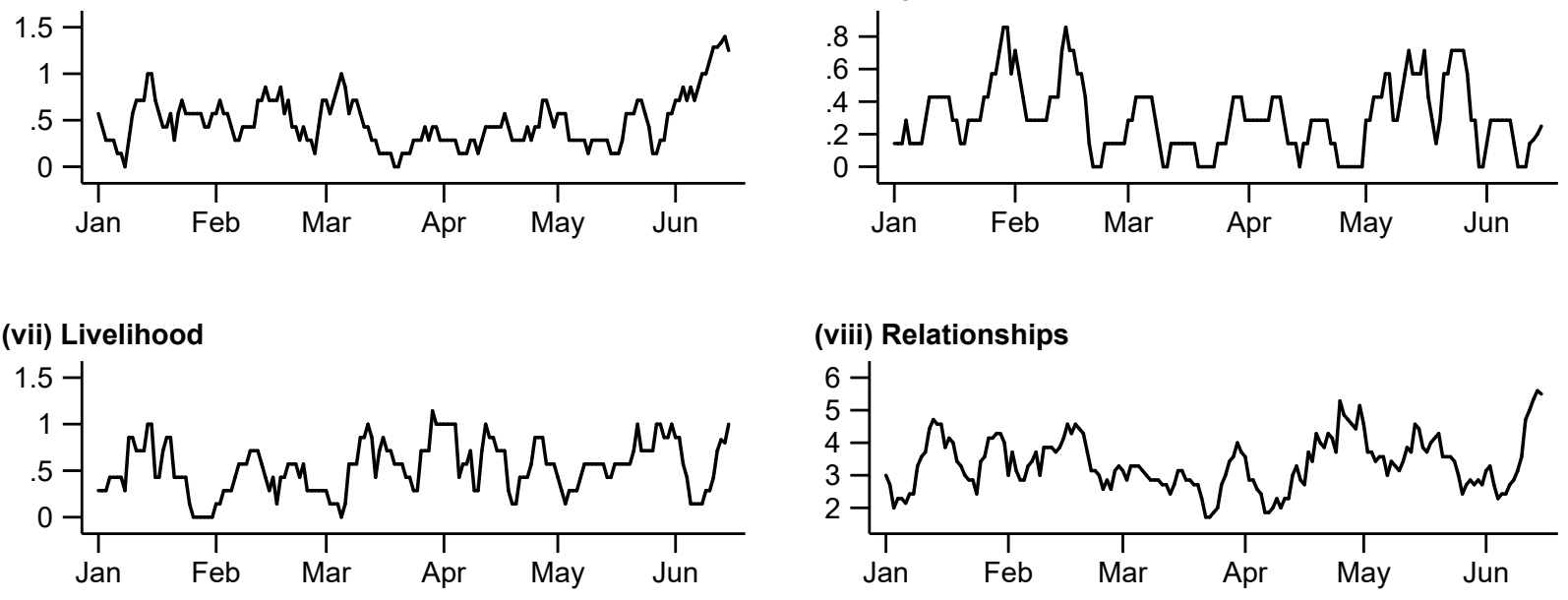

(viii) Relationships

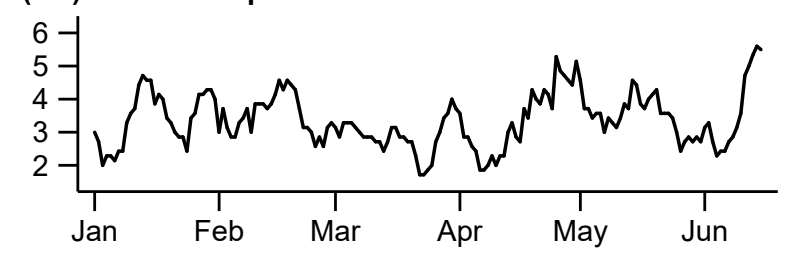

Figure S36: Caller characteristics and conversation topics, SOS Voz Amiga, Portugal 


\section{Slovenia}

Zaupni Telefon Samarijan (confidential phone Samaritan, or Samaritans of Slovenia) is a non-governmental, non-profit, humanitarian and voluntary organization offering a 24/7 helpline. The helpline is run by trained volunteers 24 hours a day, every day of the year and free of charge. For further informaion, visit www.telefonsamarijan.si.

We received data on individual calls, recorded for the period from January 1, 2019 to January 14, 2021, including information on callers' sex and age group, duration, martial status, and emotional relief. All entries are based on assessments of lay consultants. Calls labeled as Volunteer questions, mistakes, or prank calls are dropped from the analysis.

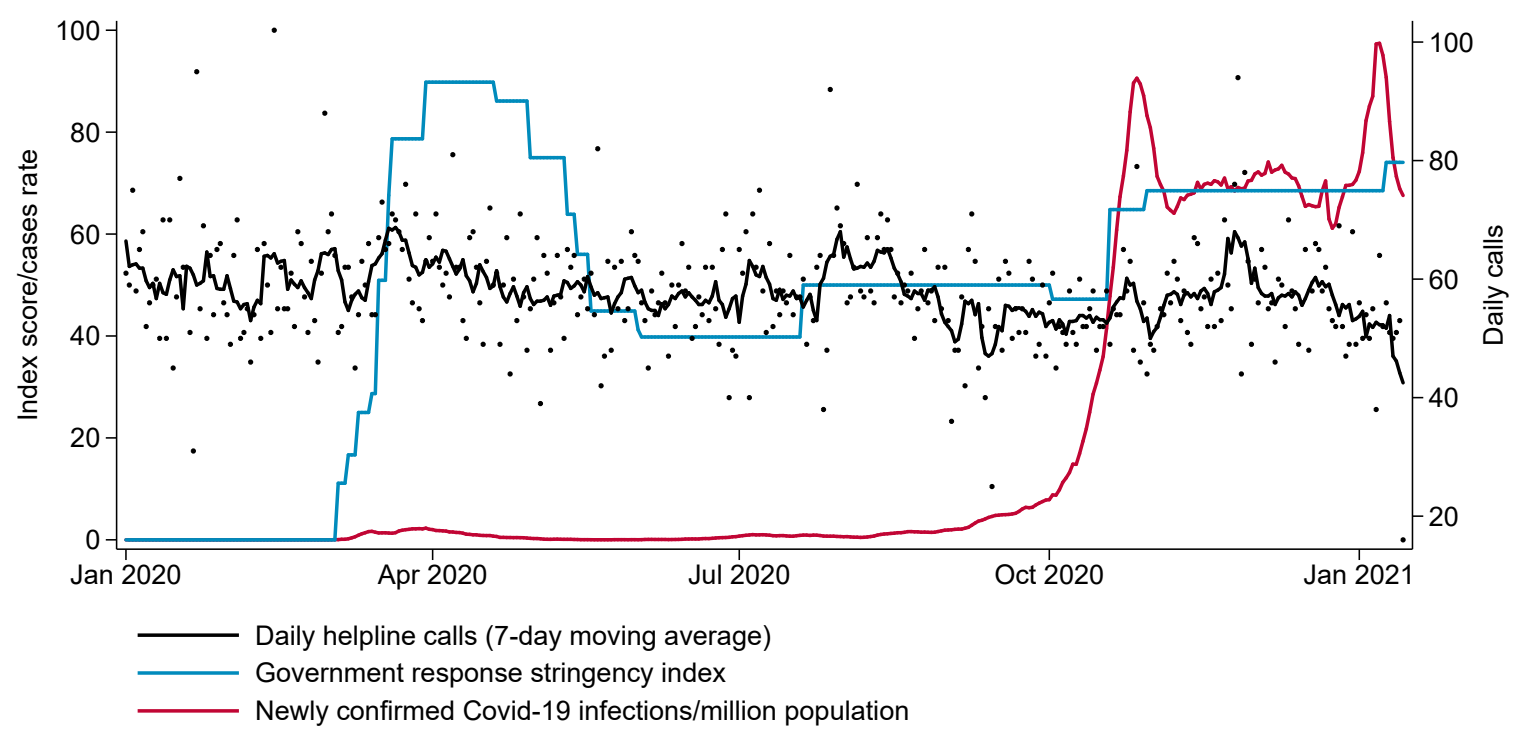

Figure S37: Daily calls to Zaupni Telefon Samarijan, COVID-19, and government response in Slovenia 
Table S21: Classification of conversation topics: Zaupni Telefon Samarijan, Slovenia

\begin{tabular}{ll}
\hline Topic & Helpline-specific topic definitions (data received in English) \\
\hline $\begin{array}{l}\text { Fears } \\
\text { Loneliness }\end{array}$ & $\begin{array}{l}\text { Loneliness; Lack of social contact } \\
\text { Suicide } \\
\text { Suicidal thoughts; Past suicide attempt; Suicide threat; Worries about the suicidal } \\
\text { tendencies of others } \\
\text { Addiction }\end{array}$ \\
$\begin{array}{l}\text { Alcohol abuse; Drug and narcotics abuse; Food abuse; Abuse of relationships; Sex } \\
\text { abuse; Other addictions (games of chance, food, computer) } \\
\text { Violence (verbal/physical/psychological/sexual/economic); Violence (ver- } \\
\text { bal/physical/psychological) in family; Violence in the social environment; Sexual } \\
\text { abuse; Workplace violence/mobbing }\end{array}$ \\
$\begin{array}{l}\text { Fhysical health } \\
\text { Livelihood } \\
\text { Relationships }\end{array}$ & $\begin{array}{l}\text { Financial problems; Accommodation/apartment } \\
\end{array}$ \\
\hline
\end{tabular}




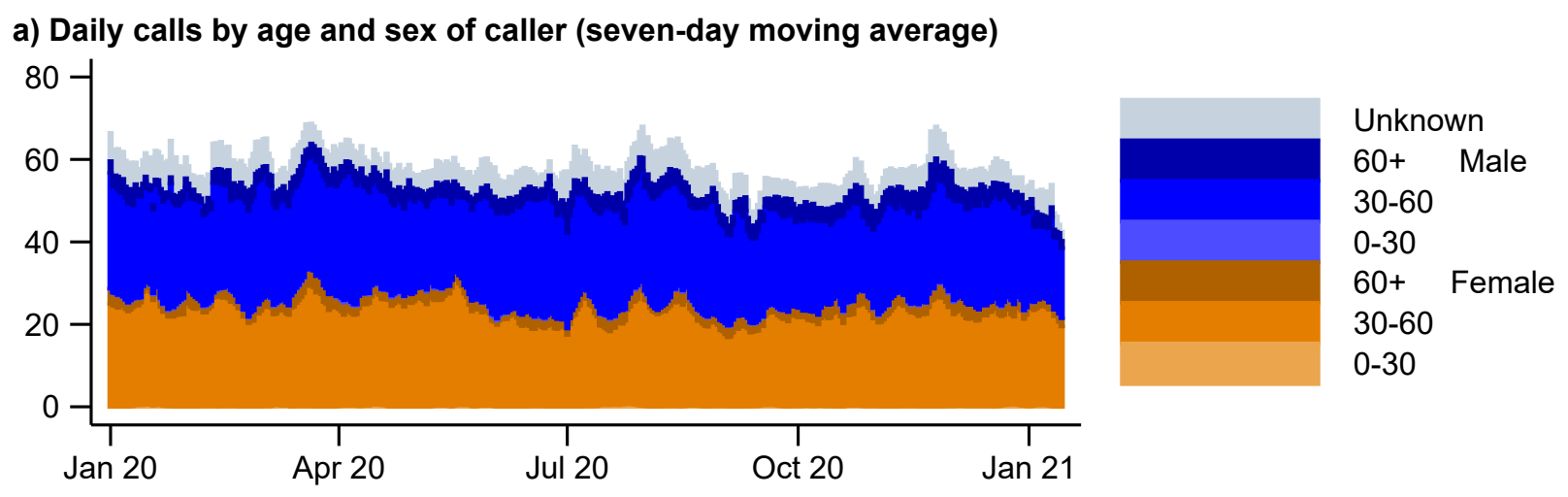

b) Daily calls by topic (seven-day moving average)

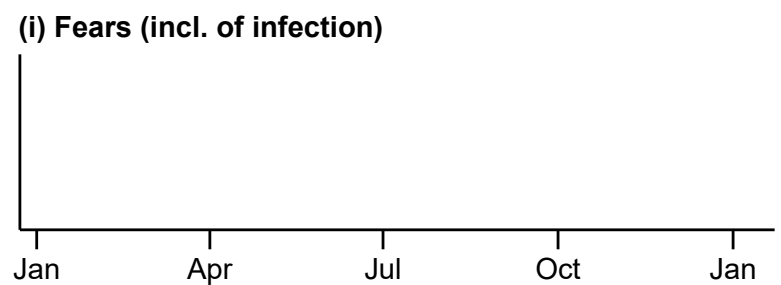

(ii) Loneliness

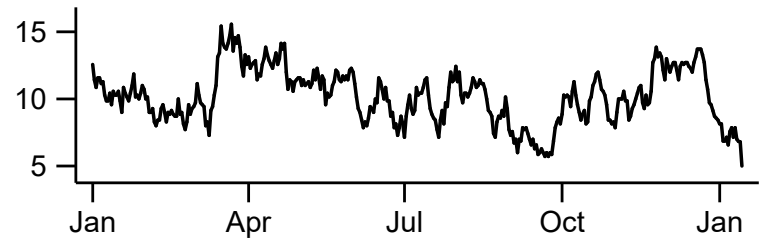

(iii) Suicide

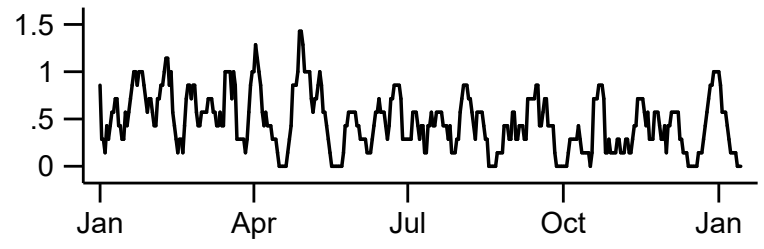

(iv) Addiction

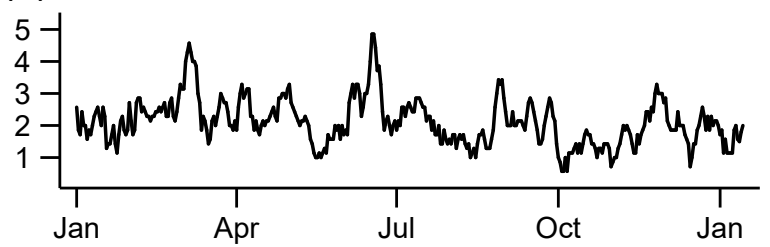

(v) Violence

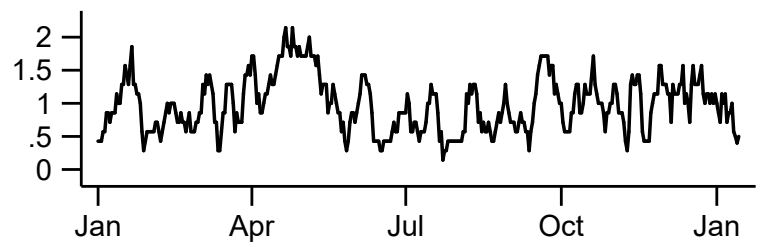

(vi) Physical health

(vii) Livelihood

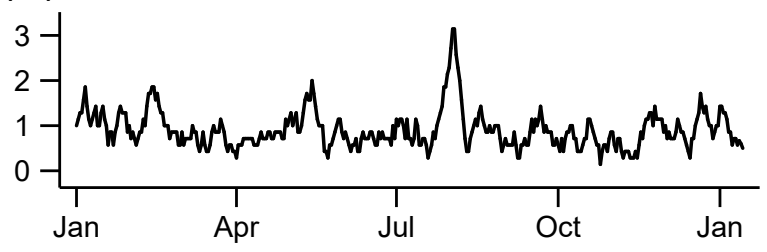

(viii) Relationships

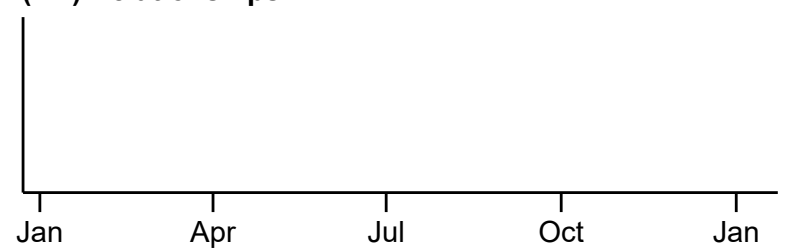

Figure S38: Caller characteristics and conversation topics, Zaupni Telefon Samarijan, Slovenia 


\section{Switzerland}

Die Dargebotene Hand (Phone: 143, web: Die Dargebotene Hand) is the national biggest helpline in Switzerland providing phone listing services in French, Italian and German. In 1957, the first telephone counseling center in Switzerland was opened in Zurich under the name "Dargebotene Hand". Today, the helpline is organized by an amalgamation of twelve locally and regionally anchored, independent organizations under a nationwide umbrella organization. The helpline is an Ifotes member.

We received time series data on daily call volumes, covering the time from February 28 to June 30, for both 2019 and 2020 (without the intermediate time in 2019 and early 2020).

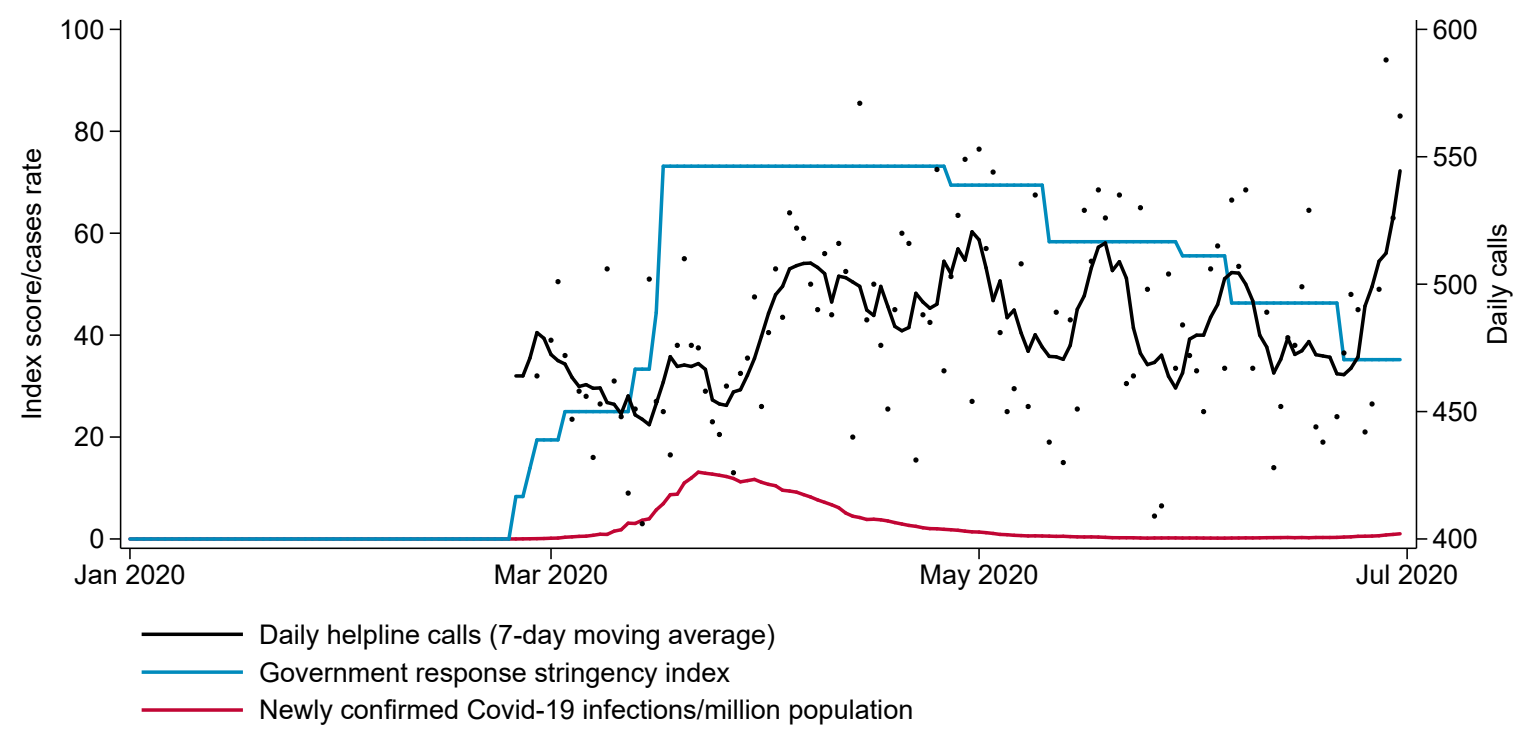

Figure S39: Daily calls to Die Dargebotene Hand, COVID-19, and government response in Switzerland 


\section{United States of America}

From Vibrant Emotional Health, we obtained information on the weekly number of calls routed to centers of the National Suicide Prevention Lifeline (Lifeline), and the Disaster Distress Helpline, from January 2019 to March 2021. The Lifeline provides 24/7, free and confidential support for people in distress, prevention and crisis resources. The U.S. Substance Abuse and Mental Health Services Administration (SAMHSA) and Vibrant Emotional Health launched the Lifeline on January 1, 2005. The Lifeline is funded by the SAMHSA and administered by Vibrant Emotional Health. All calls to the Lifeline are answered by crisis workers, who are trained by the centers with an average of 90 hours of training. While information on caller demographics is not routinely collected, estimates from reporting centers indicate that just over half of calls are from people under the age of 35 .

SAMHSA's Disaster Distress Helpline provides 24/7, 365-day-a-year crisis counseling and support to people experiencing emotional distress related to natural or human-caused disasters The service is provided by phone or text and is the nation's only hotline dedicated to providing year-round disaster crisis counseling. It was launched in 2010 as part of the former Oil Spill Distress Helpline and became the national Disaster Distress Helpline in 2012. The helpline was heavily advertised during the corona crisis. Further information on the two helplines is available online, at www.suicidepreventionlifeline.org and www.samhsa.gov/find-help/disasterdistress-helpline.

Based on the phone number of callers, it is possible to estimate the region from which most of the calls originate. While the helplines are serving only the United States, they also receive calls from Canada and other locations. For our analysis, we focus on calls from 50 US states and the District of Columbia. Information on Canadian provinces, US Territories (American Samoa, Guam, Northern Marianas, Puerto Rico, and Virgin Islands), as well as other/unknown origin are not considered, in order to maximize consistency and because of the limited availability of other data sources. 

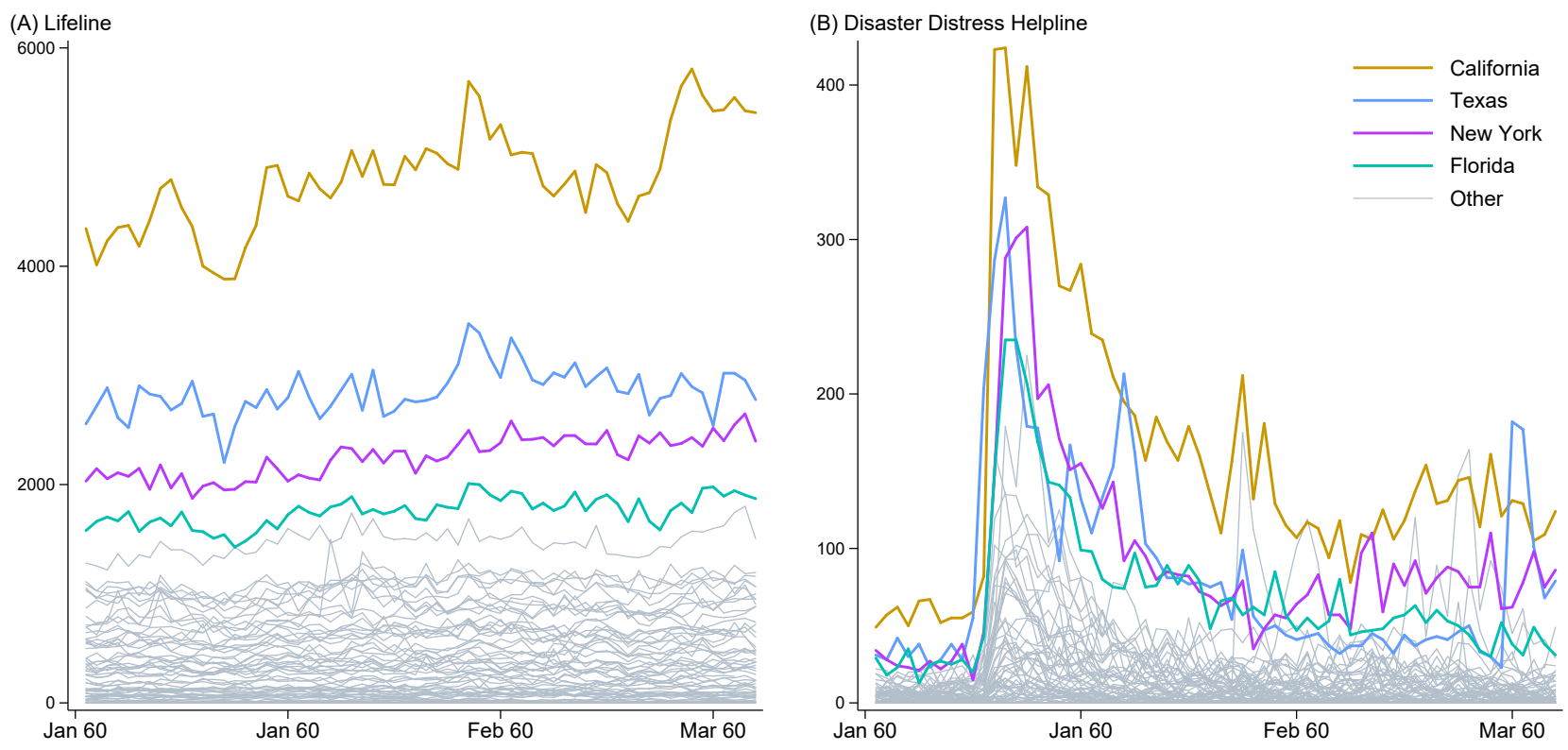

Figure S40: Weekly calls to the National Suicide Prevention Lifeline and the Disaster Distress Helpline 